\title{
Heterojunction photocatalysts for degradation of the tetracycline antibiotic: a review
}

\author{
Xinghou $\mathrm{He}^{1,2} \cdot$ Tianhan Kai ${ }^{1}$ Ping Ding ${ }^{1,2}$
}

Received: 23 March 2021 / Accepted: 28 July 2021 / Published online: 30 August 2021

(c) The Author(s), under exclusive licence to Springer Nature Switzerland AG 2021

\begin{abstract}
Antibiotic pollution is a major health issue inducing antibiotic resistance and the inefficiency of actual drugs, thus calling for improved methods to clean water and wastewater. Here we review the recent development of heterojunction photocatalysis and application in degrading tetracycline. We discuss mechanisms for separating photogenerated electron-hole pairs in different heterojunction systems such as traditional, p-n, direct Z-scheme, step-scheme, Schottky, and surface heterojunction. Degradation pathways of tetracycline during photocatalysis are presented. We compare the efficiency of tetracycline removal by various heterojunctions using quantum efficiency, space time yield, and figures of merit. Implications for the treatment of antibiotic-contaminated wastewater are discussed.
\end{abstract}

Keywords Heterojunction · Photocatalyst $\cdot$ Tetracycline $\cdot$ Photocatalysis mechanism · Degradation pathway $\cdot$ Performance evaluation

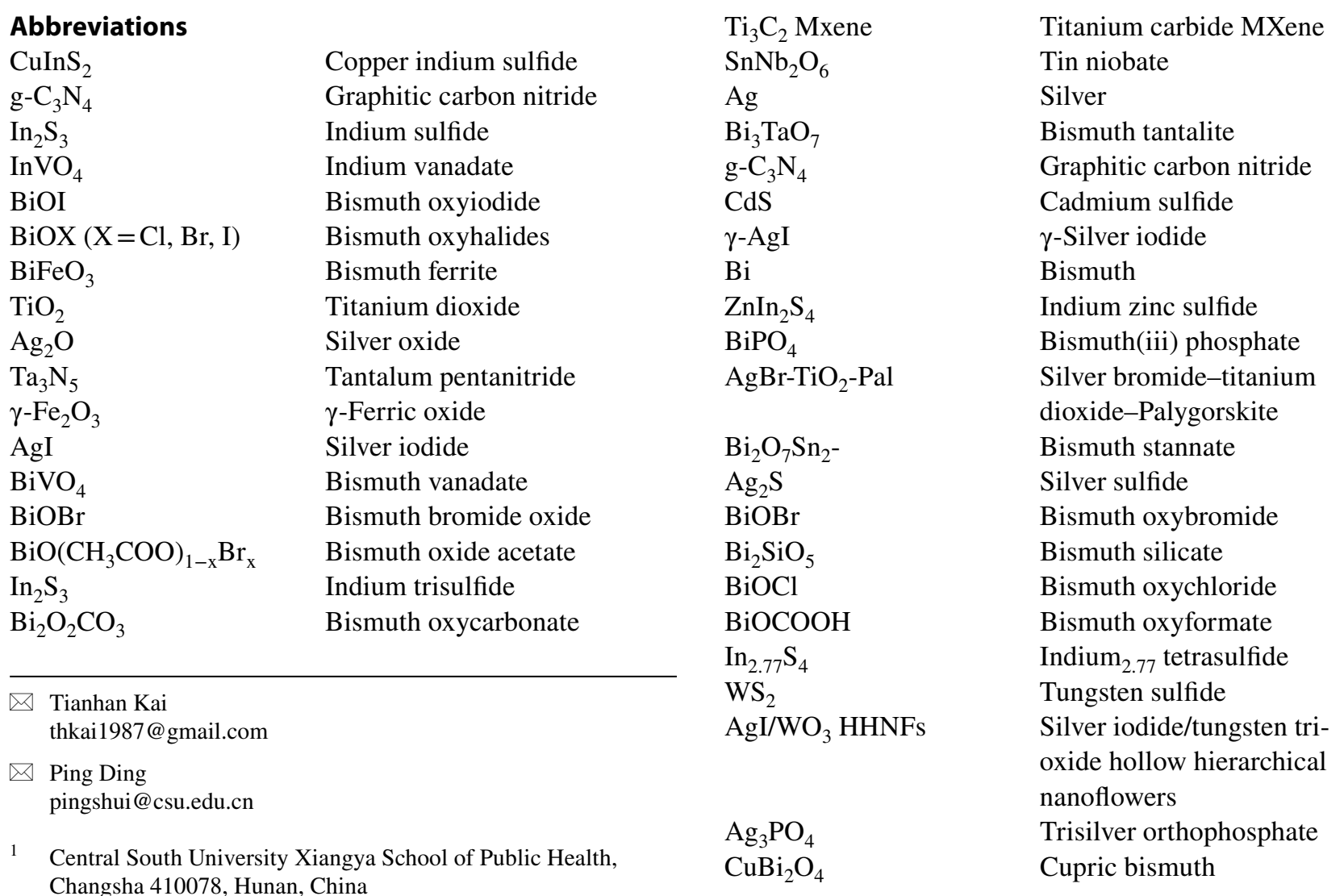

2 Hunan Provincial Key Laboratory of Clinical Epidemiology, Changsha 410078, Hunan, China 


\begin{tabular}{|c|c|c|c|}
\hline $\mathrm{CDs} / \mathrm{g}-\mathrm{C}_{3} \mathrm{~N}_{4} / \mathrm{MoO}_{3}$ & $\begin{array}{l}\text { Carbon quantum dots/graphitic } \\
\text { carbon nitride/molybdenum } \\
\text { trioxide }\end{array}$ & $\begin{array}{l}\mathrm{SnS}_{2} \\
\mathrm{BiOBr} \\
\mathrm{BiOI}\end{array}$ & $\begin{array}{l}\text { Tin disulfide } \\
\text { Bismuth bromide oxide nitride } \\
\text { Bismuth oxyiodide }\end{array}$ \\
\hline $\mathrm{Bi}_{2} \mathrm{WO}_{6}$ & Bismuth tungstate & $\mathrm{Bi}_{12} \mathrm{O}_{15} \mathrm{C}_{16}$ & Bismuth oxychloride \\
\hline $\mathrm{Ta}_{3} \mathrm{~N}_{5}$ & Tantalum nitride & $\mathrm{CO}_{3} \mathrm{O}_{4}$ & Tricobalt tetraoxide \\
\hline $\mathrm{SnFe}_{2} \mathrm{O}_{4}$ & Stannic ferrite & $\mathrm{ZnS}$ & Zinc sulfide \\
\hline $\mathrm{ZnFe}_{2} \mathrm{O}_{4}$ & Zinc ferrite & $\mathrm{Cu}_{2} \mathrm{O}$ & Cuprous oxide \\
\hline $\mathrm{CdIn}_{2} \mathrm{~S}_{4}$ & Cadmium indium sulfide & $\mathrm{Bi}_{2} \mathrm{~S}_{3}$ & Bismuth sulfide \\
\hline $\mathrm{Ag} / \mathrm{CNF}$ & Silver-loaded fiber-like carbon & $\mathrm{P}_{3} \mathrm{HT}$ & Poly (3-hexylthiophere) \\
\hline $\mathrm{Au} / \mathrm{Pt} / \mathrm{g}-\mathrm{C}_{2} \mathrm{~N}_{4}$ & $\begin{array}{l}\text { nitride } \\
\text { Gold/platinum/graphitic car- }\end{array}$ & PCN-224 & $\begin{array}{l}\text { Porous coordination } \\
\text { network- } 224\end{array}$ \\
\hline f & bon nitride & BP & Black phosphorus \\
\hline $\begin{array}{l}\mathrm{Ti}_{3} \mathrm{C}_{2} \text { MXene } \\
\mathrm{ZnIn}_{2} \mathrm{~S}_{4}\end{array}$ & $\begin{array}{l}\text { Titanium carbide MXene } \\
\text { Indium zinc sulfide }\end{array}$ & S-PCN & $\begin{array}{l}\text { Sulfur-doped porous graphite } \\
\text { carbon nitride }\end{array}$ \\
\hline $\mathrm{CoAl}-\mathrm{LDH} / \mathrm{g}-\mathrm{C}_{3} \mathrm{~N}_{4} / \mathrm{RGO}$ & $\begin{array}{l}\text { CoAl-layered double hydrox- } \\
\text { ide/graphitic carbon nitride/ } \\
\text { reduced graphene oxide }\end{array}$ & $\begin{array}{l}\mathrm{WO}_{2 \cdot 72} \\
\mathrm{CdIn}_{2} \mathrm{~S}_{4} \\
\mathrm{Bi}_{3} \mathrm{O}_{4} \mathrm{Cl}\end{array}$ & $\begin{array}{l}\text { Tungsten oxide } \\
\text { Cadmium indium sulfide } \\
\text { Bismuth Tetroxide Chloride }\end{array}$ \\
\hline 3D PANI/PDI & Three-dimensional structure & Vis & Visible light \\
\hline & Polyaniline/Perylene diimide & UV & Ultraviolet light \\
\hline $\mathrm{Bi}_{2} \mathrm{~W}_{2} \mathrm{O}_{9}$ & Bismuth tungstate & $\mathrm{CdS}$ & Cadmium sulfide \\
\hline PTI hollow tube/ZnO & $\begin{array}{l}\text { Poly(triazine imide) hollow } \\
\text { tube/zinc oxide }\end{array}$ & $\begin{array}{l}\text { NIR } \\
e^{-}\end{array}$ & $\begin{array}{l}\text { Near infrared light } \\
\text { Electron }\end{array}$ \\
\hline PVDF & Poly(vinylidene fluoride) & $\mathrm{h}^{+}$ & Hole \\
\hline $\mathrm{Bi}_{2} \mathrm{Sn}_{2} \mathrm{O}_{7}-\mathrm{C}_{3} \mathrm{~N}_{4}$ & Bismuth stannate & $\mathrm{H}_{2} \mathrm{O}_{2}$ & Hydroperoxide \\
\hline $\mathrm{NiFe}_{2} \mathrm{O}_{4}$ & Nickel ferrite & $\mathrm{HOO}$ & Hydroperoxyl radical \\
\hline SCNNR & $\begin{array}{l}\text { Sulfur-doped carbon nitride } \\
\text { nanorod }\end{array}$ & $\begin{array}{l}\mathrm{OH} \\
{ }^{1} \mathrm{O}_{2}\end{array}$ & $\begin{array}{l}\text { Hydroxyl radical } \\
\text { Singlet oxygen }\end{array}$ \\
\hline POPD & Poly-o-phenylenediamine & $\mathrm{O}_{2} \cdot-$ & Superoxide radical \\
\hline $\mathrm{CoFe}_{2} \mathrm{O}_{4}$ & Cobalt ferrite & $\mathrm{g}$ & Gram \\
\hline MIL-125(Ti) & Materials Institute Lavois- & $\mathrm{h}$ & Hour \\
\hline & ier-125 (Ti) & $\mathrm{L}$ & Liter \\
\hline $\mathrm{In}_{2} \mathrm{~S}_{3} @$ & Indium(III) sulfide & $\mathrm{mg}$ & Milligram \\
\hline$\beta-\mathrm{Bi}_{2} \mathrm{O}_{3}$ & $\beta$-Bismuth trioxide & $\mathrm{J}$ & Joule \\
\hline $\mathrm{MoS}_{2}$ & Molybdenum disulfide & W & Watt \\
\hline
\end{tabular}

$\mathrm{CuBi}_{2} \mathrm{O}_{4}$

$\mathrm{CoO}$

Cupric bismuth

Cobalt oxide

$\mathrm{Bi}_{2} \mathrm{MoO}_{6}$

$\mathrm{Ag}_{6} \mathrm{Si}_{2} \mathrm{O}_{7}$

Bismuth molybdate

Silver silicate

MIL-88B

Materials Institute

Lavoisier-88B

COF-200

Covalent organic

frameworks-200

PANI

$\mathrm{m}-\mathrm{Bi}_{2} \mathrm{O}_{4}$

Polyaniline

Monoclinic dibismuth

tetroxide

$\mathrm{BiOCl}$

Bismuth oxychloride

CdTe

Cadmium telluride quantum

dots

$\mathrm{CuInS}_{2}$

$\mathrm{Eu} / \mathrm{B}$

Copper indium sulfide

Europium/boron

C-g- $\mathrm{C}_{3} \mathrm{~N}_{4}$

Carbon-doped graphitic car-

bon nitride

$\mathrm{C}_{3} \mathrm{~N}_{5}$

Tricarbon pentanitride

\section{Introduction}

Antibiotics are one of the most emergent pollutants in natural aqueous environments worldwide due to the increased antibiotic abuse, resulting from the increased demand of the pharmaceuticals and the rapid development of the drug and medical industry (Akhil et al. 2021; Kumar et al. 2021; Madhura et al. 2018; Shi et al. 2019; Wei et al. 2020; Yang et al. 2021b). Tetracycline, one of the highly effective broadspectrum prescribed antibiotics, is extensively used in the therapeutic treatment, and livestock and poultry industry (Daghrir and Drogui 2013; Peng et al. 2021; Zheng et al. 2021). Nevertheless, tetracycline gets into the environment through urine and feces since it is incompletely absorbed in the body and has poor metabolic transformation (Barhoumi et al. 2017; Guo et al. 2019a). Moreover, tetracycline is not easily degradable because it is chemically stable, thus 
difficult to be eliminated under the natural environment (Yan et al. 2021a; Yang et al. 2018; Younis et al. 2020). Therefore, it is necessary to identify an effective and feasible technology for degrading tetracycline in water environments.

Light-activated semiconductor-based photocatalysis represents the most promising green and eco-friendly technique for wastewater treatment (Liu et al. 2019a; López et al. 2021; Saravanan et al. 2020). It has received a lot of attention due to its high efficiency, low-cost, and outstanding stability (Peng et al. 2021; Zhou et al. 2019). Electrons $\left(\mathrm{e}^{-}\right.$) and holes $\left(\mathrm{h}^{+}\right)$are generated under light irradiation and migrate to the surface of photocatalyst (López et al. 2021; Soni et al. 2021), inducing redox reactions and forming of reactive oxygen species, such as superoxide radical $\left(\mathrm{O}_{2}{ }^{-}{ }^{-}\right)$, singlet oxygen $\left({ }^{1} \mathrm{O}_{2}\right)$, hydroxyl radical $\left(\mathrm{OH}^{\cdot}\right)$, hydroperoxyl radical (HOO $)$, and hydroperoxide $\left(\mathrm{H}_{2} \mathrm{O}_{2}\right)$. The reactive oxygen species with high oxidative and reductive activity can easily degrade organic and inorganic pollutant molecules.

Although many significant advances have been made in photocatalysis, two major bottlenecks limit the practical application of pristine photocatalysts under solar light. First, several pure photocatalysts with wide band gaps can only be activated using ultraviolet light ( $\mathrm{Li}$ et al. 2020d), less than $5 \%$ of the sunlight spectrum. Second, photoproduced $\mathrm{e}^{-}$and $\mathrm{h}^{+}$pairs of single semiconductor photocatalysts generally likely to recombine, reducing quantum and photocatalytic efficiencies (Louangsouphom et al. 2018; Soltani et al. 2019). Various strategies, such as element doping (He et al. 2020b), semiconductor coupling (Guo et al. 2019b), and dye sensitization (Liu and Wang 2019) have been developed in the past decades to overcome the inherent drawbacks associated with pristine photocatalysts. However, semiconductor coupling is one of the most popular research hotspots for photocatalysis since it allows for the introduction of heterojunction systems, effectively improving the separation of $\mathrm{e}^{-}$and $\mathrm{h}^{+}$(Ifebajo et al. 2018; Trinh Duy et al. 2020).

Many studies have reported on tetracycline degradation after visible light irradiation using different heterostructure photocatalytic materials in recent years. For instance, Guo et al. (2019a) fabricated a 2D/2D Z-scheme heterojunction photocatalyst by coupling $\mathrm{CuInS}_{2}$ and g- $\mathrm{C}_{3} \mathrm{~N}_{4}$ semiconductors to efficiently remove tetracycline from water under visible illumination. Acharya et al. (2020) also reported that a boron nitride/B-doped-g- $\mathrm{C}_{3} \mathrm{~N}_{4}$ heterojunction composite could effectively inhibit the recombination of electron-hole pairs, thus degrading tetracycline antibiotics under visible light. Wang et al. (2018a) built a visible-light-driven $\mathrm{BiOBr} /$ $\mathrm{Bi}_{2} \mathrm{SiO}_{5}$ heterojunction to enhance the elimination of tetracycline in an aqueous solution. Although several articles have reviewed the development of heterojunction architectures and their application in the purification of different environmental pollutants ( $\mathrm{Li}$ and $\mathrm{Li}$ 2020; Low et al. 2017; Nemiwal et al. 2021; Wang et al. 2014; Yu et al. 2014a), none has comprehensively summarized and emphasized on tetracycline photodegradation.

This study focused on photocatalytic degradation of tetracycline using various heterojunction photocatalytic composites under light irradiation. Moreover, the fundamental mechanisms and electron-hole separation of different heterojunction systems are summarized. The proposed degradation pathways of tetracycline during heterojunction photocatalysis also are assessed. Furthermore, the photocatalytic performance of heterogeneous heterojunction photocatalysts is objectively evaluated and compared using several quantified metrics including quantum efficiency, space time yields, and figures of merit. Finally, future research requirements for heterojunctions and their applications in water environmental remediation are discussed as well.

\section{Mechanisms of semiconductor heterojunction photocatalysis and the separation of electron-hole pairs}

Several researches have reported the basic photophysical and photochemical mechanisms underlying heterojunction photocatalysis (Low et al. 2017; Wang et al. 2014; Xu et al. 2019; Yu et al. 2014a). An appropriate heterojunction interface can effectively inhibit the recombination of photoinduced $\mathrm{e}^{-}$and $\mathrm{h}^{+}$during photocatalysis, thereby enhancing the overall photoactivity of catalysts ( $\mathrm{Li}$ and $\mathrm{Li} 2020$ ). Heterojunction typically could be grouped into six categories based on the heterojunction structure: traditional (e.g., type I, type II, and type III), p-n, Z-scheme, step-scheme, Schottky, and surface heterojunctions (He et al. 2020b; Yang et al. 2021c). Various heterojunction architectures generally show diverse photocatalysis procedures and mechanisms for the separation of photoexcited carriers. 
Fig. 1 Schematic illustration of band structure and charge carries transfer of traditional heterojunction systems. a Type I: both $\mathrm{e}^{-}$and $\mathrm{h}^{+}$migrate to the same semiconductor photocatalyst. b Type II: $\mathrm{e}^{-}$and $\mathrm{h}^{+}$transfer to the photocatalyst with a lower conduction band and the photocatalyst with a higher valence band, respectively. $\mathrm{c}$ Type III: migration of $\mathrm{e}^{-}$and $\mathrm{h}^{+}$ between the two semiconductors cannot occur (Reprinted with permission of Wiley from Low et al. 2017). $\mathrm{e}^{-}$, electron; $\mathrm{h}^{+}$, hole; $\mathrm{CB}$, conduction band; $\mathrm{VB}$, valence band
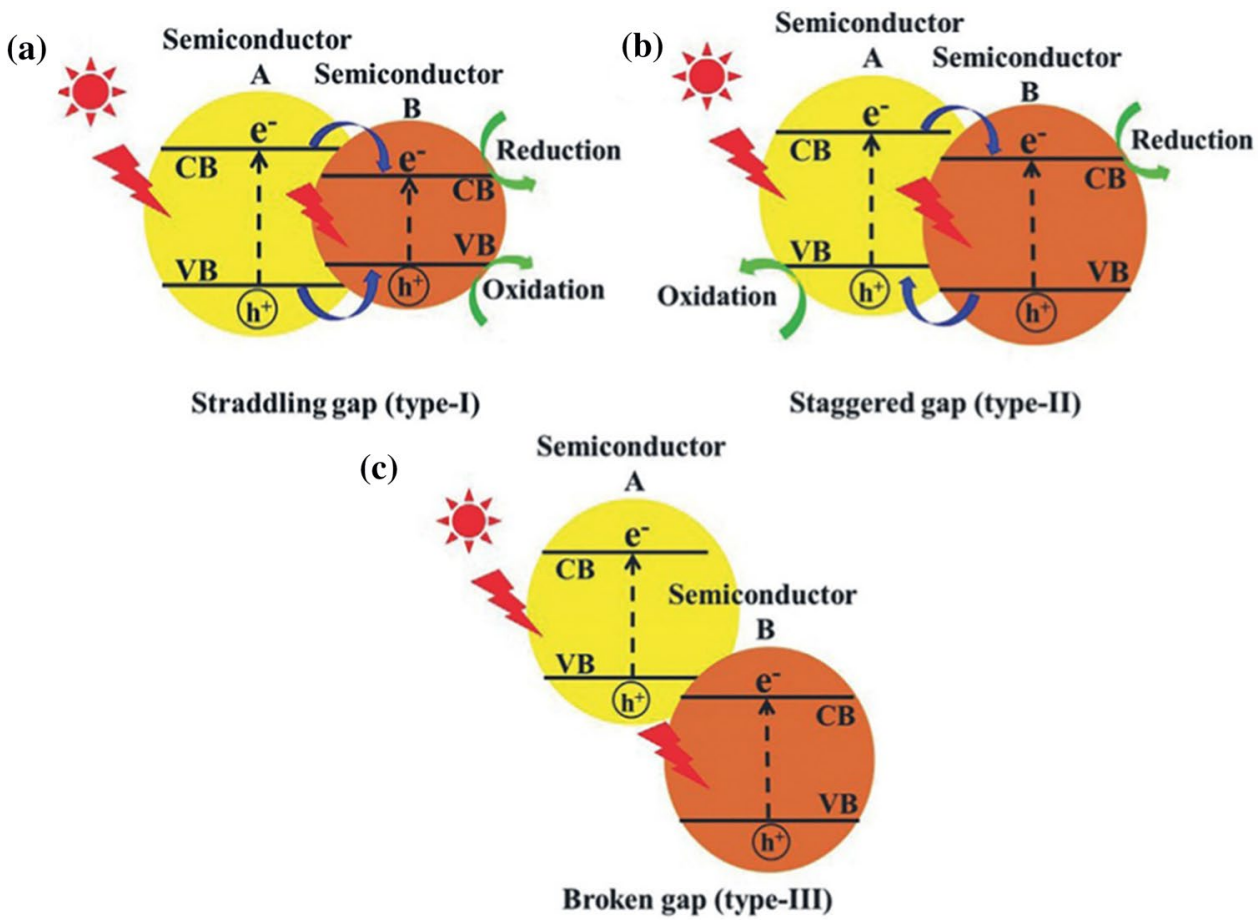

\section{Traditional heterojunction}

Both photogenerated electrons and holes in a conventional type I heterojunction photocatalyst can flow from the semiconductor with the higher conduction and lower valence bands to another semiconductor (Fig. 1a) (Marschall 2014). However, type I heterojunction cannot spatially separate charge carriers, leading to the accumulation of electron-hole pairs in the same semiconductor, thus accelerating their recombination. Besides, photocatalysis reactions occur in the semiconductor with relatively lower oxidation and reduction potential (Low et al. 2017), reducing photocatalysis performance under light irradiation. In type II heterojunctions (Fig. 1b), the electrons transfer to the semiconductor with a lower conduction band level. Meanwhile, holes transfer to the semiconductor with a higher valence band level, decreasing the contact and recombination of electron-hole pairs (Zhou et al. 2012). Although the structure of type III heterojunction (Fig. 1c) is similar to that of type II, the bandgaps of both semiconductors do not overlap in the interface since the levels of band is set so extreme (Lu et al. 2019). In terms of traditional heterojunction system, only type II heterojunction can be an ideal system to improve the separation of electron and holes.
Yuan et al. (2019b) prepared a novel type II $\mathrm{In}_{2} \mathrm{~S}_{3} / \mathrm{InVO}_{4}$ heterojunction by loading $\mathrm{Na}_{2} \mathrm{~S}$ with pre-synthesized $\mathrm{InVO}_{4}$ microspheres in a reaction solution (Fig. 2a). The as-prepared $\mathrm{In}_{2} \mathrm{~S}_{3} / \mathrm{InVO}_{4}$ composite showed outstanding photocatalytic performance for tetracycline degradation under visible light. The photo-activity of $\operatorname{In}_{2} \mathrm{~S}_{3} / \mathrm{InVO}_{4}$ was 11.71 times and 2.26 times higher than that of pristine $\mathrm{InVO}_{4}$ and $\operatorname{In}_{2} \mathrm{~S}_{3}$, respectively. The photosensitization of $\mathrm{InVO}_{4}$ by $\mathrm{In}_{2} \mathrm{~S}_{3}$ and enhanced charge separation through the compact interface junction between semiconductors significantly promoted photocatalytic activity of $\mathrm{In}_{2} \mathrm{~S}_{3} / \mathrm{InVO}_{4}$. Huang et al. (2019) also synthesized a series of different hierarchical heterojunctions, including g- $\mathrm{C}_{3} \mathrm{~N}_{4} / \mathrm{BiOI}$ (type I), g- $\mathrm{C}_{3} \mathrm{~N}_{4} / \mathrm{Bi}_{4} \mathrm{O}_{5} \mathrm{I}_{2}$ (type I), and $\mathrm{g}^{-} \mathrm{C}_{3} \mathrm{~N}_{4} / \mathrm{Bi}_{5} \mathrm{O}_{7} \mathrm{I}$ (type II) using direct precipitation and in situ calcination transformation (Fig. $2 \mathrm{~b}-\mathrm{d}$ ). g- $\mathrm{C}_{3} \mathrm{~N}_{4} / \mathrm{Bi}_{5} \mathrm{O}_{7} \mathrm{I}$ had the highest tetracycline photodegradation activity due to its increased specific surface area, leading to highly efficient charge separation in type II heterojunction.

\section{p-n heterojunction}

Internal electric field occurs on the interface between $\mathrm{p}$ - and $\mathrm{n}$-type semiconductors in the $\mathrm{p}-\mathrm{n}$ heterostructure system due to the diffusion of charge carriers between two types of semiconductors (Fig. 3) (He et al. 2021a). This internal 


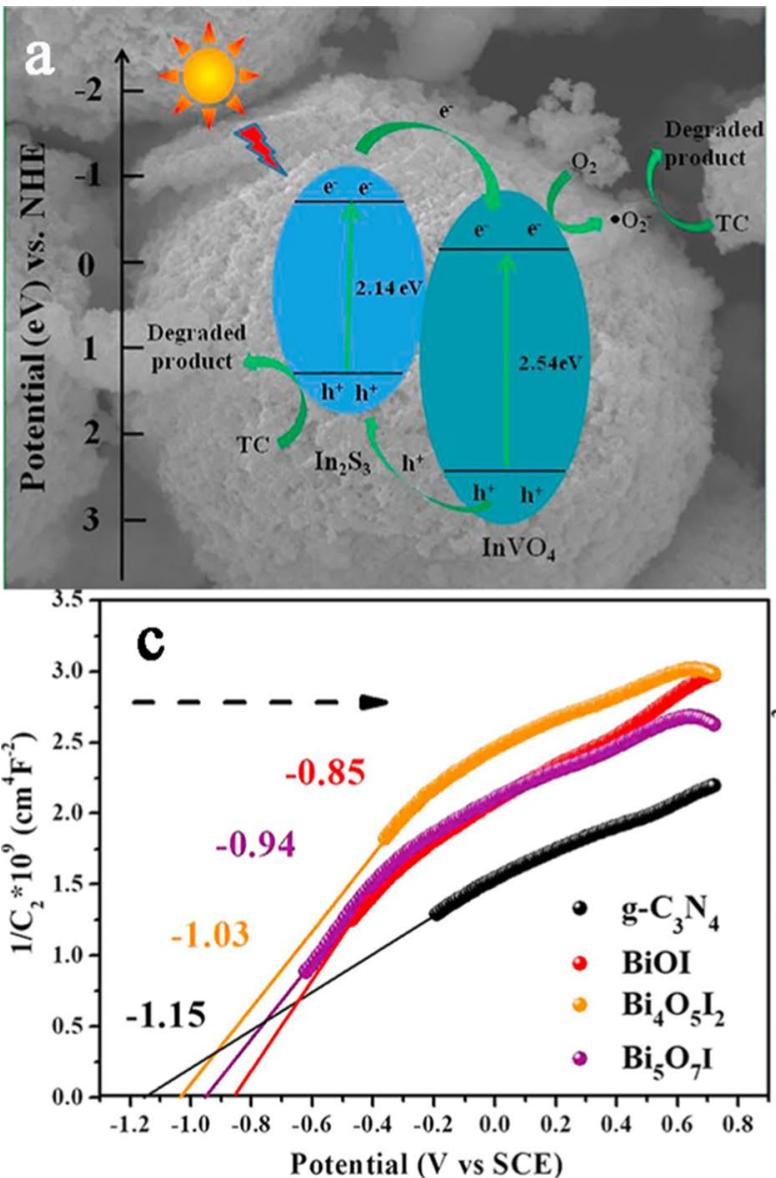

Fig. 2 a The possible charge-transfer mechanism of $\mathrm{In}_{2} \mathrm{~S}_{3} / \mathrm{InVO}_{4}$ : type II heterojunction system built between $\operatorname{In}_{2} \mathrm{~S}_{3}$ and $\mathrm{InVO}_{4}$ (Reprinted with permission of Elsevier from Yuan et al. 2019b). b The synthesis process, $\mathbf{c}$ Mott-Schottky curves, and d transient pho-

electric field quickly drives electrons to the conduction band of n-type semiconductor and holes to the valence band of p-type semiconductor. Therefore, the presence of the internal electric field in $\mathrm{p}-\mathrm{n}$ heterojunction system ultimately effectively separates electrons and holes.

Liao and co-workers (Liao et al. 2020) constructed a visible-light-driven $\mathrm{BiFeO}_{3} / \mathrm{TiO}_{2}$ p-n heterojunction composite via facile hydrolysis and precipitation method (Fig. 4a-c). $\mathrm{BiFeO}_{3} / \mathrm{TiO}_{2}, \mathrm{BiFeO}_{3}$, and $\mathrm{TiO}_{2}$ had tetracycline degradation efficiency of $72.2 \%, 64.9 \%$, and $38.3 \%$, respectively, after 180 min of visible illumination. $\mathrm{BiFeO}_{3} / \mathrm{TiO}_{2}$ had an enhanced photocatalytic performance due to the synergistic effect of the ferroelectric effect of $\mathrm{BiFeO}_{3}$ with the internal electric field of $\mathrm{BiFeO}_{3} / \mathrm{TiO}_{2} \mathrm{p}-\mathrm{n}$ heterojunction, which
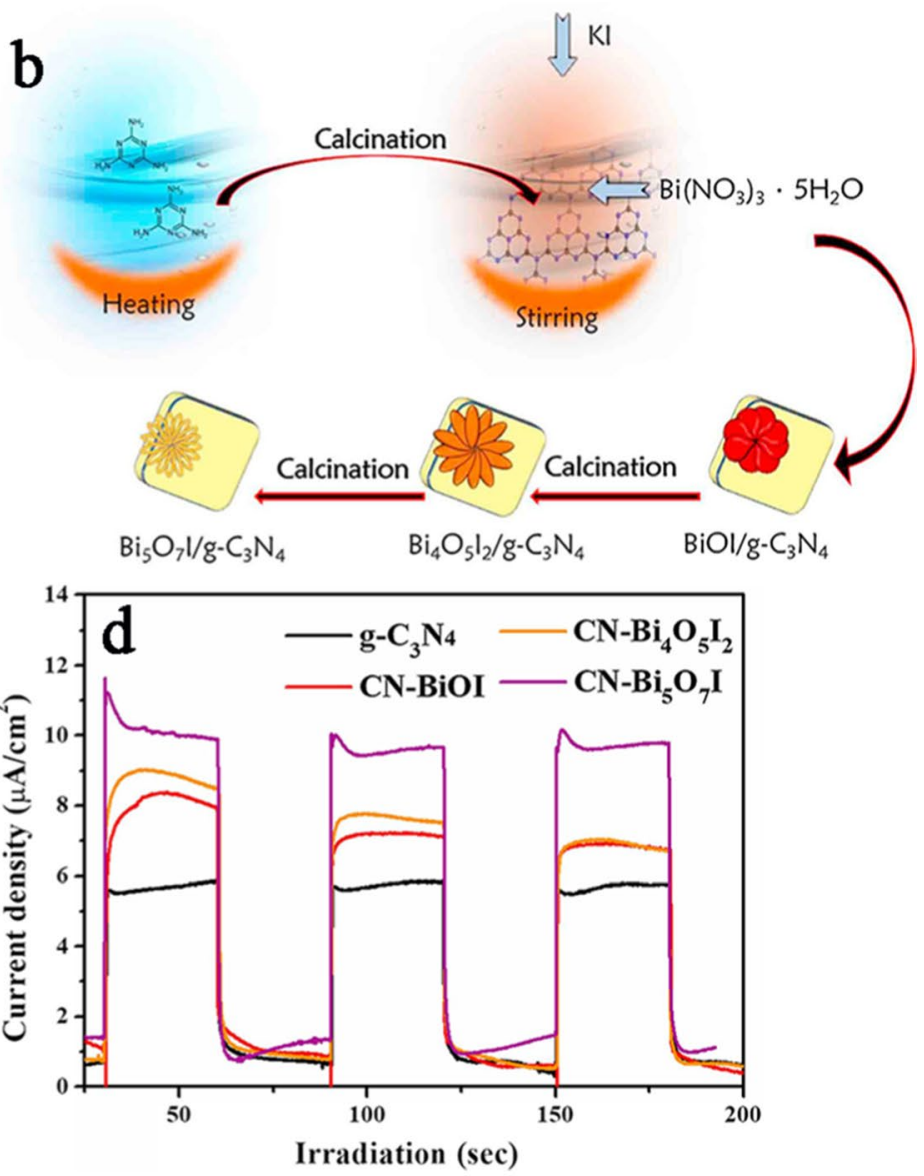

tocurrent responses of $\mathrm{g}-\mathrm{C}_{3} \mathrm{~N}_{4} / \mathrm{BiOI}, \mathrm{g}-\mathrm{C}_{3} \mathrm{~N}_{4} / \mathrm{Bi}_{4} \mathrm{O}_{5} \mathrm{I}_{2}$, and $\mathrm{g}-\mathrm{C}_{3} \mathrm{~N}_{4} /$ $\mathrm{Bi}_{5} \mathrm{O}_{7} \mathrm{I}$ under visible irradiation (Reprinted with permission of Elsevier from Huang et al. 2019). $\mathrm{e}^{-}$, electron; $\mathrm{h}^{+}$, hole; $\cdot \mathrm{O}_{2}{ }^{-}$, superoxide radical; $\mathrm{TC}$, tetracycline

significantly inhibited charge-carrier recombination. Fibershaped $\mathrm{Ag}_{2} \mathrm{O} / \mathrm{Ta}_{3} \mathrm{~N}_{5}$ p-n heterojunctions are efficient photocatalysts designed by combining porous $\mathrm{Ta}_{3} \mathrm{~N}_{5}$ nanofibers with $\mathrm{Ag}_{2} \mathrm{O}$ nanoparticles via in situ anchoring (Fig. 4d-f) (Li et al. 2017). Besides the internal electric field of the p-n junction, $\mathrm{Ag}_{2} \mathrm{O} / \mathrm{Ta}_{3} \mathrm{~N}_{5}$ had hierarchical pores and a high specific surface area, increasing the photocatalytic activity.

\section{Z-scheme heterojunction}

Z-scheme heterojunction can be classified into traditional, all-solid-state, and direct Z-scheme photocatalysts. Their charge-transfer routes are similar but no intermediate is used in direct Z-scheme system (Low et al. 2019; Yu et al. 


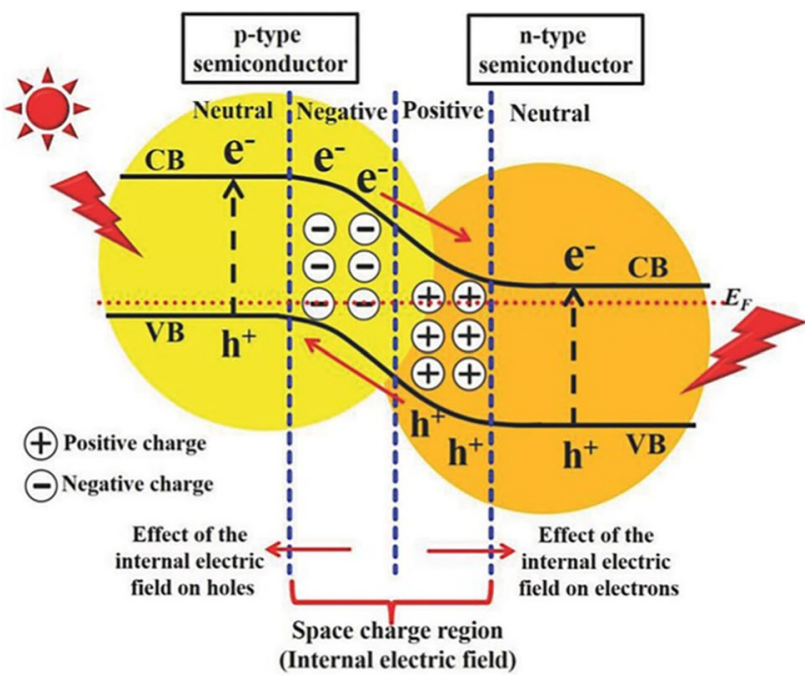

Fig. 3 Schematic illustration of the internal electric field and chargecarrier transfer of a $\mathrm{p}-\mathrm{n}$ heterojunction system: $\mathbf{i}$ before light irradiation, the diffusion of $\mathrm{e}^{-}$and $\mathrm{h}^{+}$between $\mathrm{p}$ - and $\mathrm{n}$-type semiconductors forms an internal electric field. ii After light irradiation, photogenerated $\mathrm{e}^{-}$and $\mathrm{h}^{+}$are, respectively, driven to $\mathrm{n}$ - and p-type semiconductors under the influence of the internal electric field. (Reprinted with permission of Wiley from Low et al. 2017). $\mathrm{e}^{-}$, electron; $\mathrm{h}^{+}$, hole; $\mathrm{CB}$, conduction band; VB, valence band

2018). Recombination in a direct Z-scheme photocatalyst occurs between the weak electrons from the semiconductor with less negative conduction band and holes from the semiconductor with less positive valence band (Fig. 5) (Ani et al. 2018; Qi et al. 2017). Therefore, the holes with high oxidation ability and the electrons with high reduction ability cannot recombine and be continuously maintained for further photocatalytic reactions, hence increasing the total redox potential of the Z-scheme catalyst system. Z-scheme heterojunction provides a new insight for enhancing the photocatalytic activity of photocatalysts: consuming the useless electrons and holes and remaining high redox potential of the whole system.

Li et al. (2018) fabricated a mesoporous Z-scheme heterojunction system with increased specific surface area $\left(124.09 \mathrm{~m}^{2} / \mathrm{g}\right)$ via anchoring $\gamma-\mathrm{Fe}_{2} \mathrm{O}_{3}$ nanoparticles on the surface of $\mathrm{g}-\mathrm{C}_{3} \mathrm{~N}_{4}$ nanosheet to further enhance tetracycline photodegradation under visible light. $\gamma-\mathrm{Fe}_{2} \mathrm{O}_{3} / g-\mathrm{C}_{3} \mathrm{~N}_{4}$ presented the best photocatalytic performance in the case of 5\% $\gamma-\mathrm{Fe}_{2} \mathrm{O}_{3}$ loaded, with a rate constant tetracycline degradation value of $0.0134 \mathrm{~min}^{-1}$ (higher than that of pure $\mathrm{g}-\mathrm{C}_{3} \mathrm{~N}_{4}$, $0.0020 \mathrm{~min}^{-1}$ ). The more superior photocatalytic activity of $\gamma-\mathrm{Fe}_{2} \mathrm{O}_{3} / \mathrm{g}-\mathrm{C}_{3} \mathrm{~N}_{4}$ is due to the extended response range of visible light and improved separation of photogenerated charge carriers in Z-scheme heterostructure. Chen et al. (2016) synthesized a direct $\mathrm{Z}$-scheme heterostructured photocatalyst $\mathrm{AgI} / \mathrm{BiVO}_{4}$ via an in situ precipitation approach (Fig. 6). The $\mathrm{AgI} / \mathrm{BiVO}_{4}$ (1:4 mass ratio) heterojunction demonstrated higher tetracycline degradation efficiency $(94.91 \%)$ than the original $\mathrm{BiVO}_{4}(62.68 \%)$ and $\mathrm{AgI}(75.43 \%)$. The emergence of Ag during photocatalysis process transforms the composite structure from $\mathrm{AgI} / \mathrm{BiVO}_{4}$ into $\mathrm{AgI} / \mathrm{Ag} / \mathrm{BiVO}_{4}$, developing a sandwich-like Z-scheme photocatalyst in AgI, $\mathrm{Ag}$, and $\mathrm{BiVO}_{4}$, thus efficiently enhancing the separation of electron-hole pairs.

\section{Step-scheme heterojunction}

Step-scheme systems are exhibited between two n-type semiconductors with staggered band structure, closely resembling that of type II except for the greatly different path of charge migration (Fig. 7) (Fu et al. 2019; He et al. 2020a; $\mathrm{Xu}$ et al. 2020a). "Step-scheme" is a new concept that can be used to describe the photocatalytic mechanisms clearly. An electric field is formed from the semiconductor with greater work function and lower Fermi level (semiconductor A) to that with smaller work function and higher Fermi level (semiconductor B) due to the spontaneous diffusion of electrons from semiconductor A to B across their interface until the Fermi energy levels of two semiconductors are equal (Hasija et al. 2021; He et al. 2020b). In the same time, the energy band gap of semiconductor A bends upward due to electron depletion, and that of semiconductor B bends downward due to electron accumulation (Hasija et al. 2021; $\mathrm{He}$ et al. 2020a). Therefore, the weak reductive electrons from the conduction band of semiconductor B will recombine with the weak oxidative holes from the valence band of semiconductor A under the effect of built-in electric field, band edge bending, and Coulombic interactions, similar to Z-scheme heterostructure. (Fan et al. 2020). Photocatalytic reduction and oxidation reactions occur on the surface of the high-potential semiconductor B and A, respectively (Li et al. 2021b). The concept of step-scheme is the first to propose the transfer of charge carriers under the effect of band bending, which is similar to how water flows downhill.

Step-scheme heterostructure has been widely designed and used to decompose tetracycline antibiotics in an aqueous solution. For instance, a flower-like step-scheme $\mathrm{BiOBr} /$ $\mathrm{BiO}\left(\mathrm{CH}_{3} \mathrm{COO}\right)_{1-\mathrm{x}} \mathrm{Br}_{\mathrm{x}}$ was successfully constructed by Jia et al. (2020) through a simple co-precipitation procedure at room temperature (Fig. 8). The pre-synthesized stepscheme junction exhibited outstanding visible-light-driven photocatalytic properties especially when the molar ratio 

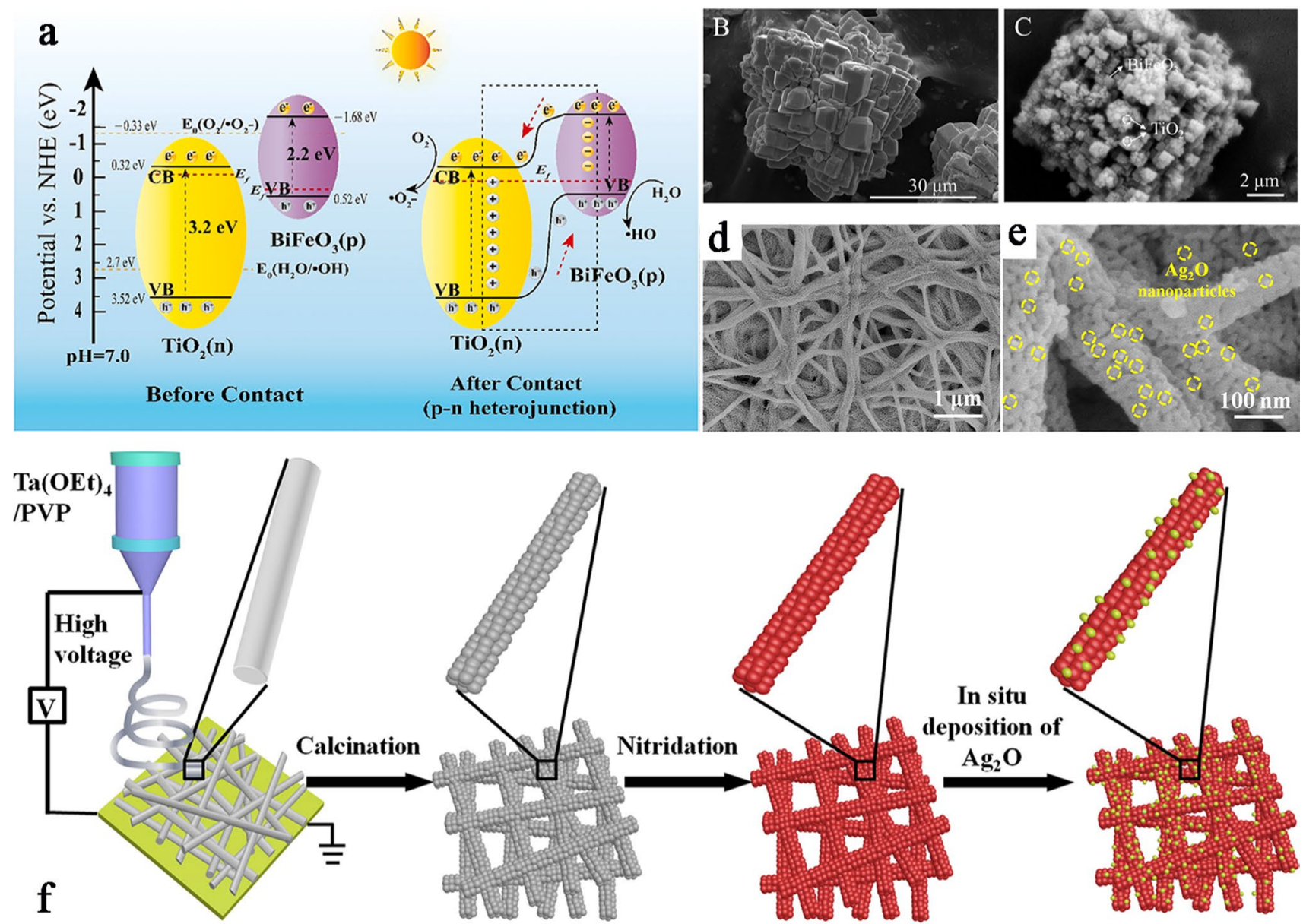

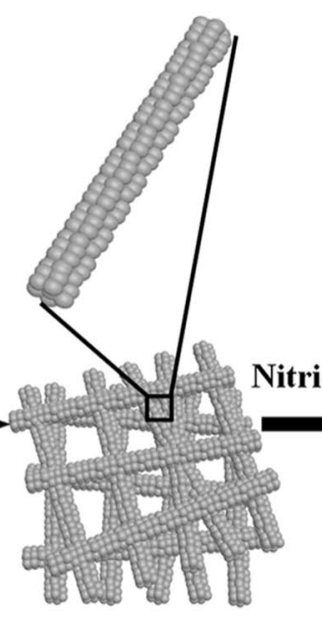

$\mathrm{Ta}_{2} \mathrm{O}_{5} / \mathrm{Ta}(\mathrm{OEt})_{4} / \mathrm{PVP}$ nonwoven cloth
$\mathrm{Ta}_{2} \mathrm{O}_{5}$ nonwoven cloth
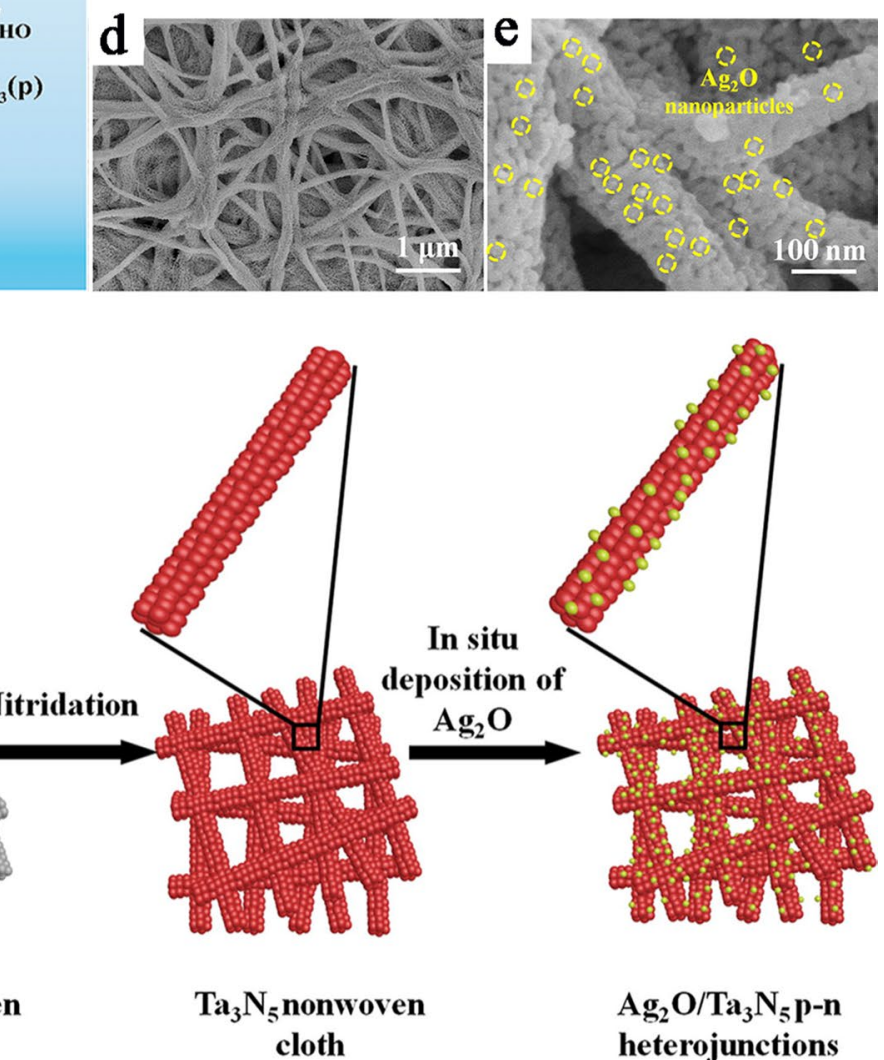

Fig. 4 a The degradation mechanism and charge-transfer pathway of $\mathrm{BiFeO}_{3 /} \mathrm{TiO}_{2}$. $\mathrm{p}$-n heterojunction system occurred between $\mathrm{BiFeO}_{3}$ and $\mathrm{TiO}_{2}$ b and $\mathbf{c}$ Scanning electron microscopy images of $\mathrm{BiFeO}_{3 /} \mathrm{TiO}_{2}$ p-n heterojunction (Reprinted with permission of Elsevier from Liao et al. 2020). d and e Scanning electron microscopy

of $\mathrm{Br} / \mathrm{Bi}$ was 0.8 with tetracycline degradation efficiency of $99.2 \%$ after $2 \mathrm{~h}$ of illumination. The enhanced photocatalytic activity of $\mathrm{BiOBr} / \mathrm{BiO}\left(\mathrm{CH}_{3} \mathrm{COO}\right)_{1-\mathrm{x}} \mathrm{Br}_{\mathrm{x}}$ photocatalyst was due to: (i) flower-like contour greatly improved the dispersion, thereby accelerating the migration of charge carrier at the interfaces and photocatalyst surface; (ii) the visible light response of the whole composite was enlarged, developing a step-scheme junction owing to the formation of the solid solution $\mathrm{BiOBr} / \mathrm{BiO}\left(\mathrm{CH}_{3} \mathrm{COO}\right)_{1-\mathrm{x}} \mathrm{Br}_{\mathrm{x}}$. Fan et al. (2020) images and $\mathbf{f}$ preparation process of $\mathrm{Ag}_{2} \mathrm{O} / \mathrm{Ta}_{3} \mathrm{~N}_{5}$ p-n heterojunction (Reprinted with permission of Elsevier from Li et al. 2017). $\mathrm{e}^{-}$, electron; $\mathrm{h}^{+}$, hole; $\mathrm{CB}$, conduction band; $\mathrm{VB}$, valence band; $\mathrm{OH}$, hydroxyl radical

fabricated a face-to-face hierarchical $\operatorname{In}_{2} \mathrm{~S}_{3} / \mathrm{Bi}_{2} \mathrm{O}_{2} \mathrm{CO}_{3}$ photocatalyst. The pre-prepared composite had a two-dimension 2D/2D step-scheme structure and excellent photocatalytic performance and cycling ability for tetracycline. This optimized photodegradation capability of the $\mathrm{In}_{2} \mathrm{~S}_{3} / \mathrm{Bi}_{2} \mathrm{O}_{2} \mathrm{CO}_{3}$ heterostructure was ascribed to the increased visible response region and restrained electron-hole recombination in step-scheme heterojunction. 


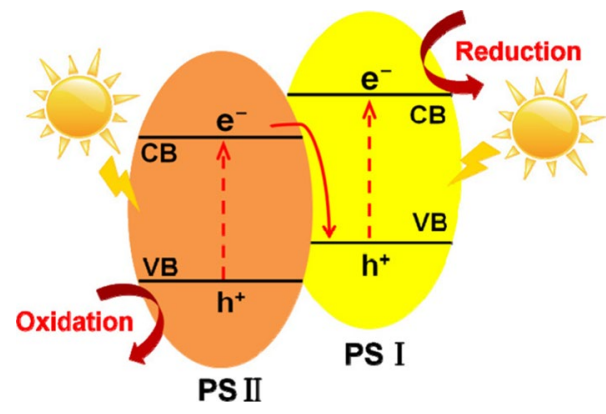

Fig. 5 Schematic illustration of the energy band structure and chargecarrier transfer on a direct Z-scheme heterojunction system: $\mathrm{e}^{-}$from PS II directly recombine with $\mathrm{h}^{+}$from PS I. Thus, $\mathrm{e}^{-}$with high reduction potential in PS I and $\mathrm{h}^{+}$with high oxidation potential in PS II can be remained. (Reprinted with permission of Elsevier from Qi et al. 2017). $\mathrm{e}^{-}$, electron; $\mathrm{h}^{+}$, hole; $\mathrm{CB}$, conduction band; VB, valence band; PS, photosystem

\section{Schottky heterojunction}

Schottky junctions are formed by contact between a semiconductor photocatalyst and a metal (Fig. 9) (Di Bartolomeo 2016). Photogenerated electron can transfer from metal to a semiconductor due to their unequal Fermi energies, thus building the Schottky barrier (Yang et al. 2021c), which suppresses the recombination of charge carrier.

2D/2D ultrathin interfacial Schottky $\mathrm{Ti}_{3} \mathrm{C}_{2}$ Mxene/ $\mathrm{SnNb}_{2} \mathrm{O}_{6}$ nanosheets were synthesized by Wang and coworkers (Wang et al. 2021a) through an ultrasonicationassisted hydrothermal procedure (Fig. 10a-d). The 2D/2D $\mathrm{Ti}_{3} \mathrm{C}_{2} / \mathrm{SnNb}_{2} \mathrm{O}_{6}$ had broadened visible response and larger interfacial contact area. The internal electric field effectively separated the charge in $\mathrm{Ti}_{3} \mathrm{C}_{2} / \mathrm{SnNb}_{2} \mathrm{O}_{6}$ system, leading to a higher photocatalytic degradation efficiency of tetracycline with a high optimal reaction rate, which was 2.53 times that of pure $\mathrm{SnNb}_{2} \mathrm{O}_{6}$. Luo et al. (2015) prepare a $\mathrm{Ag} / \mathrm{Bi}_{3} \mathrm{TaO}_{7}$ plasmonic photocatalyst with a Schottky junction using a facile photoreduction method (Fig. 10e). The synergistic effect of the surface plasmon resonance of $\mathrm{Ag}$ particle on the surface of $\mathrm{Bi}_{3} \mathrm{TaO}_{7}$ improved the separation process of carriers, thus heightening the photocatalytic activity of the whole composite. The best performance of tetracycline degradation of $85.42 \%$ by $\mathrm{Ag} / \mathrm{Bi}_{3} \mathrm{TaO}_{7}$ was exhibited when $1 \mathrm{wt}$ $\% \mathrm{Ag}$ loaded on the surface of $\mathrm{Bi}_{3} \mathrm{TaO}_{7} . \mathrm{Ag} / \mathrm{Bi}_{3} \mathrm{TaO}_{7}$ also showed excellent recyclability and only a slight degradation efficiency loss after five successive cycles.

\section{Surface heterojunction}

Surface heterojunction mainly consists of two different crystal facets of a single semiconductor (Fig. 11) (Sajan et al. 2016; Yu et al. 2014b). The proposed mechanism underlying the separation of photosensitized carriers in surface heterojunction is similar to that of type II (Zhou and Li 2012). Nevertheless, the redox potential of surface heterojunction is lower than that of type II heterojunction due to the insignificantly different band structures of two coexposed facets of a single semiconductor (He et al. 2020b).

The aforementioned heterojunctions are binary systems, and the behavior of electrons and holes has been discussed based on binary photocatalyst structures. Various ternary and quaternary heterojunction composites have been recently constructed to enhance photocatalytic activity (Jo and Tonda 2019; Yang et al. 2020).

Some studies have indicated that the separation mechanisms of charge carriers in ternary and quaternary heterojunction following that of binary heterojunction systems. $\mathrm{Ni}$ et al. (2020) successfully synthesized a ternary sandwichlike $\mathrm{TiO}_{2-\mathrm{x}}$ /ultrathin $\mathrm{g}-\mathrm{C}_{3} \mathrm{~N}_{4} / \mathrm{TiO}_{2-\mathrm{x}}$ for efficient degradation of tetracycline under visible light and found that direct Z-scheme system was introduced to this ternary heterojunction (Fig. 12). Liu et al. (2021) synthesized a visible-lightdriven $\mathrm{g}^{-} \mathrm{C}_{3} \mathrm{~N}_{4} / \mathrm{TiO}_{2} / \mathrm{CdS}$ ternary heterojunction nanocomposite to effectively remove tetracycline antibiotics from wastewater (Fig. 13a, b). The separation mechanism of electron-hole pair in $\mathrm{g}-\mathrm{C}_{3} \mathrm{~N}_{4} / \mathrm{TiO}_{2} / \mathrm{CdS}$ was similar to that of Z-scheme heterojunction. Yan et al. (2021a) developed an $\mathrm{Ag} / \gamma-\mathrm{AgI} / \mathrm{Bi}_{2} \mathrm{O}_{2} \mathrm{CO}_{3} / \mathrm{Bi}$ quaternary composite photocatalyst via a solvothermal-precipitation method and obtained a step-scheme structure (Fig. 13c, d). However, the transfer process of carriers of many other ternary and quaternary heterojunction systems is so complex and cannot be clearly and systematically explained. Heterogeneous heterojunction systems and their corresponding mechanisms regarding the migration of photogenerated carriers and degradation of tetracycline antibiotics are listed in Table 1.

\section{Proposed photodegradation pathways of tetracycline}

Various heterojunction photocatalysts have been used for the photodestruction of tetracycline in aqueous solutions. The breakdown of tetracycline molecules involves the attack of some sites by various reactive oxygen species generated during the heterogeneous photocatalysis processes. Tetracycline degradation during photocatalytic reactions generally arises from the breakdown of double bonds, phenolic group, $\mathrm{N}$-dimethyl group, and the amine group of the tetracycline molecule (Wang et al. 2018b). These sites are highly functional groups and electron-rich positions that can be attacked by active radicals, including $\mathrm{O}_{2}{ }^{-}, \mathrm{OH}, \mathrm{h}^{+}$, and $\mathrm{H}_{2} \mathrm{O}_{2}$ (Ren et al. 2019). Extensive studies have reported on the possible photocatalytic degradation pathways of tetracycline antibiotics. Herein, we summarized the five plausible routes for photocatalytic mineralization of tetracycline based on the 

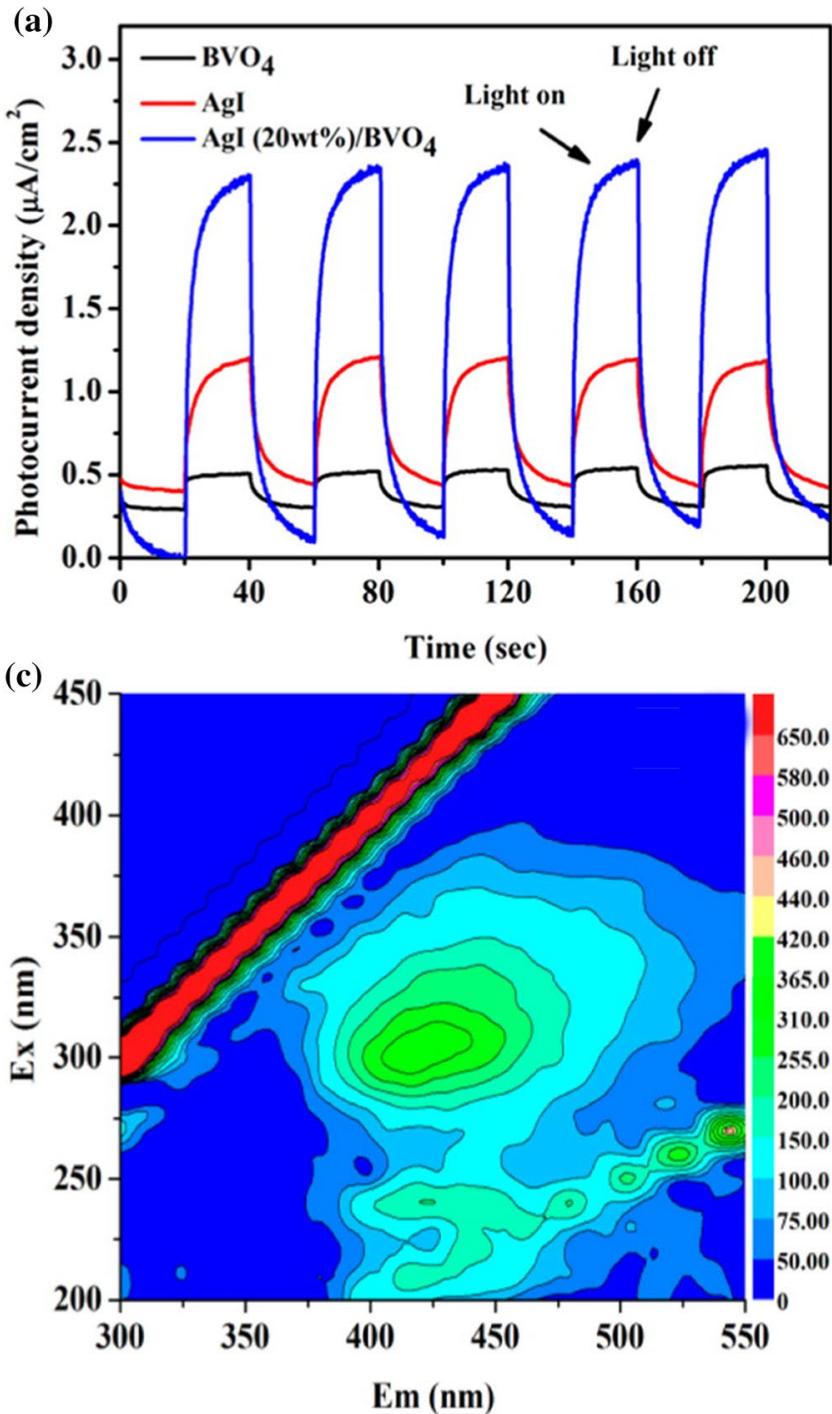

Fig. 6 a Photocurrent responses of $\mathrm{AgI}, \mathrm{BiVO}_{4}$, and $\mathrm{AgI} / \mathrm{BiVO}_{4}$ b Photocatalysis mechanism of tetracycline degradation under visible light illumination using $\mathrm{AgI} / \mathrm{BiVO}_{4}$ photocatalyst: Z-scheme heterojunction system. 3D EEMs after c 30 and d 60 min irradiation: fluorescence signals increased with the irradiation time, suggesting the

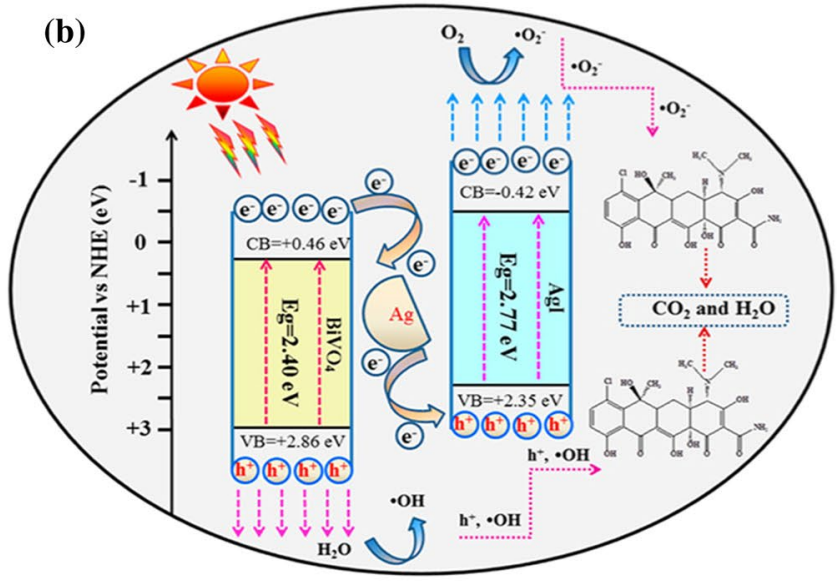

(d)

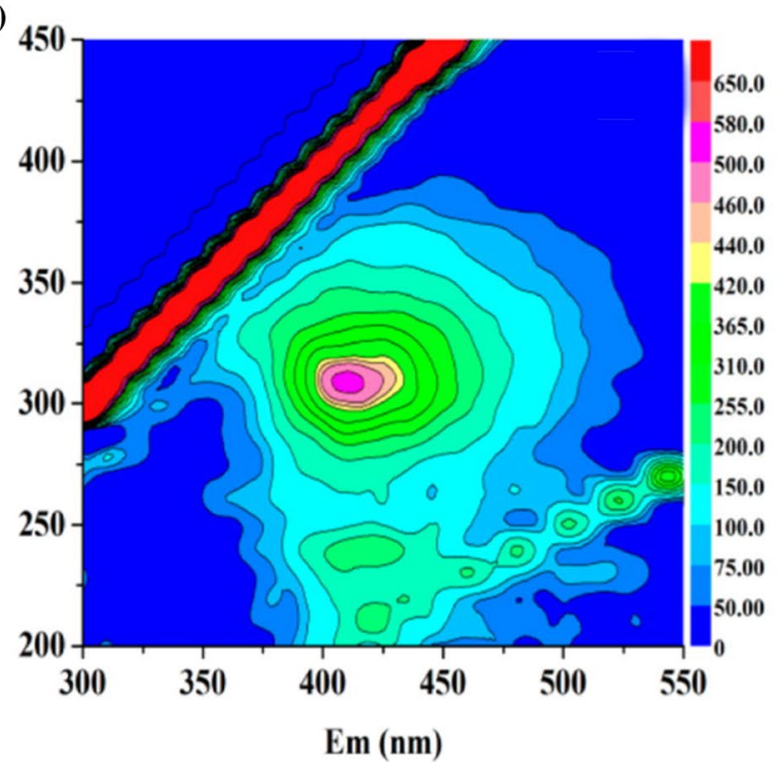

decomposition of tetracycline under light over $\mathrm{AgI} / \mathrm{BiVO}_{4}$ (Reprinted with permission of American Chemical Society from Chen et al. 2016). 3D, three-dimensional; EEMs, excitation-emission matrix fluorescence spectroscopy

tetracycline also may take place an addition reaction to form A3 $(\mathrm{m} / \mathrm{z}=450)$. A4 $(\mathrm{m} / \mathrm{z}=248)$ is formed when the A3 is further broken down, producing A5 $(\mathrm{m} / \mathrm{z}=190)$ after the loss of hydroxyl and methyl groups.

It has been proposed that $\mathrm{O}_{2}{ }^{-{ }^{-}}$and $\mathrm{H}_{2} \mathrm{O}_{2}$ can also attack the benzene ring of tetracycline to generate product $\mathrm{A} 6$ ( $\mathrm{m} / \mathrm{z}=525) \cdot \mathrm{O}_{2}{ }^{-}$- radical and $\mathrm{H}_{2} \mathrm{O}_{2}$ can further oxidize $\mathrm{N}$-dimethyl group at $\mathrm{C} 12$ and $-\mathrm{C}(\mathrm{O}) \mathrm{NH}_{2}$ group at $\mathrm{C} 2$ to produce $\mathrm{A} 7(\mathrm{~m} / \mathrm{z}=496)$ and $\mathrm{A} 8(\mathrm{~m} / \mathrm{z}=451)$, respectively. Subsequently, oxidization at the double bond of A8 can then form A9 $(\mathrm{m} / \mathrm{z}=367)$ (Xie et al. 2018). A9 can then be transformed to an identical ketone derivative A10 $(\mathrm{m} / \mathrm{z}=351)$. 


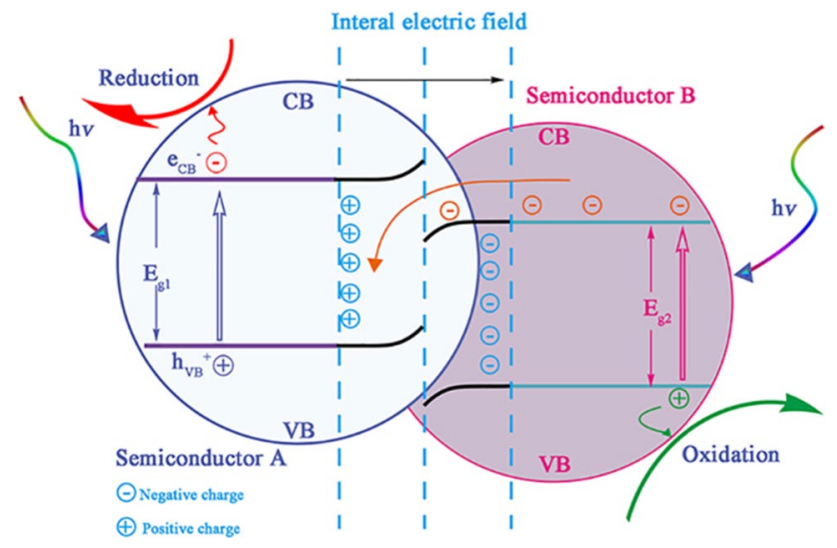

Fig. 7 Schematic illustration of the internal electric field and chargecarrier migration on a step-scheme heterojunction system: i An internal electric field is built due to the Femi energy equilibrium; ii Femi levels of semiconductor A and B bend upward and downward, respectively; iii recombination occurs between $\mathrm{e}_{\mathrm{CB}}{ }^{-}$of semiconductor $\mathrm{B}$ and $\mathrm{h}_{\mathrm{VB}}{ }^{+}$of semiconductor A (Reprinted with permission of Elsevier from $\mathrm{He}$ et al. 2020b). $\mathrm{e}_{\mathrm{CB}}{ }^{-}$, electron; $\mathrm{h}_{\mathrm{VB}}{ }^{+}$, hole; $\mathrm{CB}$, conduction band; $\mathrm{VB}$, valence band; $\mathrm{E}_{\mathrm{g}}$, energy gap

In the end, $\mathrm{O}_{2}{ }^{-}$and $\mathrm{H}_{2} \mathrm{O}_{2}$ continue decomposing $\mathrm{A} 10$ to carboxylic acids $\mathrm{A} 11(\mathrm{~m} / \mathrm{z}=255), \mathrm{CO}_{2}$, and $\mathrm{H}_{2} \mathrm{O}$.

For fragment $\mathrm{A} 1 \mathrm{~b},-\mathrm{OH}$ and $-\mathrm{CH}_{3}$ in $\mathrm{N}$-dimethyl group and $\mathrm{C} 8$ site are removed after attacking by $\mathrm{h}^{+}$, producing A12 $(\mathrm{m} / \mathrm{z}=447)$ and A13 (m/z=433) (Yan et al. 2021b). Then, A13 is further transformed into A14 $(\mathrm{m} / \mathrm{z}=288)$ and A15 $(\mathrm{m} / \mathrm{z}=211)$. Finally, A15 split into small fragments, including A16a $(\mathrm{m} / \mathrm{z}=135)$ and A16b $(\mathrm{m} / \mathrm{z}=121)$.

\section{Second possible pathway: attack on amide group}

The attack of the acylamino group at the $\mathrm{C} 1$ site is the second possible degradation site for tetracycline via heterojunction photocatalysis (Scheme 2). The attack of $\mathrm{OH}$ results in the deamidation of the tetracycline structure, forming an intermediate B1 ( $\mathrm{m} / \mathrm{z}=429)$ (Ma et al. 2019). By-products B2 $(\mathrm{m} / \mathrm{z}=386)$ (Shi et al. 2020a) and B3 $(\mathrm{m} / \mathrm{z}=352)$ are obtained via the cleavage of $\mathrm{N}, \mathrm{N}$-dimethyl group and subsequent dehydration of B1. The loss of the aldehyde group and breaking of the carbon-carbon diene bonds of B3 form B4 $(\mathrm{m} / \mathrm{z}=344)$ and B5 $(\mathrm{m} / \mathrm{z}=332)$ (Zhang et al. 2021). A further attack by reactive oxygen species produces B6 $(\mathrm{m} / \mathrm{z}=276)$. B7 with $\mathrm{m} / \mathrm{z}=246$ can also be produced via the cleavage of the double bonds of B3. Finally, further dehydroxylation and hydrogenation of B7 form B8 $(\mathrm{m} / \mathrm{z}=218)$.

It is inferred that acylamino group of tetracycline lost to boost $\mathrm{B} 9(\mathrm{~m} / \mathrm{z}=402)$. $\mathrm{OH}$ radicals can damage the carbon ring of $\mathrm{B} 9$, thus forming $\mathrm{B} 10(\mathrm{~m} / \mathrm{z}=418)$ via hydroxylation (Wang et al. 2019). Two molecular hydrogens can then be removed from B10 to form B11 (m/z=416) via dehydrogenation reaction. (Chen et al. 2020b) proposed that
$-\mathrm{NH}_{2}$ group of tetracycline could be oxidized to produce $\mathrm{B} 12(\mathrm{~m} / \mathrm{z}=446)$. B12 dehydroxylation, deamidation, demethylation, and deamination form B13 $(\mathrm{m} / \mathrm{z}=408), \mathrm{B} 14$ $(\mathrm{m} / \mathrm{z}=390)$, and B15 $(\mathrm{m} / \mathrm{z}=320)$.

\section{Third possible pathway: attack on $\mathrm{N}$-dimethyl group}

The attack on the $\mathrm{N}$-dimethyl group is the third possible degradation route of tetracycline during the photocatalysis process (Scheme 3 ). It is suggested that the decomposition of tetracycline after successive losing of methyl on the $\mathrm{N}$-dimethyl group (Mahamallik et al. 2015) and C8 site induces the formation of D1 $(\mathrm{m} / \mathrm{z}=416)$ and $\mathrm{D} 2(\mathrm{~m} / \mathrm{z}=402)$ (Shi et al. 2020c). The attack of $h^{+}$promotes the process of N-demethylation. Separation of $-\mathrm{C}(\mathrm{O}) \mathrm{NH}_{2}$ group from cyclic structure and hydroxylation addition reaction on C2 transforms D2 into D3 $(\mathrm{m} / \mathrm{z}=377)$. Intermediates D4 $(\mathrm{m} / \mathrm{z}=274)$ and $\mathrm{D} 5(\mathrm{~m} / \mathrm{z}=186)$ associated with the destruction of carbon-carbon ring of D3. D5 can be further fragmented into D6 $(\mathrm{m} / \mathrm{z}=160)$ via losing $-\mathrm{CH}=\mathrm{CH}_{2}$ group.

Pervious research found that area of high energy in D1 molecule can be further damaged to form D7 $(\mathrm{m} / \mathrm{z}=400)$ and $\mathrm{D} 8(\mathrm{~m} / \mathrm{z}=353)$ (Ren et al. 2019). D8 then can be decomposed into $\mathrm{D} 9 \mathrm{a}(\mathrm{m} / \mathrm{z}=233)$ and $\mathrm{D} 9 \mathrm{~b}(\mathrm{~m} / \mathrm{z}=183)$ due to the synergistic effect of $\mathrm{OH}, \mathrm{O}_{2}{ }^{-}$, and $\mathrm{h}^{+}$. Further attack of $\mathrm{O}_{2}{ }^{-}{ }^{-}$and $\mathrm{h}^{+}$will result in the formation of A11. Jiang et al. (2017) suggested that D2 can be transformed into D10 $(\mathrm{m} / \mathrm{z}=333)$. Also, the removal of carboxyl groups and addition reaction on $\mathrm{C} 7$ generate $\mathrm{D} 11(\mathrm{~m} / \mathrm{z}=244)$.

Lai et al. (2021) found that N-dimethyl group in tetracycline can be directly oxidized into carbonyl group and generate $\mathrm{E} 1(\mathrm{~m} / \mathrm{z}=415)$. Then, $\mathrm{E} 1 \mathrm{can}$ undergo ring opening reaction to form $\mathrm{E} 2(\mathrm{~m} / \mathrm{z}=332)$, which is further converted into $\mathrm{E} 3(\mathrm{~m} / \mathrm{z}=318)$. Intermediate $\mathrm{E} 4(\mathrm{~m} / \mathrm{z}=430)$ generates when $-\mathrm{CH}_{3}$ is separated from the $\mathrm{N}$-dimethyl group. The removal of $-\mathrm{NH}-\mathrm{CH}_{3}$ and $-\mathrm{CONH}_{2}$ group of $\mathrm{E} 4$ forms $\mathrm{E} 5 \mathrm{a}$ $(\mathrm{m} / \mathrm{z}=358)$, which splits into $\mathrm{E} 6(\mathrm{~m} / \mathrm{z}=276), \mathrm{CO}_{2}$, and $\mathrm{H}_{2} \mathrm{O}$.

Xie et al. (2018) indicated that E4 can be transferred into D1 or E5b $(\mathrm{m} / \mathrm{z}=395)$ after the attack of $h^{+}$. Ring opening due to the fracture of carbon-carbon single bone forms $\mathrm{E} 9(\mathrm{~m} / \mathrm{z}=359)$. $\mathrm{E} 7(\mathrm{~m} / \mathrm{z}=359)$ is generated from the detachment of the hydroxyl functional group on $\mathrm{C} 8$ site and $-\mathrm{CONH}_{2}$ group of D1 (Yang et al. 2020). Further attack of free radicals transforms E7 into E8 $(\mathrm{m} / \mathrm{z}=248)$. Eventually, all intermediates are decomposed into inorganic substances.

It has been suggested that $\mathrm{C}-\mathrm{N}$ bond of tetracycline is easily fractured, and substitution of the hydroxyl group may occur in position of $\mathrm{C} 12$, forming $\mathrm{E} 10(\mathrm{~m} / \mathrm{z}=389)$. Several compounds, such as E11 $(\mathrm{m} / \mathrm{z}=387), \mathrm{E} 12(\mathrm{~m} / \mathrm{z}=371)$, and $\mathrm{E} 13(\mathrm{~m} / \mathrm{z}=355)$ can be formed after carbonylation, demethylation, and dihydroxylation of the E10 derivate. The removal of benzene ring from E13 directly forms E14 $(\mathrm{m} / \mathrm{z}=337)$, which further mineralized into small molecule 


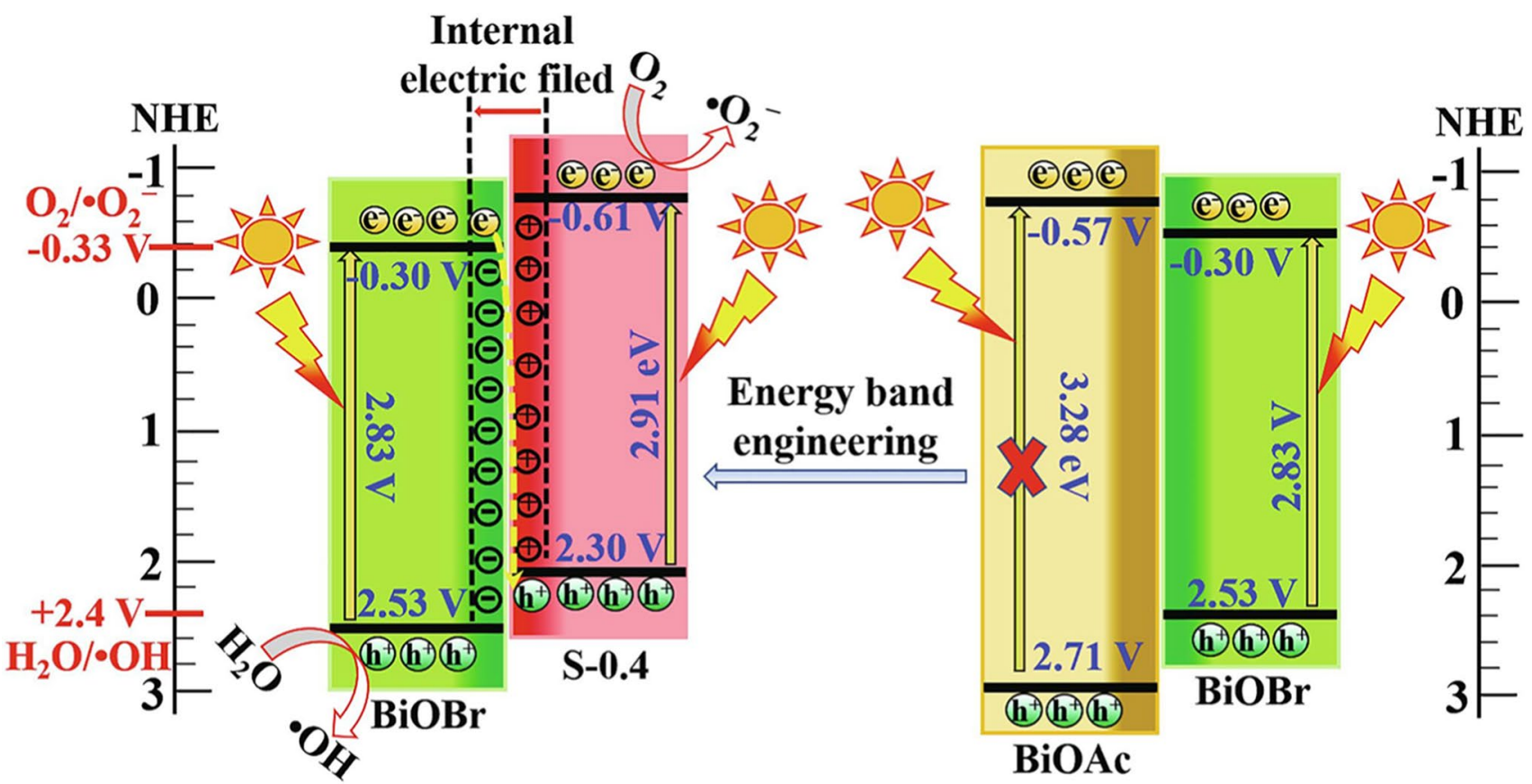

(a) $\mathrm{S}$-scheme $\mathrm{BiOBr} / \mathrm{BiOAc}_{1-x} \mathrm{Br}_{x}$ (b) Type-I BiOBr/BiOAc

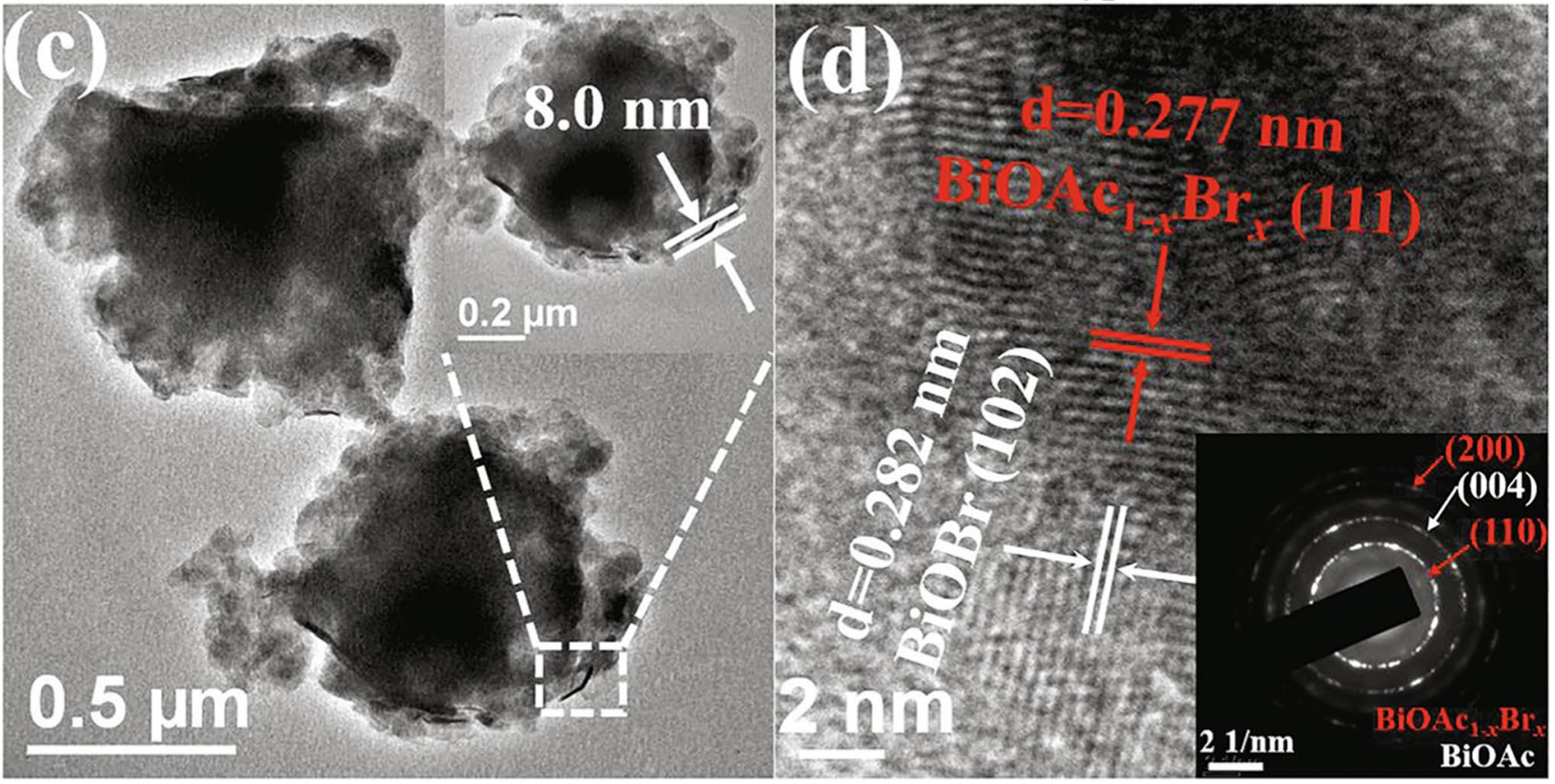

Fig. 8 a Photocatalysis mechanism of step-scheme $\mathrm{BiOBr} /$ $\mathrm{BiO}\left(\mathrm{CH}_{3} \mathrm{COO}\right)_{1-x} \mathrm{Br}_{\mathrm{x}}$ systems: band gap of $\mathrm{BiO}\left(\mathrm{CH}_{3} \mathrm{COO}\right)_{1-\mathrm{x}} \mathrm{Br}_{\mathrm{x}}$ decreased to $2.91 \mathrm{eV}$ and both $\mathrm{BiOBr}$ and $\mathrm{BiO}\left(\mathrm{CH}_{3} \mathrm{COO}\right)_{1-x} \mathrm{Br}_{x}$ photocatalysts could be excited by visible light. b Photocatalysis mechanism of type $\mathrm{I} \mathrm{BiOBr} / \mathrm{BiO}\left(\mathrm{CH}_{3} \mathrm{COO}\right)$ : only $\mathrm{BiOBr}$ could be excited by visible light. c Transmission electron microscopy and $\mathbf{d}$ high-resolution transmission electron microscopy images of $\mathrm{BiOBr} /$ $\mathrm{BiO}\left(\mathrm{CH}_{3} \mathrm{COO}\right)_{1-\mathrm{x}} \mathrm{Br}_{\mathrm{x}}$ (Reprinted with permission of Elsevier from Jia et al. 2020). $\mathrm{e}^{-}$, electron; $\mathrm{h}^{+}$, hole; $\cdot \mathrm{O}_{2}{ }^{-}$, superoxide radical; $\mathrm{S}-0.4, \mathrm{BiOBr} / \mathrm{BiO}\left(\mathrm{CH}_{3} \mathrm{COO}\right)_{0.6} \mathrm{Br}_{0.4}$ 


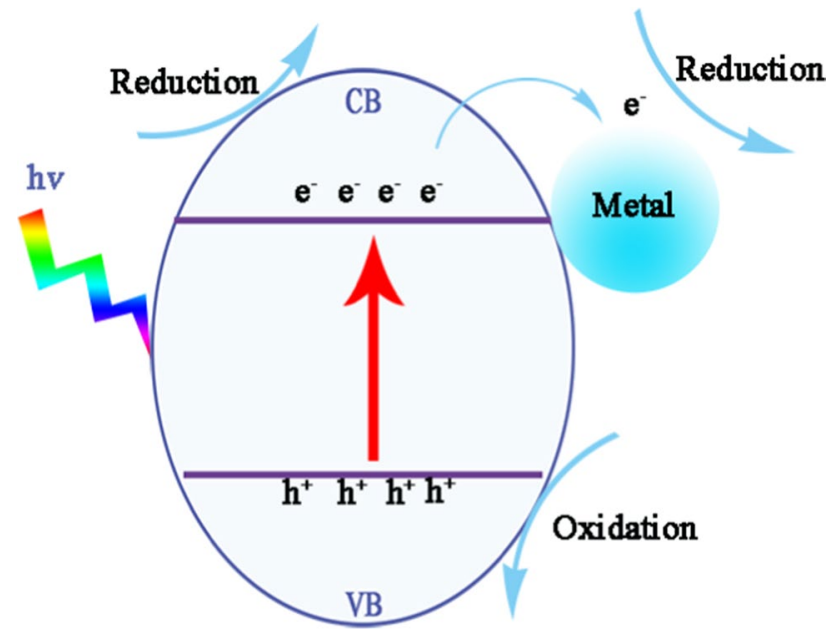

Fig. 9 Schematic illustration of the energy band structure and chargecarrier transfer on a Schottky junction system: $\mathrm{e}^{-}$of the semiconductor tends to transfer to the metal rather than recombined with $\mathrm{h}^{+} . \mathrm{e}^{-}$, electron; $\mathrm{h}^{+}$, hole; $\mathrm{CB}$, conduction band; $\mathrm{VB}$, valence band

fragments, including E15 (m/z=297), E16 (m/z=223), and $\mathrm{E} 17(\mathrm{~m} / \mathrm{z}=107)$.

\section{Fourth possible pathway: attack on double bonds}

The unsaturated double bonds could be the major oxidization sites in tetracycline due to the high electrophilicity of hydroxyl radicals (Scheme 4). In the fourth degradation route of tetracycline, two different intermediates (F1a and F1b) with $\mathrm{m} / \mathrm{z}=461$ are generated after the substitution reaction on the conjugate bond between $\mathrm{C} 5$ and $\mathrm{C} 6$ or $\mathrm{C} 2$ and $\mathrm{C} 13$ (Ren et al. 2019). Further, $\mathrm{OH}$ damage on different positions of F1a and F1b forms isomers F2, F3, and $\mathrm{F} 19(\mathrm{~m} / \mathrm{z}=477)$ via hydroxylation or oxidization reactions (Yang et al. 2018). The breaking of the $\mathrm{C}-\mathrm{C}$ bonds in the ring structure of F3 and F1a generates $F 4(m / z=277), F 5$ $(\mathrm{m} / \mathrm{z}=209)$, and F6 $(\mathrm{m} / \mathrm{z}=149)$.

Dealkylation of N-dimethyl group of F1a after the attack by $\mathrm{h}^{+}$generates compound $\mathrm{F} 7(\mathrm{~m} / \mathrm{z}=432)$. Cyclic structure of F7 immediately breaks to form F8 $(\mathrm{m} / \mathrm{z}=363)$ or F13 $(\mathrm{m} / \mathrm{z}=376) . \mathrm{F} 13$ is further oxidized to form $\mathrm{F} 14(\mathrm{~m} / \mathrm{z}=279)$ and $\mathrm{F} 15(\mathrm{~m} / \mathrm{z}=121)$, which is completely decomposed into $\mathrm{CO}_{2}, \mathrm{H}_{2} \mathrm{O}$, and other smaller molecular inorganic products (Chen et al. 2020a). F20 $(\mathrm{m} / \mathrm{z}=493)$ is formed after hydroxyl substitution on the aromatic ring of F19. Both F19 and F20 can form F7 (Yang et al. 2020). The attack of $\mathrm{h}^{+}$ and reactive oxygen species also can degrade F7 into F21 $(\mathrm{m} / \mathrm{z}=387)$. Subsequent destruction of carbonyl group forms $\mathrm{F} 22(\mathrm{~m} / \mathrm{z}=214)$. One of the methyl groups of $-\mathrm{N}\left(\mathrm{CH}_{3}\right)_{2}$ in F19 and F1a can be oxidized by $\mathrm{OH}$ to generate $\mathrm{F} 23$ $(\mathrm{m} / \mathrm{z}=491)$ and $\mathrm{F} 24(\mathrm{~m} / \mathrm{z}=475)$, respectively.

Xia et al. (2020) also indicated that the double bond between $\mathrm{C} 2$ and $\mathrm{C} 13$ of tetracycline could be attacked by $\mathrm{h}^{+}$radical, inducing the cleavage of unsaturated bond and forming an amino-free fragment $\mathrm{F} 9(\mathrm{~m} / \mathrm{z}=389)$. A series of processes including loss of $-\mathrm{N}\left(\mathrm{CH}_{3}\right)_{2}$ - $\mathrm{CHO}$ group, dihydroxylation, and demethylation of $\mathrm{F} 9$ yield products $\mathrm{F} 10$ $(\mathrm{m} / \mathrm{z}=346), \mathrm{F} 11(\mathrm{~m} / \mathrm{z}=304)$, and $\mathrm{F} 12(\mathrm{~m} / \mathrm{z}=258)$. Yu et al. (2020) suggested that the degradation pathway of tetracycline $\rightarrow \mathrm{F} 16(\mathrm{~m} / \mathrm{z}=459) \rightarrow \mathrm{F} 17(\mathrm{~m} / \mathrm{z}=485) \rightarrow \mathrm{F} 18$ $(\mathrm{m} / \mathrm{z}=559)$ occurs via the substitution reaction on conjugated bonds.

\section{Fifth possible pathway: attack on hydroxyl of C8 site}

The fifth photocatalytic degradation pathway (Scheme 5) begins with the loss of hydroxyl at the $\mathrm{C} 8$ site of tetracycline to form $\mathrm{G} 1(\mathrm{~m} / \mathrm{z}=426)$. $\mathrm{G} 1$ dealkylation or dehydration then produces E5b and $\mathrm{G} 2(\mathrm{~m} / \mathrm{z}=383)$. Further splitting of the ring structure converts of $\mathrm{G} 2$ into $\mathrm{E} 9$ or $\mathrm{G}_{2}(\mathrm{~m} / \mathrm{z}=301)$ (Lai et al. 2021; Xie et al. 2018). An intermediate $\mathrm{G} 4(\mathrm{~m} / \mathrm{z}=337)$ is obtained after a series of continuous reactions including dehydration, demethylation, and deamination of G2 (Ma et al. 2019). Ring opening and multi-dehydroxylation reactions then yield $\mathrm{G} 5(\mathrm{~m} / \mathrm{z}=318)$ and $\mathrm{G} 6(\mathrm{~m} / \mathrm{z}=282)$.

It has been revealed that tetracycline can also simultaneously lose hydroxyl and methyl groups at C8 to form G7 $(\mathrm{m} / \mathrm{z}=413)$, which can then undergo dehydrogenation to produce $\mathrm{G} 8(\mathrm{~m} / \mathrm{z}=411)$. G8 has two main photocatalytic mineralization pathways: (1) $\mathrm{G} 8 \rightarrow \mathrm{G} 9(\mathrm{~m} / \mathrm{z}=318) \rightarrow \mathrm{G} 10$ $(\mathrm{m} / \mathrm{z}=270)$ or $\mathrm{G} 11(\mathrm{~m} / \mathrm{z}=280) \rightarrow \mathrm{G} 12(\mathrm{~m} / \mathrm{z}=148) \rightarrow \mathrm{G} 13$ $(\mathrm{m} / \mathrm{z}=104) \rightarrow \mathrm{CO}_{2}, \mathrm{H}_{2} \mathrm{O}$, and $\mathrm{NH}_{3}$; (2) $\mathrm{G} 8 \rightarrow \mathrm{G} 14$ $(\mathrm{m} / \mathrm{z}=389) \rightarrow \mathrm{G} 15(\mathrm{~m} / \mathrm{z}=359) \rightarrow \mathrm{G} 16(\mathrm{~m} / \mathrm{z}=337) \rightarrow \mathrm{E} 15$ $\rightarrow \mathrm{E} 16 \rightarrow \mathrm{E} 17 \rightarrow \mathrm{CO}_{2}, \mathrm{H}_{2} \mathrm{O}$, and $\mathrm{NH}_{3}$.

In summary, hydroxylation, dealkylation, dehydration, oxidation, deamination, and deamidation are the fundamental mechanistic steps for the decomposition of the molecular structure of tetracycline by various reactive oxygen species. 

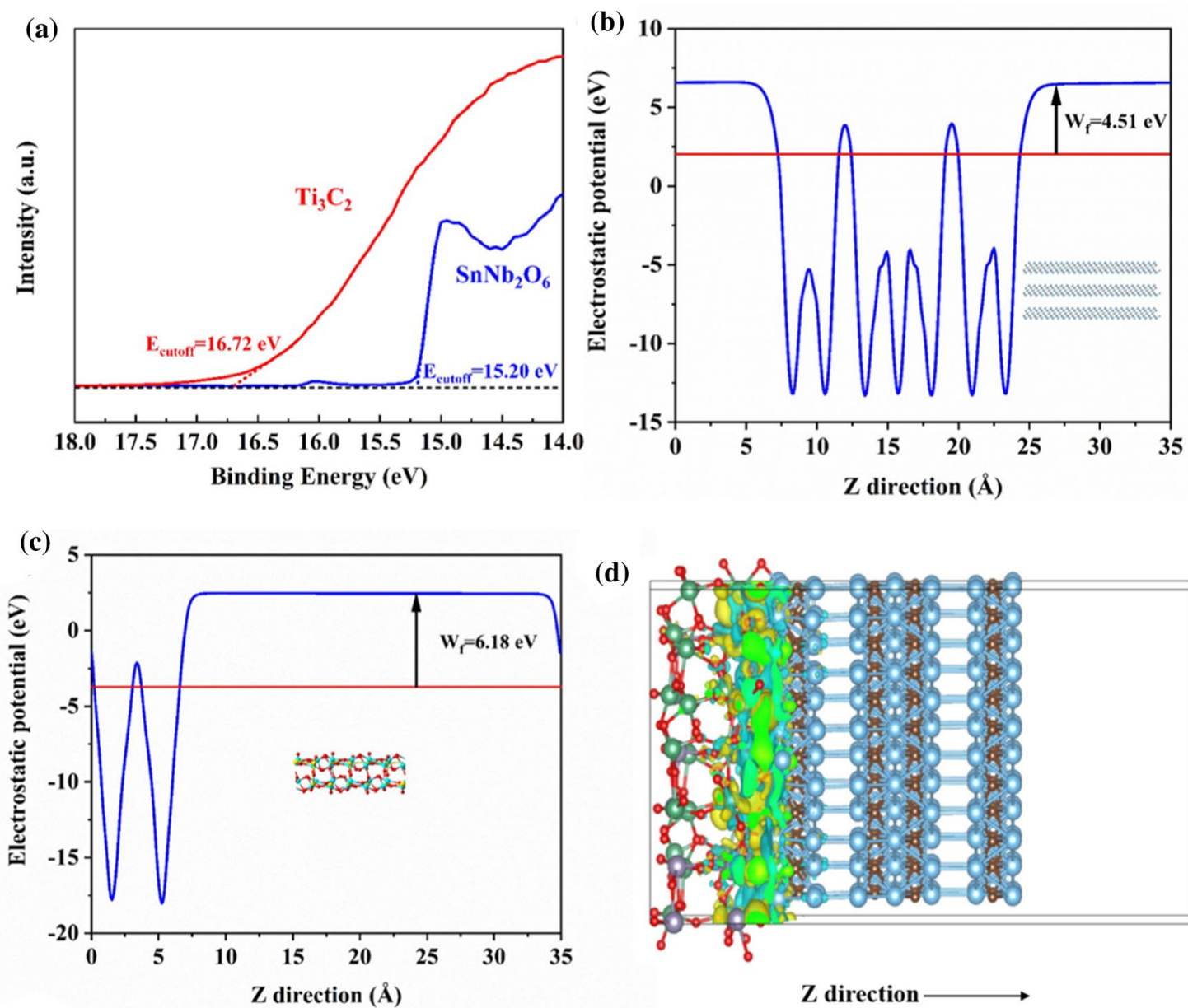

(d)
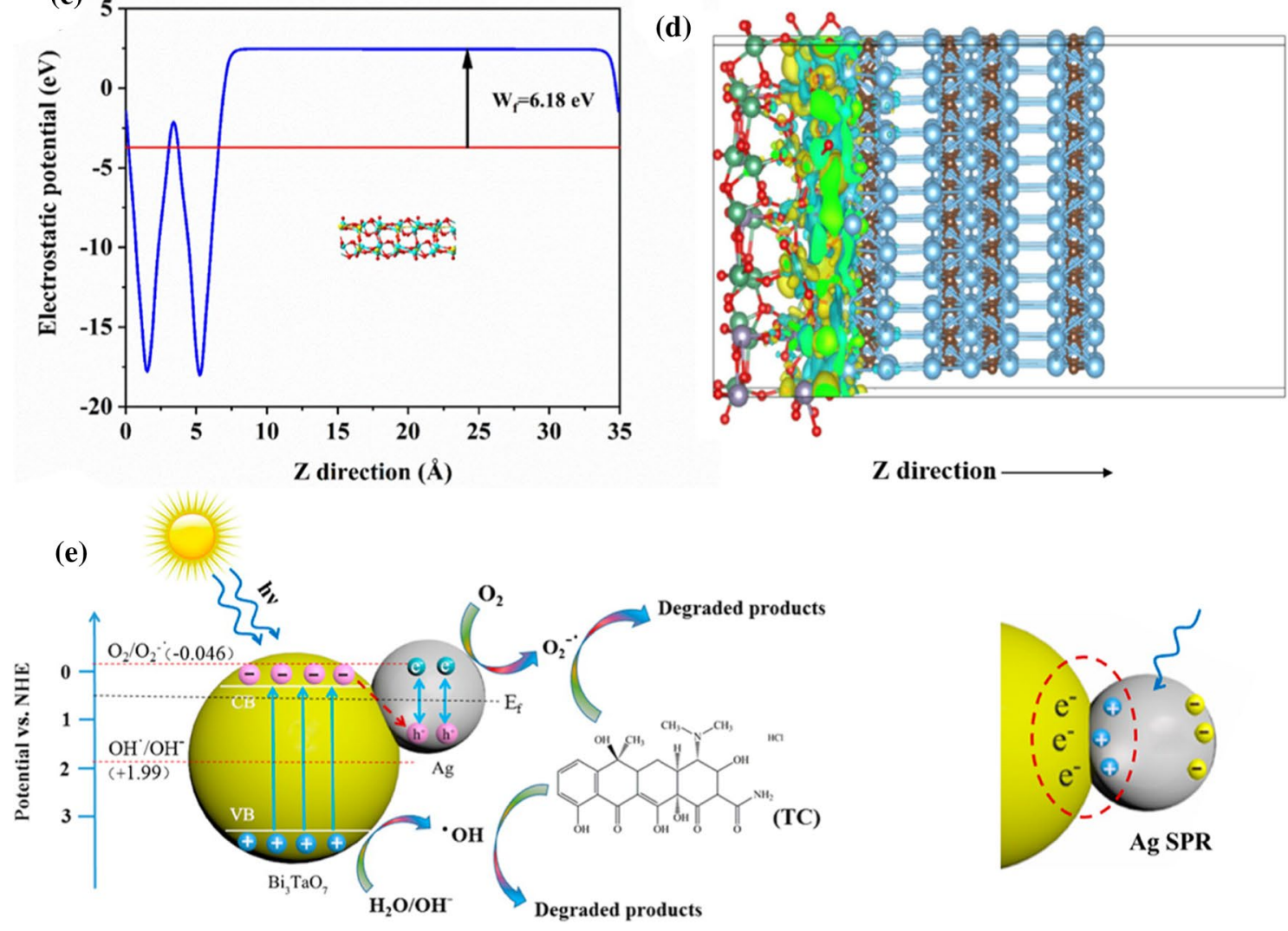

$\mathrm{Ag} / \mathrm{Bi}_{3} \mathrm{TaO}_{7}$ plasmonic photocatalyst

\section{inner electromagnetic field}

Fig. 10 a Ultraviolet photoelectron spectra edges of $\mathrm{Ti}_{3} \mathrm{C}_{2}$ and $\mathrm{SnNb}_{2} \mathrm{O}_{6}$. Theoretical calculations of work function values of $\mathbf{b}$ $\mathrm{Ti}_{3} \mathrm{C}_{2}$ and $\mathbf{c} \mathrm{SnNb}_{2} \mathrm{O}_{6}$. d Charge density difference diagram of $\mathrm{Ti}_{3} \mathrm{C}_{2} /$ $\mathrm{SnNb}_{2} \mathrm{O}_{6}$ (d) (Reprinted with permission of Elsevier from Wang et al. 2021a). e Proposed photocatalytic mechanism of $\mathrm{Ag} / \mathrm{Bi}_{3} \mathrm{TaO}_{7}$ for degradation of tetracycline under visible irradiation: SPR absorbance of metallic Ag nanoparticles and charge carriers transfer in Schottky heterojunction of $\mathrm{Ag} / \mathrm{Bi}_{3} \mathrm{TaO}_{7}$ (Reprinted with permission of American Chemical Society from Luo et al. 2015). TC, tetracycline; $\mathrm{O}_{2}$ -, superoxide radical; $\cdot \mathrm{OH}$ hydroxyl radical; SPR, surface plasmon resonance 


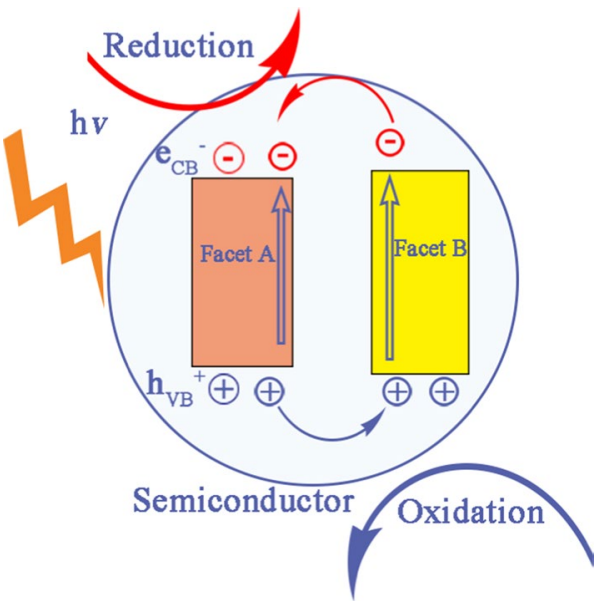

Fig. 11 Charge-carrier migration of surface heterojunction system under light irradiation: different exposed facts of a single semiconductor have different band structures, leading to the formation of heterojunction system and migration of photogenerated $\mathrm{e}_{\mathrm{CB}}{ }^{-}$and $\mathrm{h}_{\mathrm{VB}}{ }^{+}$. $\mathrm{e}_{\mathrm{CB}}^{-}$, electron; $\mathrm{h}_{\mathrm{VB}}{ }^{+}$, hole
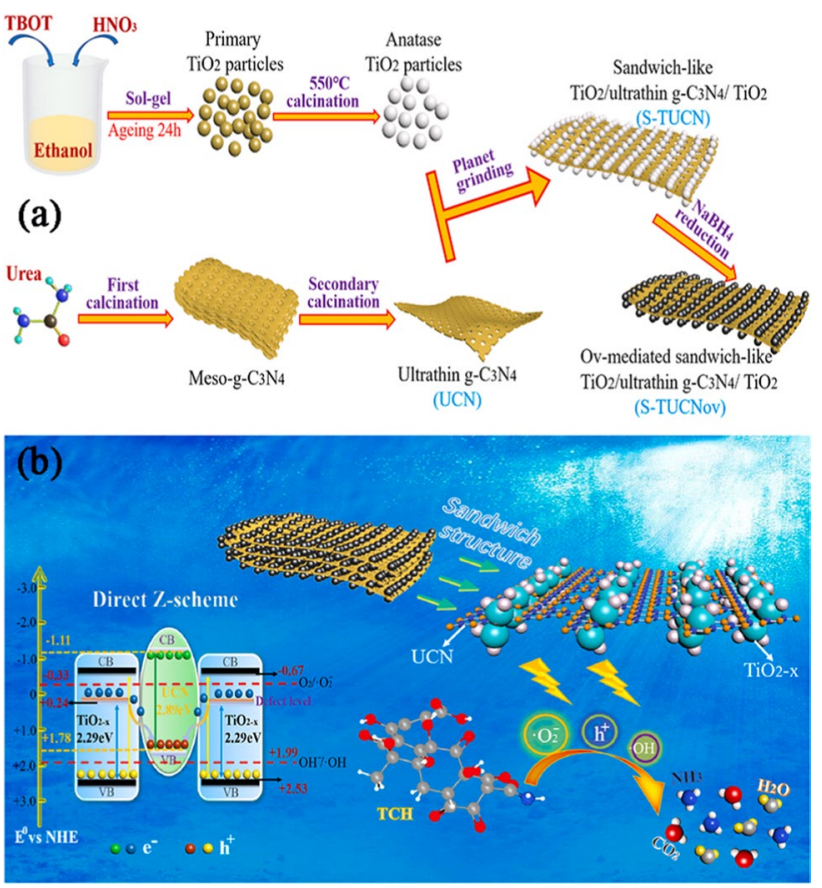

Fig. 12 a Formation route of $\mathrm{TiO}_{2-\mathrm{x}} /$ ultrathin $\mathrm{g}^{-} \mathrm{C}_{3} \mathrm{~N}_{4} / \mathrm{TiO}_{2-\mathrm{x}}$ : planetary grinding method. b Possible photocatalytic mechanism diagram of $\mathrm{TiO}_{2-\mathrm{x}}$ /ultrathin $\mathrm{g}_{-} \mathrm{C}_{3} \mathrm{~N}_{4} / \mathrm{TiO}_{2-\mathrm{x}}$ : direct $\mathrm{Z}$-scheme heterojunction model (Reprinted with permission of Elsevier from Ni et al. 2020). $\mathrm{TCH}$, tetracycline hydrochloride; $\mathrm{O}_{2}{ }^{\cdot}{ }^{-}$, superoxide radical; $\cdot \mathrm{OH}$ hydroxyl radical; UCN, ultrathin $\mathrm{g}_{-} \mathrm{C}_{3} \mathrm{~N}_{4}$; S-TUCN, sandwich-like $\mathrm{TiO}_{2}$ /ultrathin $\mathrm{g}-\mathrm{C}_{3} \mathrm{~N}_{4} / \mathrm{TiO}_{2} ; \mathrm{S}$-TUCNov, ov-mediated sandwich-like $\mathrm{TiO}_{2}$ /ultrathin $\mathrm{g}-\mathrm{C}_{3} \mathrm{~N}_{4} / \mathrm{TiO}_{2}$

\section{Performance of tetracycline degradation by heterojunction systems}

Previous studies have been recorded on the development of various heterojunction photocatalysts for tetracycline photodegradation under light illumination (Guo et al. 2019a; Yan et al. 2019; Zheng et al. 2021). Therefore, it is necessary to assess their practical performance to validate their efficiency in removing tetracycline. The existing literature on the performance of heterojunction photocatalysts only focused on removal efficiency and degradation rate under identical conditions. Photocatalysis reaction is highly dependent on varying parameters (e.g., pH, temperature, initial substrate content, photocatalysts mass, the types of catalysts, and especially light wavelength and intensity), and performance of photocatalysts cannot simply be determined via degradation efficiency and rate alone (Anwer et al. 2019; He et al. 2021b). Also, degradation efficiency cannot directly reflect the actual performance or practical application value of different photocatalytic materials. In this regard, more objective and credible numeric metrics that can include as many parameters as possible are pressingly needed to be introduced to quantitatively evaluate the performance of photocatalytic systems (Vikrant et al. 2019).

\section{Performance evaluation methods}

Researchers have suggested using quantum efficiency as an elaborated index for assessing the performances of different photocatalytic systems for comparison purposes (Anwer and Park 2018; Younis et al. 2020). Recently, quantum efficiency has generally become one of the preferred performance metrics for removing various organic pollutants from water environments using photocatalytic materials (Rajput et al. 2021; Vellingiri et al. 2020). Quantum efficiency is defined as the per unit amount of absorbed photons used to effectively decompose the molecular number of pollutants (Vikrant et al. 2020). The quantum efficiency of photocatalysts during photocatalytic degradation is calculated as shown in Eq. (1) (Raza et al. 2020).

Nevertheless, quantum efficiency alone is not sufficiently standard for parallel comparing the performance of various heterojunction photocatalysts since it cannot take into account all operational variables during photocatalysis processes (He et al. 2021b). In recent years, Anwer et al. (2019) has proposed space time yield and figure of merit are proposed as new concepts for assessing photocatalytic degradation efficiency. Space time yield and figures of merit 

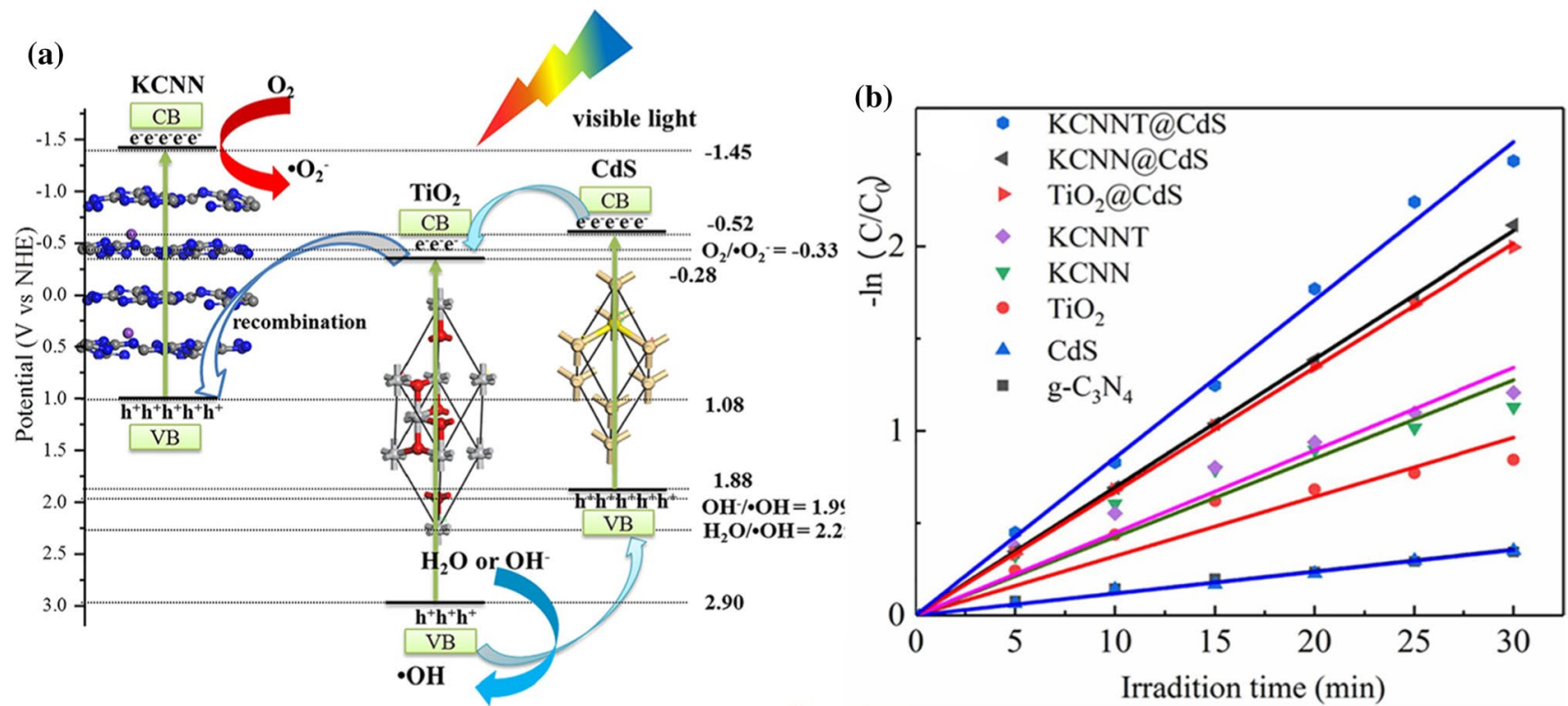

(c)

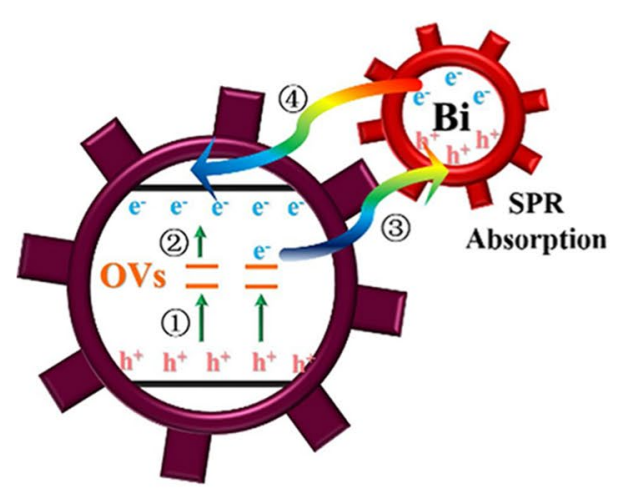

(d)

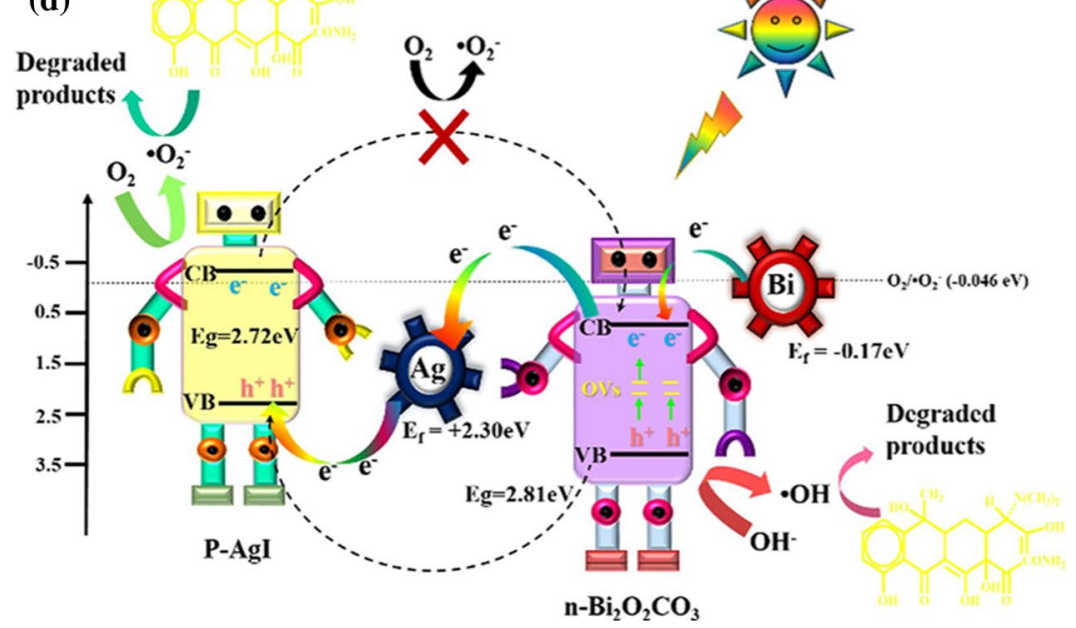

Fig. 13 a Migration of charge carriers in $\mathrm{g}-\mathrm{C}_{3} \mathrm{~N}_{4} / \mathrm{TiO}_{2} / \mathrm{CdS}$ : a type II and Z-scheme synergistic heterojunction mechanism. CdS acts as an $\mathrm{e}^{-}$source and $\mathrm{h}^{+}$acceptor. b First-order kinetics of $\mathrm{g}-\mathrm{C}_{3} \mathrm{~N}_{4}, \mathrm{Cds}$, $\mathrm{TiO}_{2}, \mathrm{KCNN}, \mathrm{KCNNT}, \mathrm{TiO}_{2} @ \mathrm{CdS}, \mathrm{KCNN} @ \mathrm{CdS}$ and KCNNT@ $\mathrm{CdS}$ for tetracycline removal under visible light (Reprinted with permission of Elsevier from Liu et al. 2021). c The effects of Bi metal and oxygen vacancies on the carrier transfer: oxygen vacancies acted as intermediate to transfer $\mathrm{e}^{-}$to $\mathrm{Bi}$ metal. Then, $\mathrm{e}^{-}$in $\mathrm{Bi}$ metal moved

are effective performance metrics that can control the effects of catalyst dosage, pollutant content, irradiation time, and applied power. The values of space time yield and figures of merit of photocatalytic materials are obtained using Eqs. 2 and 3 , respectively. The metrics have been used to determine the photocatalytic performances of the degradation of organic dye (Abbas et al. 2021; Anwer et al. 2019; Raza et al. 2021), $\mathrm{CO}_{2}$ reduction (Cortes et al. 2019), microcystin-LR removal (He et al. 2020b), gaseous benzene photomineralization (Vikrant et al. 2019), purification of volatile organic compounds (Talaiekhozani et al. 2021), and the inactivation to the conduction band due to SPR effect. d Proposed photocatalytic mechanism of $30 \% \mathrm{Ag} / \gamma-\mathrm{AgI} / \mathrm{Bi}_{2} \mathrm{O}_{2} \mathrm{CO}_{3} / \mathrm{Bi}$ : a novel S-scheme heterojunction mechanism. (Reprinted with permission of Elsevier from Yan et al. 2021a). $\mathrm{e}^{-}$, electron; $\mathrm{h}^{+}$, hole; $\mathrm{CB}$, conduction band; $\mathrm{VB}$, valence band; $\mathrm{O}_{2}{ }^{-}{ }^{-}$, superoxide radical; $\cdot \mathrm{OH}$ hydroxyl radical; KCNN, K doped g- $\mathrm{C}_{3} \mathrm{~N}_{4}$ nanosheet; KCNNT, K doped $\mathrm{g}-\mathrm{C}_{3} \mathrm{~N}_{4}$ nanosheet-TiO ${ }_{2} ; \mathrm{E}_{\mathrm{g}}$, energy gap; $\mathrm{SPR}$, surface plasmon resonance

of harmful algae (He et al. 2021b) were evaluated between various reported photocatalytic materials.

Quantum efficiency $=\frac{\text { Degradation rate }(\text { molecules per second })}{\text { Photon flux }(\text { photons per second })}$

Space time yield $=\frac{\text { Quantum efficiency }(\text { molecules per photon })}{\text { Photocatalyst mass }(\mathrm{g})}$ 
Table 1 Photocatalysis mechanisms of various heterojunctions photocatalysts for the removal of tetracycline under light irradiation

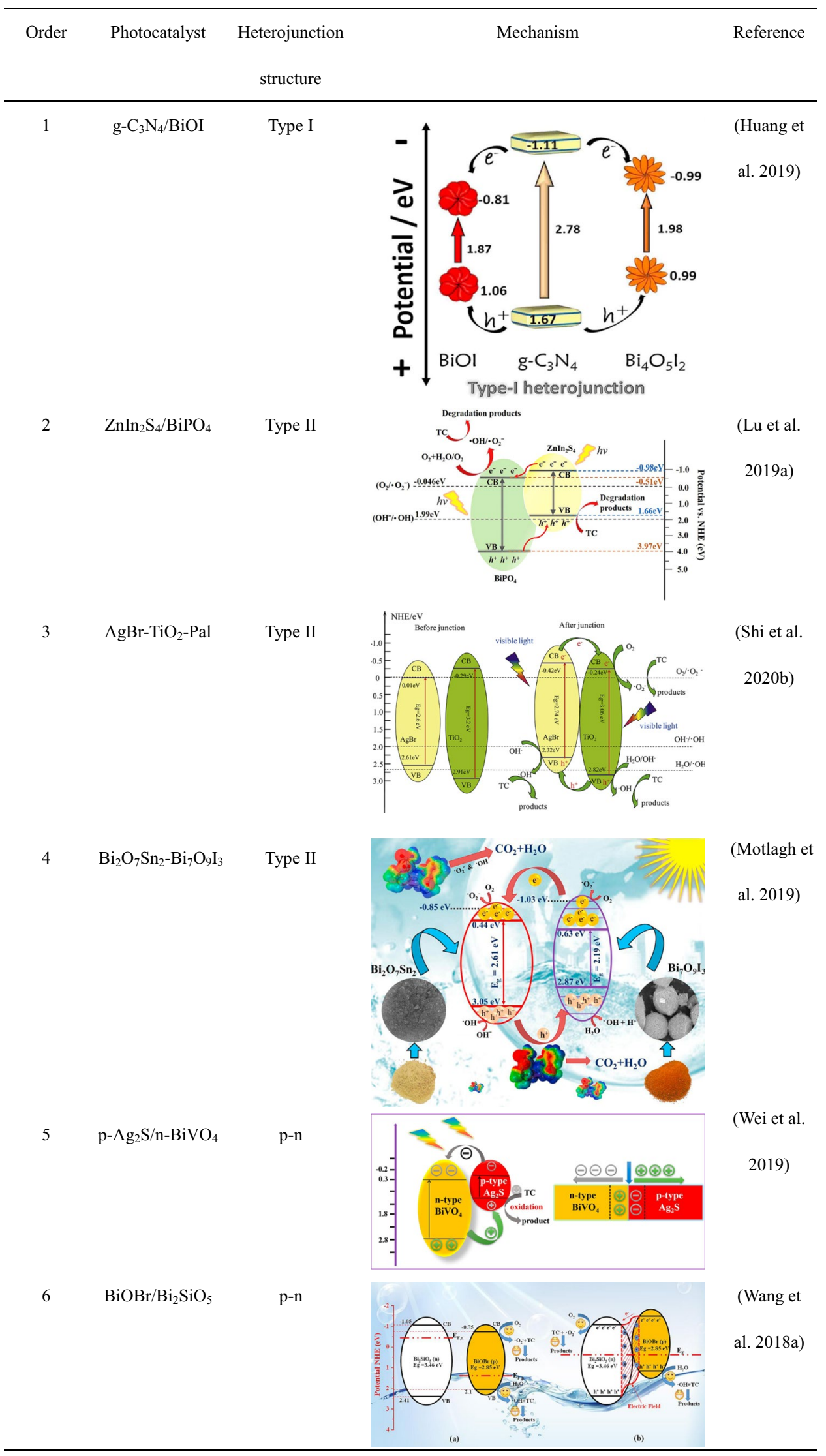


Table 1 (continued)

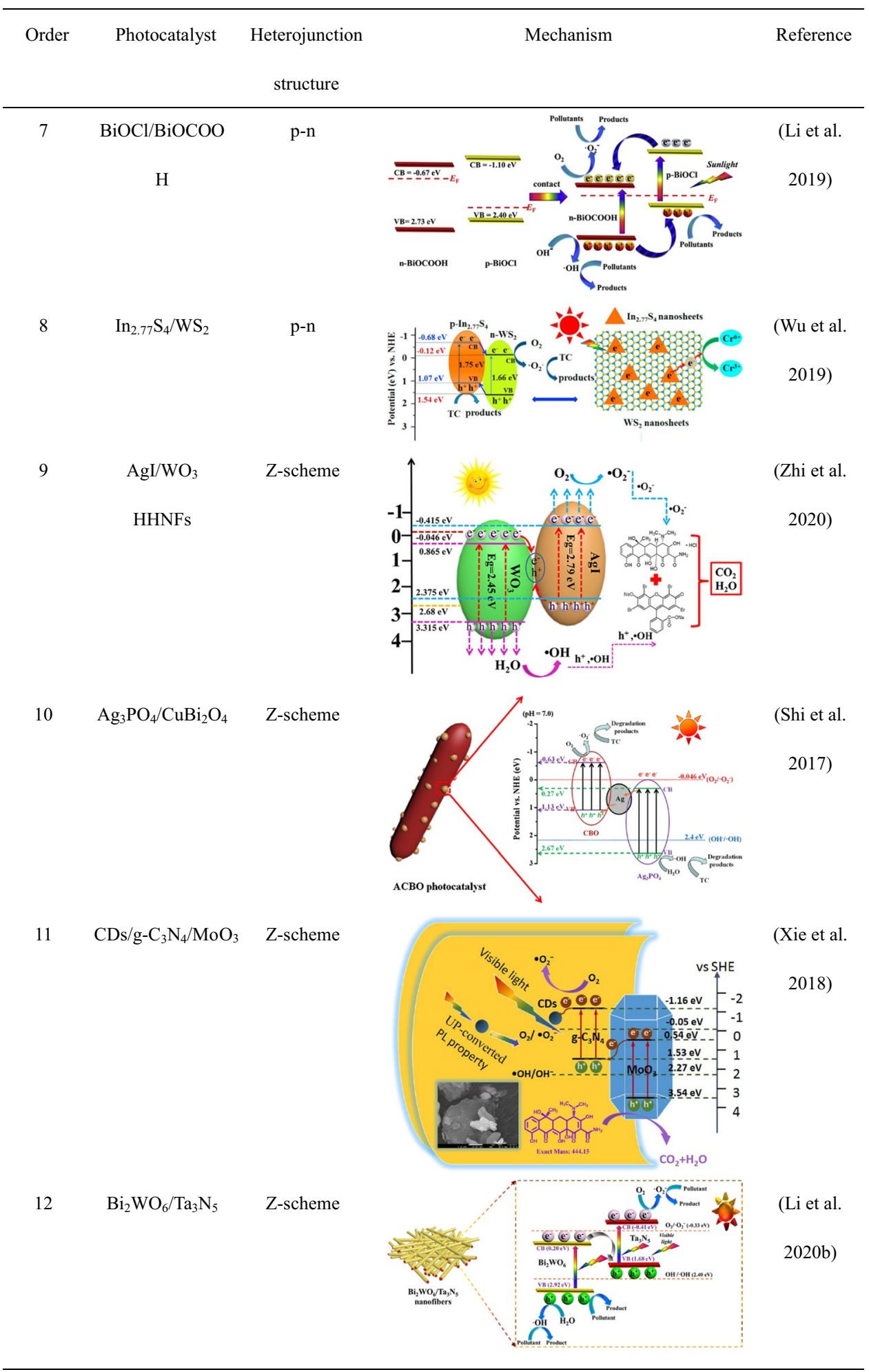


Table 1 (continued)

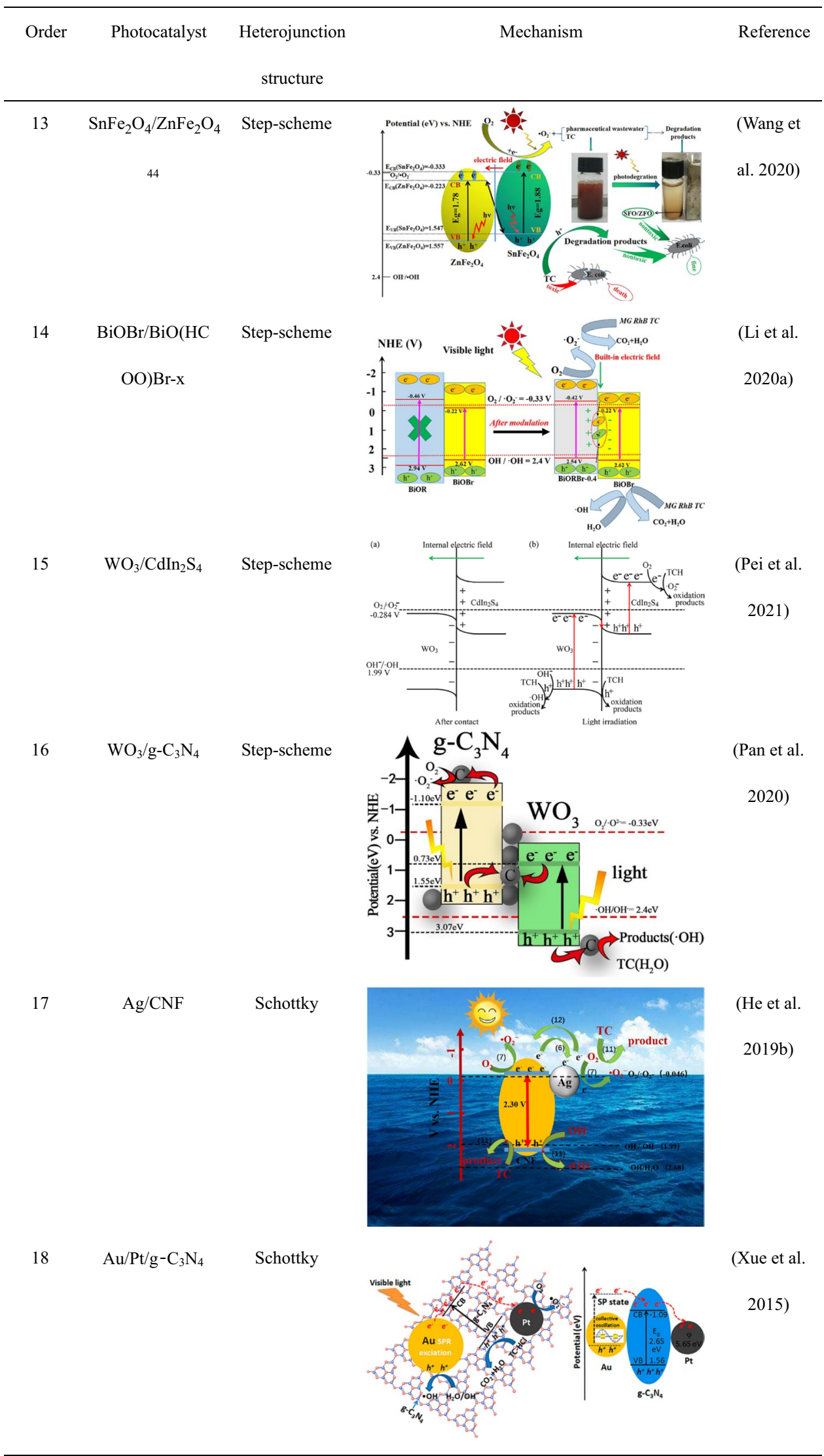


Table 1 (continued)

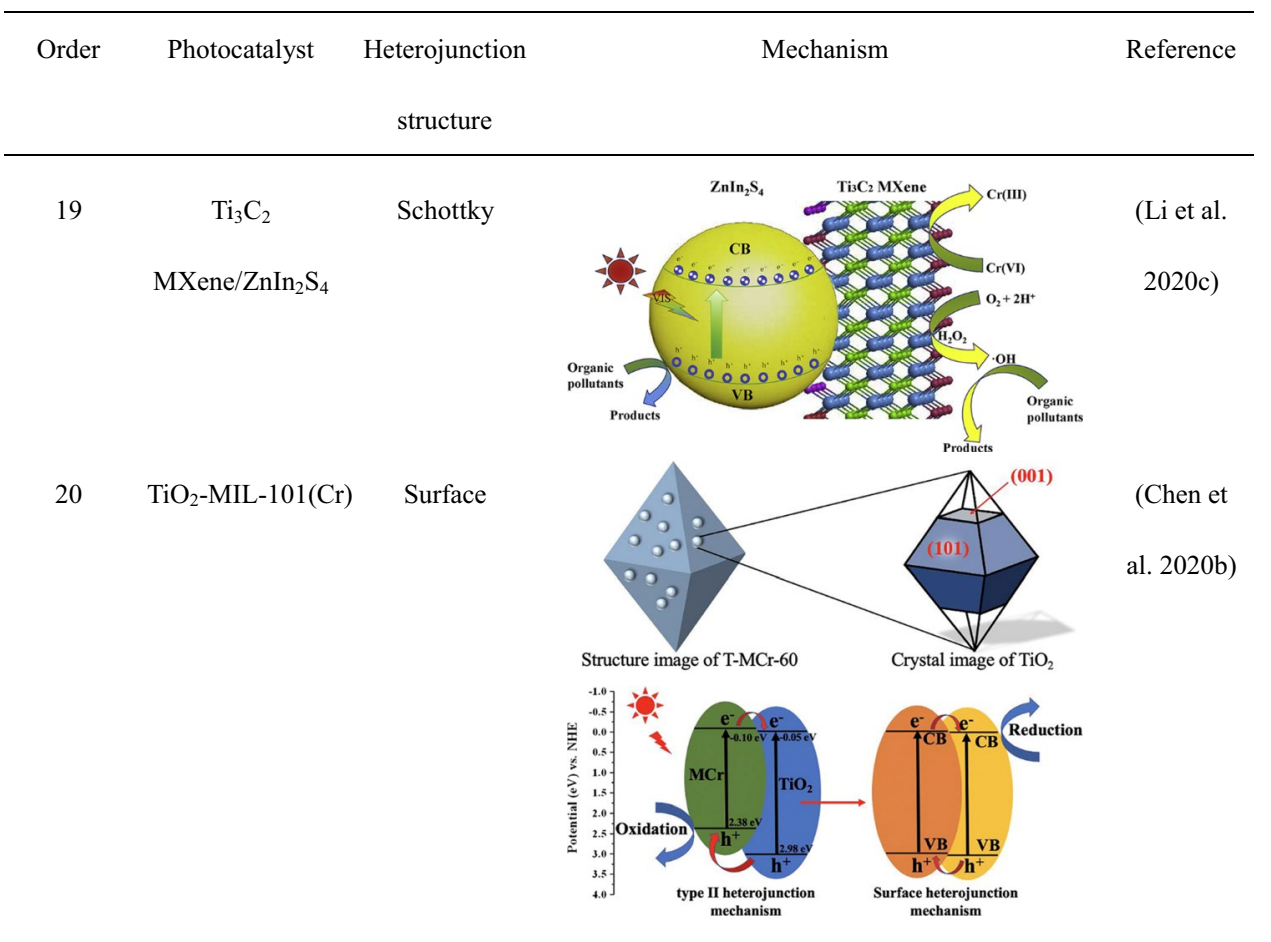

$e^{-}$, electron; $h^{+}$, hole; $C B$, conduction band; $V B$, valence band; $O_{2}$, oxygen; $O_{2}{ }^{--}$, superoxide radical; ${ }^{I} O_{2}$, singlet oxygen; $\mathrm{OH}$, hydroxyl radical; $\mathrm{OH}^{-}$, hydroxide ion; $\mathrm{H}_{2} \mathrm{O}$, water; $\mathrm{CO}_{2}$, carbon dioxide; $\mathrm{HOO}$, hydroperoxyl radical; $\mathrm{H}_{2} \mathrm{O}_{2}$, hydroperoxide; $T C$, tetracycline; $T C H$, tetracycline hydrochloride; $H H N F s$, hollow hierarchical nanoflowers; Pal, Palygorskite; $C D s$, carbon quantum dots; $C N F$, fiber-like carbon nitride.

Figures of merit $=\frac{\text { Product obtained }(\mathrm{L})}{\text { Photocatalyst mass }(\mathrm{g}) \times \text { Irradiation time }(\mathrm{h}) \times \text { Energy consumption }(\mathrm{W} \times \mathrm{h} / \mathrm{mol})}$

Herein, recent relevant reports regarding the photocatalytic degradation of tetracycline in aqueous systems with heterojunction photocatalysts have been summarized (Table 2). Moreover, we introduced quantum efficiency, space time yield, and figures of merit to gauge the photocatalytic activity of these heterojunction composites. Their photocatalytic performance was also evaluated based on calculated quantum efficiency, space time yield, and figures of merit. To perform more intuitive assessment, the score of photocatalyst with the highest figures of merit value was adjusted to 100 as a reference, and the score of other photocatalysts was graded from 0 to 100 via conversion calculation (He et al. 2020b). 


\section{Performance comparison of various heterojunction photocatalysts for tetracycline degradation}

As for photocatalytic decontamination of tetracycline, the best performance was displayed by a ternary composite $\mathrm{Ag}_{3} \mathrm{PO}_{4} / \mathrm{AgBr} / \mathrm{g}-\mathrm{C}_{3} \mathrm{~N}_{4}$ with dual Z-scheme heterojunction, which showed quantum efficiency of $4.56 \times 10^{-6} \mathrm{~mol}-$ ecules/photon, space time yield of $9.13 \times 10^{-5}$ molecules/ (g.photon), and figures of merit of $7.68 \times 10^{-11} \mathrm{~mol} \cdot \mathrm{L} /$ (g.J.h) (Yu et al. 2020). $\mathrm{Ag}_{3} \mathrm{PO}_{4} / \mathrm{AgBr} / \mathrm{g}-\mathrm{C}_{3} \mathrm{~N}_{4}$ had a small arc radius, indicating low charge migration resistance and recombination of charge pairs. Ag element behaved as the electron transfer mediator during photodegradation to promote the recombination of electrons and holes of $\mathrm{Ag}_{3} \mathrm{PO}_{4} /$ $\mathrm{AgBr}$ and $\mathrm{AgBr} / \mathrm{g}-\mathrm{C}_{3} \mathrm{~N}_{4}$ (double $\mathrm{Z}$-scheme systems). Therefore, better redox ability of the whole system could be obtained, improving the photocatalysis performance (Fig. 14). $\mathrm{Ag}_{3} \mathrm{PO}_{4} / \mathrm{AgBr} / \mathrm{g}-\mathrm{C}_{3} \mathrm{~N}_{4}$ could represent one of the most promising heterojunctioned photocatalysts for the efficient purification of the antibiotic-contaminated sewage. $\mathrm{Ag}_{3} \mathrm{PO}_{4} / \mathrm{AgBr}$ also showed excellent photocatalysis activity for tetracycline degradation with a score of 87.5, quantum efficiency of $3.99 \times 10^{-6}$ molecules/photon, space time yield of $7.99 \times 10^{-5}$ molecules/(g.photon), and figures of merit of $6.72 \times 10^{-11} \mathrm{~mol} \cdot \mathrm{L} /(\mathrm{g} \cdot \mathrm{J} \cdot \mathrm{h}) . \mathrm{Ag}_{3} \mathrm{PO}_{4} / \mathrm{AgBr}$ was able to mineralize $70 \%$ of tetracycline under visible light (initial tetracycline content of $40 \mathrm{mg} / \mathrm{L}$ ).

The 2D/2D/2D configuration ternary heterojunction synthesized using $\mathrm{g}_{-} \mathrm{C}_{3} \mathrm{~N}_{4}, 15 \mathrm{wt} \%$ CoAl-layered double hydroxide, and $1 \mathrm{wt} . \%$ reduced graphene oxide (CoAl$\mathrm{LDH} / \mathrm{g}-\mathrm{C}_{3} \mathrm{~N}_{4} / \mathrm{RGO}$ ) (Jo and Tonda 2019) also exhibited a high value of figure of merit, correlative quantum efficiency, and space time yield of $3.30 \times 10^{-11} \mathrm{~mol} \cdot \mathrm{L} /(\mathrm{g} \cdot \mathrm{J} \cdot \mathrm{h})$ ), $2.35 \times 10^{-6}$ molecules/photon, and $4.71 \times 10^{-5}$ molecules/ (g.photon), respectively. Almost $99.0 \%$ of tetracycline with initial concentration of $20 \mathrm{mg} / \mathrm{L}$ was decomposed from antibiotic-contaminated sewage by $0.25 \mathrm{~g} / \mathrm{L}$ CoAl-LDH/g$\mathrm{C}_{3} \mathrm{~N}_{4} / \mathrm{RGO}$ photocatalyst within 60 min of visible light illumination. Excellent photodegradation performance of CoAl-LDH/g- $\mathrm{C}_{3} \mathrm{~N}_{4} / \mathrm{RGO}$ was attributed to two factors: (i) the notable $2 \mathrm{D} / 2 \mathrm{D} / 2 \mathrm{D}$ arrangement structure increased the synergy effect of the $\mathrm{g}-\mathrm{C}_{3} \mathrm{~N}_{4}$, layered double hydroxide, and reduced graphene oxide, thus accelerating the interfacial charge migration direct and separation of photogenerated electron-hole pairs; (ii) Enhanced light response in the visible range of RGO and intimate interactions between the constituents. In summary, the outstanding photocatalytic performance of heterojunction catalysts against tetracycline is mainly attributed to the formation of a favorable heterojunction structure, which improving interfacial charge transfer and hindering the recombination of charge carriers.

On a comparative note, several heterojunction composites such as g- $\mathrm{C}_{3} \mathrm{~N}_{4} / \mathrm{Bi}_{4} \mathrm{O}_{5} \mathrm{I}_{2}, \mathrm{~g}_{-} \mathrm{C}_{3} \mathrm{~N}_{4} / \mathrm{BiOI}, \mathrm{g}^{-} \mathrm{C}_{3} \mathrm{~N}_{4} / \mathrm{Bi}_{5} \mathrm{O}_{7} \mathrm{I}, \mathrm{In}_{2} \mathrm{~S}_{3} /$ $\mathrm{Bi}_{2} \mathrm{O}_{2} \mathrm{CO}_{3}$, and g- $\mathrm{C}_{3} \mathrm{~N}_{4} / \mathrm{Ag} / \mathrm{P}_{3} \mathrm{HT}$ showed poor photodegradation ability against tetracycline under visible light (Fan et al. 2020; Huang et al. 2019; Liu et al. 2019b), and their value of figures of merit was $3.52 \times 10^{-15}, 6.64 \times 10^{-15}$, $2.30 \times 10^{-14}, 3.65 \times 10^{-14}$, and $4.16 \times 10^{-14} \mathrm{~mol} \cdot \mathrm{L} /(\mathrm{g} \cdot \mathrm{J} \cdot \mathrm{h})$ ), respectively. The unsatisfactory photocatalytic performance of these composites could be explained by some reasons as followings: (i) these photocatalysts had deficiency in at least one of parameters in Eq. (1) or/ and Eq. (3) (Anwer et al. 2019); (ii) the formation of type I heterojunction in $\mathrm{g}^{-} \mathrm{C}_{3} \mathrm{~N}_{4} /$ $\mathrm{Bi}_{4} \mathrm{O}_{5} \mathrm{I}_{2}$ and $\mathrm{g}-\mathrm{C}_{3} \mathrm{~N}_{4} / \mathrm{BiOI}$ accelerated the recombination of charge carriers and also decreased oxidation and reduction potential of the whole composite; (iii) relatively lower specific surface areas of g- $\mathrm{C}_{3} \mathrm{~N}_{4} / \mathrm{Bi}_{4} \mathrm{O}_{5} \mathrm{I}_{2}, \mathrm{~g}-\mathrm{C}_{3} \mathrm{~N}_{4} / \mathrm{BiOI}, \mathrm{g}-\mathrm{C}_{3} \mathrm{~N}_{4} /$ $\mathrm{Bi}_{5} \mathrm{O}_{7} \mathrm{I}, \mathrm{In}_{2} \mathrm{~S}_{3} / \mathrm{Bi}_{2} \mathrm{O}_{2} \mathrm{CO}_{3}$, and $\mathrm{g}-\mathrm{C}_{3} \mathrm{~N}_{4} / \mathrm{Ag} / \mathrm{P}_{3} \mathrm{HT}$ compared with other photocatalytic materials in Table 2. This indicates that photochemical and photophysical properties, especially the visible light response of these photocatalytic systems should be further improved for to enhance their practical application in the future.

Besides, quantum efficiency values of excellent photocatalytic systems were suggested to be higher than $1.00 \times 10^{-7}$ 


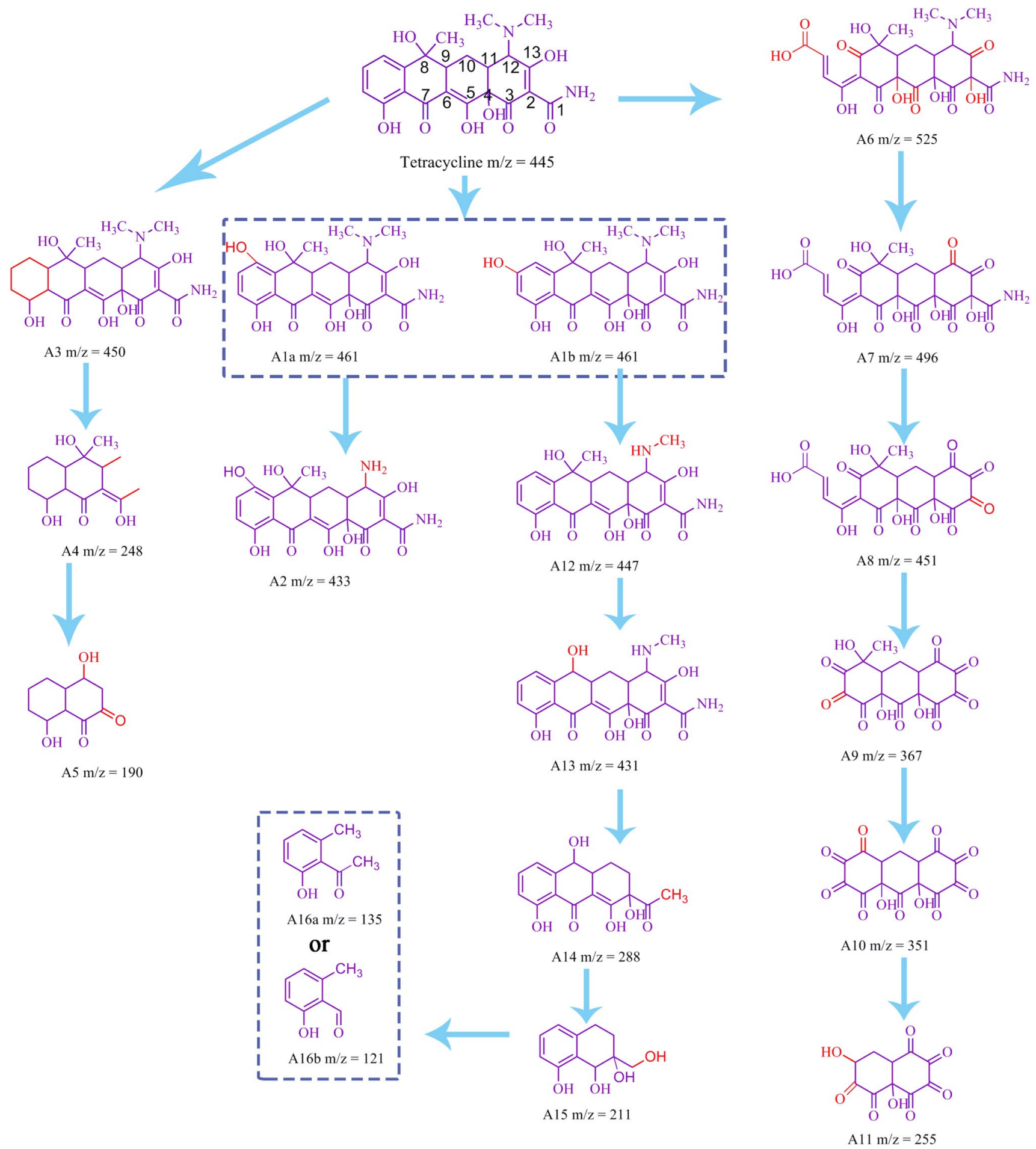

Scheme 1 First proposed degradation route of tetracycline during heterojunction photocatalysis. Reactive oxygen species from photocatalysis are likely to attack the aromatic ring of tetracycline 
<smiles>CN(C)C1C(O)=C(C=O)C(=O)[C@]2(O)C(O)=C3C(=O)c4c(O)cccc4C(C)(O)C3CC12</smiles>

$\mathrm{B} 1 \mathrm{~m} / \mathrm{z}=429$<smiles>CC1(O)c2cccc(O)c2C(=O)C2=C(O)C3(O)C(=O)C(C=O)=C(O)CC3CC21</smiles>

$\mathrm{B} 2 \mathrm{~m} / \mathrm{z}=386$<smiles>O=CC1=C(O)CC2CC3C(=C(O)C2(O)C1=O)C(=O)c1c(O)cccc1C3O</smiles>

B3 $\mathrm{m} / \mathrm{z}=352$<smiles>CCCC1CC(O)=CC(=O)C1(O)C(O)=C1C(=O)c2c(O)cccc2C(O)C1C</smiles>

B4 $\mathrm{m} / \mathrm{z}=344$<smiles>CCC1CC2C(=C(O)C1(C=O)CC=O)C(=O)c1c(O)cccc1C2O</smiles>

B5 $\mathrm{m} / \mathrm{z}=332$<smiles>CCC1CC(C)C(O)C(O)=C1C(=O)c1c(C)cccc1O</smiles>

B6 $\mathrm{m} / \mathrm{z}=276$

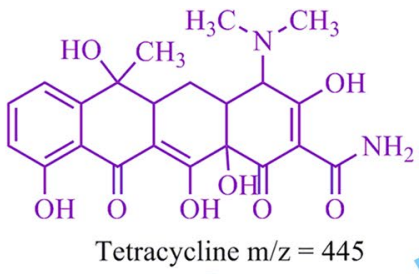

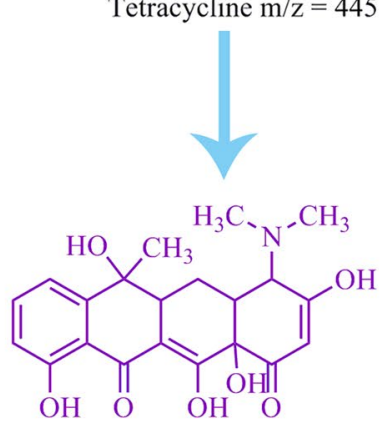

B9 $\mathrm{m} / \mathrm{z}=402$<smiles>CN(C)C1C(O)=C(O)C(=O)[C@]2(O)C(O)=C3C(=O)c4c(O)cccc4C(O)(O)C3CC12</smiles>

$\mathrm{B} 10 \mathrm{~m} / \mathrm{z}=418$<smiles>CN(C)C1C(O)=C(O)C(=O)C2(O)C(O)=C3C(=O)c4c(O)cccc4C(O)(O)C3=CC12</smiles>

$\mathrm{B} 11 \mathrm{~m} / \mathrm{z}=416$<smiles>O=C1CC(C/C=C/CO)C(O)c2cccc(O)c21</smiles>

B7 $\mathrm{m} / \mathrm{z}=246$<smiles>CCCC1CC(=O)c2c(O)cccc2C1O</smiles>

B8 m/z $=218$<smiles>CN(C)C1C(O)=C(C(=O)O)C(=O)[C@]2(O)C(O)=C3C(=O)c4c(O)cccc4C(O)(O)C3CC12</smiles>

$\mathrm{B} 12 \mathrm{~m} / \mathrm{z}=446$<smiles>CC1(O)c2cccc(O)c2C(=O)C2=C(O)C3(O)C(=O)C(O)C(=O)C(O)C3CC21</smiles><smiles>C=C1/C(=C\O)C(=O)C2=C(O)C(O)(C(=O)C(O)C(=O)O)C(CO)CC2C1(C)O</smiles>

$\mathrm{B} 14 \mathrm{~m} / \mathrm{z}=390$<smiles>CC(C)(C)CC1CC(CO)C(=O)C(=O)C12OC(=O)c1c(O)cccc1C2(C)O</smiles>

$\mathrm{B} 15 \mathrm{~m} / \mathrm{z}=320$ 
४Scheme 2 Second proposed degradation route of tetracycline during heterojunction photocatalysis. Attack of amide group by reactive oxygen species results in the deamidation of tetracycline

molecules/photon (Anwer et al. 2019). Quantum efficiency values of heterojunctioned systems are listed in Table 2 generally between $4.01 \times 10^{-9}$ and $1.25 \times 10^{-5}$ molecules/photon. Note that most systems had a corresponding quantum efficiency value higher than $10^{-7}$, which due to the fact that heterojunction systems generally pose better photogenerated charge-pair separation and light-harvesting properties.

A 3D architecture organic heterojunction (PANI/PDI) developed by combining polyaniline and perylene diimide exhibited the highest quantum efficiency and space time yield $\left(4.99 \times 10^{-4}\right.$ molecules/(g.photon) $)$ under visible light (Fig. 15) (Dai et al. 2020). Therefore, the 3D PANI/PDI per mass unit could effectively utilize a unit photon to decompose more tetracycline molecules than other photocatalysts. PANI/PDI showed excellent visible light harvest because PDI and PANI have strong absorption ability at about $713 \mathrm{~nm}$ and the whole UV-Vis light region, respectively (Jiang et al. 2016). Such outstanding photocatalytic ability of the 3D PANI/PDI system was due to: (i) the formation of energy-matched heterojunction and larger delocalized $\pi$-electron conjugated system caused by $\pi-\pi$ bonds between PANI and PDI, which restrained the recombination of $\mathrm{e}^{-}-\mathrm{h}^{+}$ pairs; (ii) structural superiority of 3D framework providing more reactive sites and charge transport channels; (iii) coupling with PANI polymer backbone enhances the strength of the PDI hydrogel, thereby increasing the catalytic stability of the whole composite. PANI/PDI might be one of the promising candidates as visible-light-driven photocatalytic system for environmental applications. Therefore, future studies should explore such photocatalytic materials with high visible light response.

A novel type II heterojunction composite $\mathrm{Bi}_{2} \mathrm{~W}_{2} \mathrm{O}_{9} / \mathrm{g}-\mathrm{C}_{3} \mathrm{~N}_{4}$ also showed high quantum efficiency of $6.45 \times 10^{-6}$ molecules/photon, space time yield of $3.23 \times 10^{-5}$ molecules/(g.photon), and removal efficiency of $95 \%$ (3.8 and 2.6 times higher than that of the pristine $\mathrm{Bi}_{2} \mathrm{~W}_{2} \mathrm{O}_{9}$ and $\mathrm{g}-\mathrm{C}_{3} \mathrm{~N}_{4}$ catalysts) after 90 min of simulated sunlight irradiation (Fig. 16) (Obregón et al. 2020). The enhanced photocatalytic performance of $\mathrm{Bi}_{2} \mathrm{~W}_{2} \mathrm{O}_{9} / g-\mathrm{C}_{3} \mathrm{~N}_{4}$ mainly attributed to the establishment of type II heterojunction caused by the difference of conduction band and valence band of both $\mathrm{Bi}_{2} \mathrm{~W}_{2} \mathrm{O}_{9}$ and $\mathrm{g}-\mathrm{C}_{3} \mathrm{~N}_{4}$ semiconductors, which accelerated the effective separation of photoexcited charge carriers. Also, $\mathrm{Bi}_{2} \mathrm{~W}_{2} \mathrm{O}_{9} / \mathrm{g}-\mathrm{C}_{3} \mathrm{~N}_{4}\left(4.3 \mathrm{~m}^{2} / \mathrm{g}\right)$ had a larger surface area than that of pure $\mathrm{Bi}_{2} \mathrm{~W}_{2} \mathrm{O}_{9}\left(1.5 \mathrm{~m}^{2} / \mathrm{g}\right)$ and a lower band gap value $(2.70 \mathrm{eV})$ than that of pure $\mathrm{Bi}_{2} \mathrm{~W}_{2} \mathrm{O}_{9}$ $(2.91 \mathrm{eV})$, enhancing the photocatalytic degradation of tetracycline. It is widely suggested that photocatalysis performance of photocatalysts is influenced by their textural, morphological, and crystalline properties such as surface area, crystalline size, porosity, pore size, crystallinity.

$\mathrm{ZnO} / \mathrm{GO} / \mathrm{Ag}_{3} \mathrm{PO}_{4}$ ternary heterojunction system, one of $\mathrm{ZnO}$-based representative heterojunction, was constructed through a facile ultrasonic-assisted precipitation method and exhibited superior performance for tetracycline removal (quantum efficiency $=3.17 \times 10^{-6}$ molecules/photon, and space time yield $=6.34 \times 10^{-5}$ molecules $/(g \cdot$ photon $)$ ) $(\mathrm{Zhu}$ et al. 2020). $\mathrm{ZnO} / \mathrm{GO} / \mathrm{Ag}_{3} \mathrm{PO}_{4}$ system had higher tetracycline removal efficiency (96.32\%) than $\mathrm{ZnO}(51.33 \%), \mathrm{Ag}_{3} \mathrm{PO}_{4}$ (48.35\%), GO/ $\mathrm{Ag}_{3} \mathrm{PO}_{4}(80.61 \%), \mathrm{ZnO} / \mathrm{GO}(79.60 \%)$, and $\mathrm{ZnO} / \mathrm{Ag}_{3} \mathrm{PO}_{4}(70 \%)$ after $75 \mathrm{~min}$ of visible irradiation. Enhanced adsorption ability, accelerated electron transfer, increased number of active species, and effective separation of photoproduced charge carriers enhanced photocatalytic activity of $\mathrm{ZnO} / \mathrm{GO} / \mathrm{Ag}_{3} \mathrm{PO}_{4}$.

The heterojunction systems in Table 2 with poor photocatalytic performance and quantum efficiency less than $1.00 \times 10^{-7}$ molecules/photon showed a relatively low degradation efficiency $<80 \%$ for tetracycline antibiotic, except for $\mathrm{Ag}-\mathrm{C}_{3} \mathrm{~N}_{4} /$ $\mathrm{SnS}_{2}(\approx 90 \%)$. For instance, a noble-metal-free $\mathrm{p}-\mathrm{n}$ heterojunction $\mathrm{CuBi}_{2} \mathrm{O}_{4} / \mathrm{MoS}_{2}$ displayed a low quantum efficiency of $2.26 \times 10^{-8}$ molecules/photon and removal ratio of $76.0 \%$ after $120 \mathrm{~min}$ of visible light illumination (Guo et al. 2019b). $\mathrm{Bi}_{4} \mathrm{NbO}_{8} \mathrm{Cl} / \mathrm{g}-\mathrm{C}_{3} \mathrm{~N}_{4}$ nanosheets with $\{001\}$ exposing facets prepared via a molten-salt growth method degraded $78.0 \%$ of tetracycline after $180 \mathrm{~min}$ of photocatalysis with a quantum efficiency of $7.72 \times 10^{-8}$ molecules/photon (Xu et al. 2020b). Among three performance metrics, quantum efficiency is an essential quantitative measurement tool for performance of photocatalysts. The photocatalytic system with low quantum efficiency cannot exhibit high value of space time yield and figures of merit, indicating poor practical application potential. 


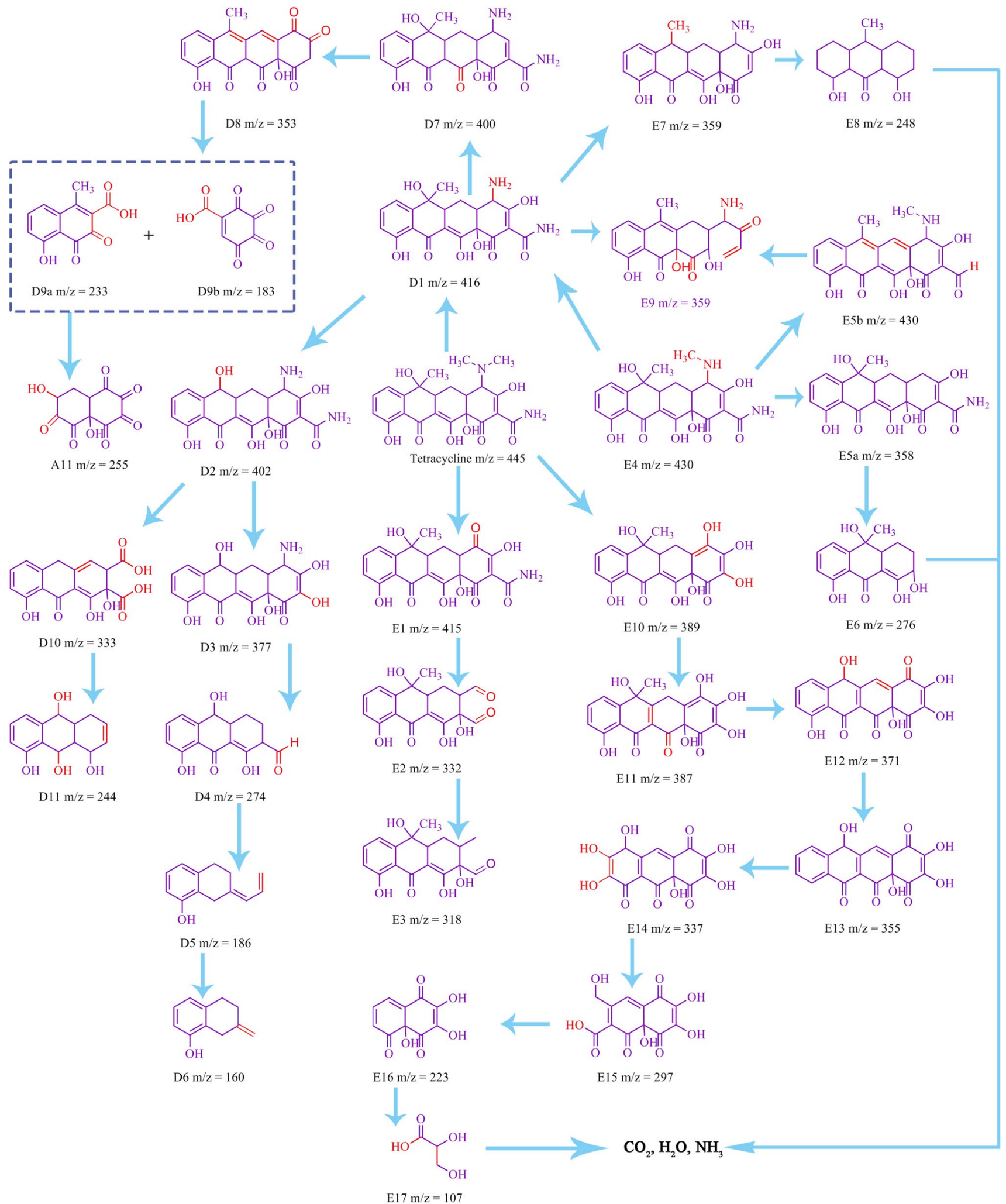

Scheme 3 Third proposed degradation route of tetracycline during heterojunction photocatalysis. The degradation of tetracycline may start with the loss of N-dimethyl group structure 
<smiles>CN(C)C1C(O)=C(C(N)=O)C(=O)[C@]2(O)C(=O)C3(O)C(=O)c4c(O)cccc4C(C)(O)C3=CC12</smiles>

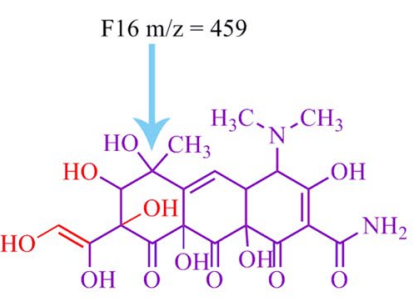

$\mathrm{F} 17 \mathrm{~m} / \mathrm{z}=485$

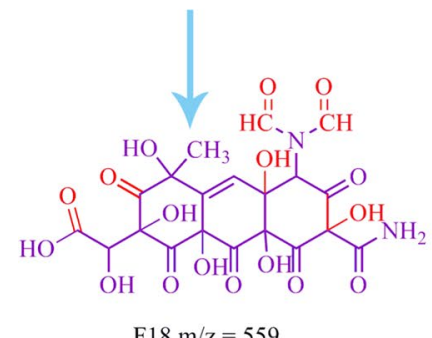

$\mathrm{F} 18 \mathrm{~m} / \mathrm{z}=559$<smiles>NC1C(=O)C(=O)C(=O)[C@@]2(O)C(=O)[C@]3(O)C(=O)c4c(O)cccc4C(=O)C3CC12</smiles>

$\mathrm{F} 21 \mathrm{~m} / \mathrm{z}=387$<smiles>CCC1CCCC2C(=O)c3ccccc3C(=O)C12</smiles>

$\mathrm{F} 22 \mathrm{~m} / \mathrm{z}=214$<smiles>CCCC(C)C</smiles><smiles>O=C(O)CO</smiles><smiles>CC(C)CC(O)C(=O)O</smiles>

$\mathrm{F} 15 \mathrm{~m} / \mathrm{z}=121$

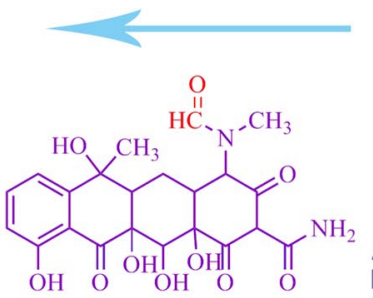

$\mathrm{F} 23 \mathrm{~m} / \mathrm{z}=491$<smiles>CN(C)C1C(=O)C(C(N)=O)C(=O)[C@]2(O)C1CC1C(O)(O)c3cccc(O)c3C(=O)C1(O)C2O</smiles>

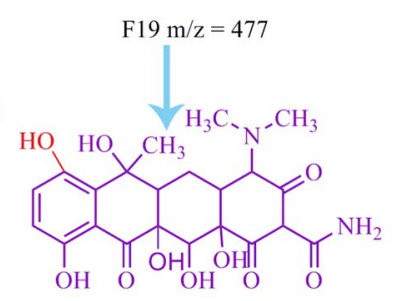

$\mathrm{F} 20 \mathrm{~m} / \mathrm{z}=493$

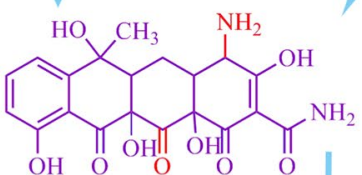

$\mathrm{F} 7 \mathrm{~m} / \mathrm{z}=432$

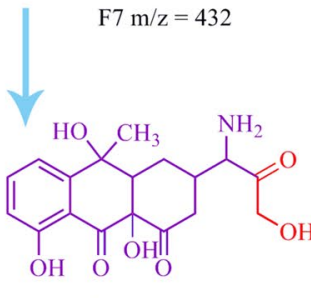

$\mathrm{F} 8 \mathrm{~m} / \mathrm{z}=363$<smiles>CC1(O)c2cccc(O)c2C(=O)C2(O)C(=O)C(O)C(C(N)C(=O)C=O)=CC21</smiles>

$\mathrm{F} 13 \mathrm{~m} / \mathrm{z}=376$<smiles>CC(O)C1CCCCCCCCCCCC1</smiles><smiles>CC1(C)c2cccc(O)c2C(=O)C2(O)C(=O)C(O)CCC21</smiles>

$\mathrm{F} 14 \mathrm{~m} / \mathrm{z}=279$<smiles>CN(C)C1C(O)=C(C(N)=O)C(=O)C2(O)C(O)=C3C(=O)c4c(O)cccc4C(O)(O)C3CC12</smiles>

Tetracycline $\mathrm{m} / \mathrm{z}=445$<smiles>CN(C)C1C2CC3C(=C(O)C2(O)C(=O)C(CI)(C(N)=O)C1O)C(=O)c1c(O)cccc1C3(O)I</smiles>

$\mathrm{F} 1 \mathrm{~b} \mathrm{~m} / \mathrm{z}=461$

or

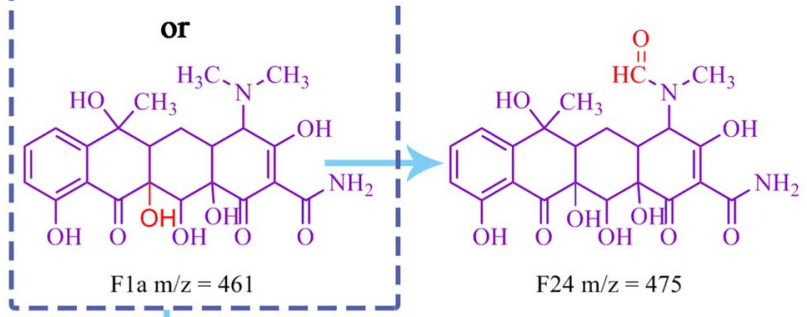

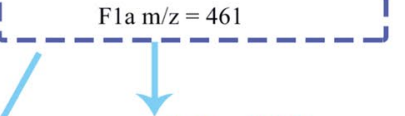<smiles>CC1C2(O)c3cccc(O)c3C(=O)C2(O)C12C(=O)C1C(N(C)C)C(O)C(O)(C(N)=O)C(=O)C1(O)C2O</smiles>

$\mathrm{F} 2 \mathrm{~m} / \mathrm{z}=477$<smiles>CN(C=O)C1C(O)=C(C(N)=O)C(=O)[C@@]2(O)C1CC1C(C)(O)c3cccc(O)c3C(=O)C1(O)C2O</smiles>

$\mathrm{F} 3 \mathrm{~m} / \mathrm{z}=477$<smiles>CC(C)(C)C1(O)c2cccc(O)c2C(=O)C2=C(O)C(O)CCC21</smiles>

$\mathrm{F} 4 \mathrm{~m} / \mathrm{z}=277$<smiles>COC1(C)CC(O)C(=O)c2c(O)cccc21</smiles><smiles>CC1(O)c2cccc(O)c2C(=O)C2=C(O)C(C=O)(C=O)C(CC=O)CC21</smiles>

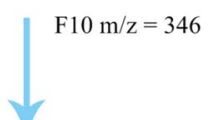<smiles>CC1(O)CCC2C(=C1O)C(=O)c1c(O)cccc1C(C)(O)C2(C)O</smiles>

$\mathrm{F} 11 \mathrm{~m} / \mathrm{z}=304$<smiles>O=CC1CCC2Cc3cccc(O)c3C(=O)C2=C1O</smiles>

$\mathrm{F} 12 \mathrm{~m} / \mathrm{z}=304$

F $5 \mathrm{~m} / \mathrm{z}=209$<smiles>CCCCC(=O)O</smiles>

$\mathrm{F} 6 \mathrm{~m} / \mathrm{z}=149$

Scheme 4 Fourth proposed degradation route of tetracycline during heterojunction photocatalysis. Double bonds generally have a high affinity with reactive oxygen species and can be the main attack sites 
<smiles>CC1=C2CC3=C(C(=O)C=C(O)C3N)C(O)=C2C(=O)c2c(O)cccc21</smiles><smiles>CN(C)C1C(O)=C(C(N)=O)C(=O)[C@]2(O)C(O)=C3C(=O)c4c(O)cccc4C(O)(O)C3CC12</smiles>

$\mathrm{G} 4 \mathrm{~m} / \mathrm{z}=337$<smiles>CCCC1CC2=C(C)c3cccc(O)c3C(=O)C2C(O)C1C(=O)O</smiles>

$\mathrm{G} 5 \mathrm{~m} / \mathrm{z}=318$<smiles>CC1=C2CC3COC(=O)C3=CC2C(=O)c2c(O)cccc21</smiles>

$\mathrm{G} 6 \mathrm{~m} / \mathrm{z}=282$<smiles>C=CC(=O)C(N)C1CC2=C(C)c3cccc(O)c3C(=O)C2(O)C(=O)C1O</smiles>

E9 $\mathrm{m} / \mathrm{z}=359$<smiles>CC1=C2CC3C(O)=C(C(N)=O)C(=O)[C@@](O)(C(O)=C2C(=O)c2c(O)cccc21)C3N(C)C</smiles>

$\mathrm{G} 1 \mathrm{~m} / \mathrm{z}=426$<smiles>CC1=C2CC3C(N(C)C)C(O)=CC(=O)C3(O)C(O)=C2C(=O)c2c(O)cccc21</smiles>

$\mathrm{G} 2 \mathrm{~m} / \mathrm{z}=383$<smiles>CC1=C2C(=C(O)C1(O)C=O)C(=O)c1c(O)cccc1C2C</smiles>

$\mathrm{G} 3 \mathrm{~m} / \mathrm{z}=301$<smiles>CN(C)C1C(O)=C(C(N)=O)C(=O)[C@]2(O)C(O)=C3C(=O)c4c(O)cccc4C=C3CC12</smiles>

$\mathrm{G} 7 \mathrm{~m} / \mathrm{z}=413$
$\mathrm{G} 14 \mathrm{~m} / \mathrm{z}=389$<smiles>CN(C)C1C2=CC3=C(C(=O)C(=O)C=C3)C(=O)C2(O)C(=O)C(C(N)=O)=C1O</smiles>

$\mathrm{G} 15 \mathrm{~m} / \mathrm{z}=359$

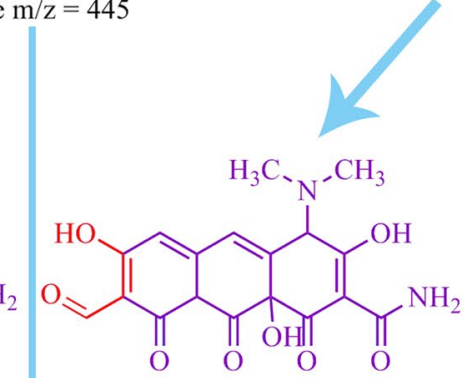<smiles>CN(C)C1C2=CC3=CC(O)=C(C=O)C(=O)C3C(=O)C2(O)C(=O)C(C(N)=O)=C1O</smiles><smiles>CCCCC</smiles><smiles>NC(=O)C1=C(O)C(O)C2=CCC(O)C(=O)C2(O)C1=O</smiles>

$\mathrm{G} 10 \mathrm{~m} / \mathrm{z}=270$<smiles>CN(C)C1C2=CC3=Cc4cccc(O)c4C(=O)C3C(=O)C2(O)C(=O)C(C(N)=O)=C1O</smiles>

G8 $\mathrm{m} / \mathrm{z}=411$<smiles>CCC1=CC2=CC=CC(=O)C2C(=O)C1(O)C(=O)C(CC)C(N)=O</smiles>

G9 $\mathrm{m} / \mathrm{z}=318$<smiles>CCC1=CCC(C=O)C(=O)C12OC(=O)C(C(N)=O)=C(O)C2=O</smiles>

$\mathrm{G} 11 \mathrm{~m} / \mathrm{z}=280$<smiles>O=C(O)C1=C(CO)C=C2C(=O)C(O)=C(O)C(=O)C2(O)C1=O</smiles>

$\mathrm{E} 15 \mathrm{~m} / \mathrm{z}=297$<smiles>O=C1C2=CC=CC(=O)C2(O)C(=O)C(O)=C1O</smiles>

$\mathrm{E} 16 \mathrm{~m} / \mathrm{z}=223$<smiles>O=C(O)C(O)CO</smiles>

$\mathrm{E} 17 \mathrm{~m} / \mathrm{z}=107$
$\mathrm{CO}_{2}, \mathrm{H}_{2} \mathrm{O}, \mathrm{NH}_{3}$<smiles>NC(=O)/C(O)=C(\O)C(=O)O</smiles>

$\mathrm{G} 12 \mathrm{~m} / \mathrm{z}=148$<smiles>C/C=C(/O)C(N)=O</smiles>

$\mathrm{G} 13 \mathrm{~m} / \mathrm{z}=104$

Scheme 5 Fifth proposed degradation route of tetracycline during heterojunction photocatalysis. Attack of reactive oxygen species results in the loss of hydroxyl in C8 site 


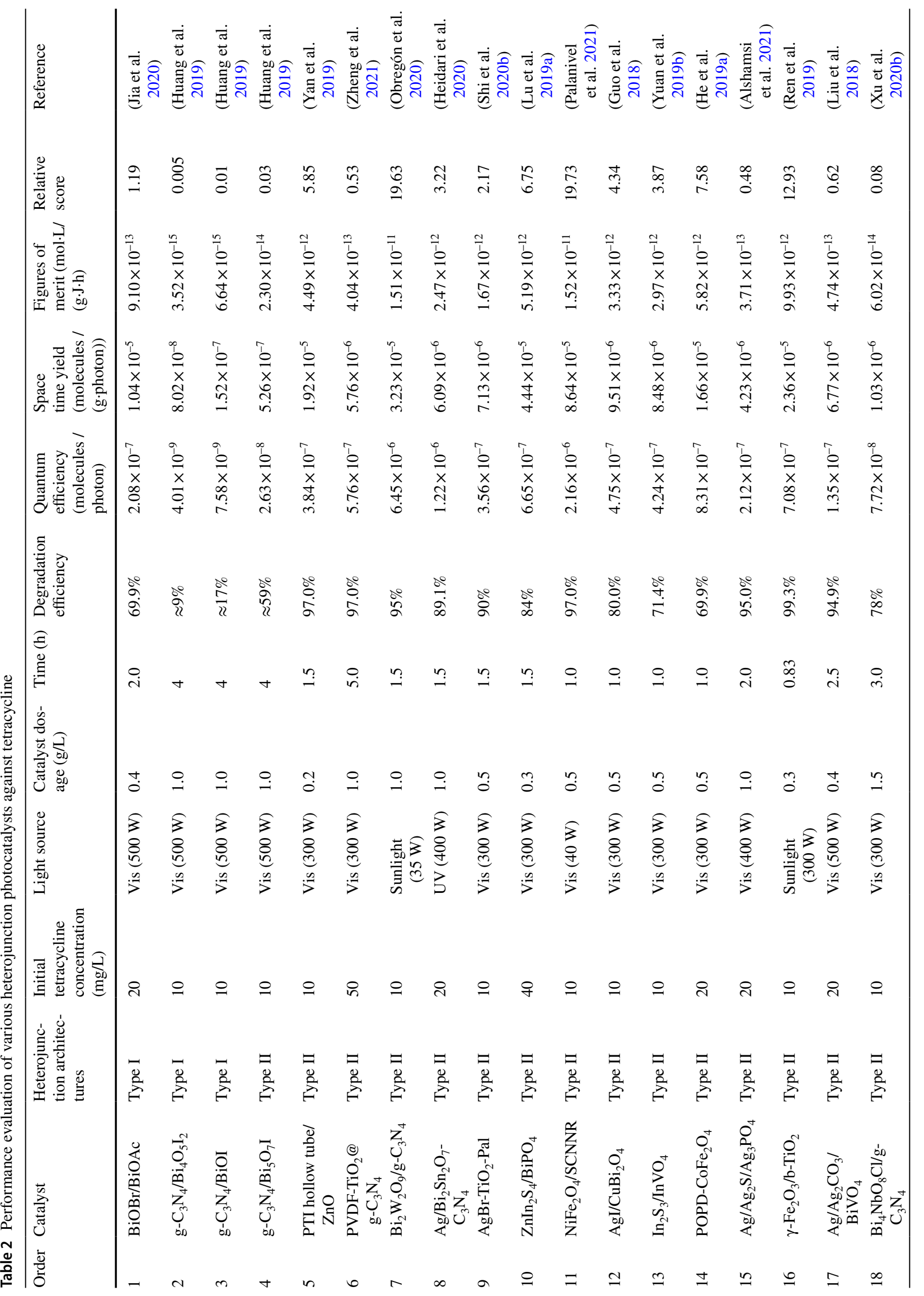




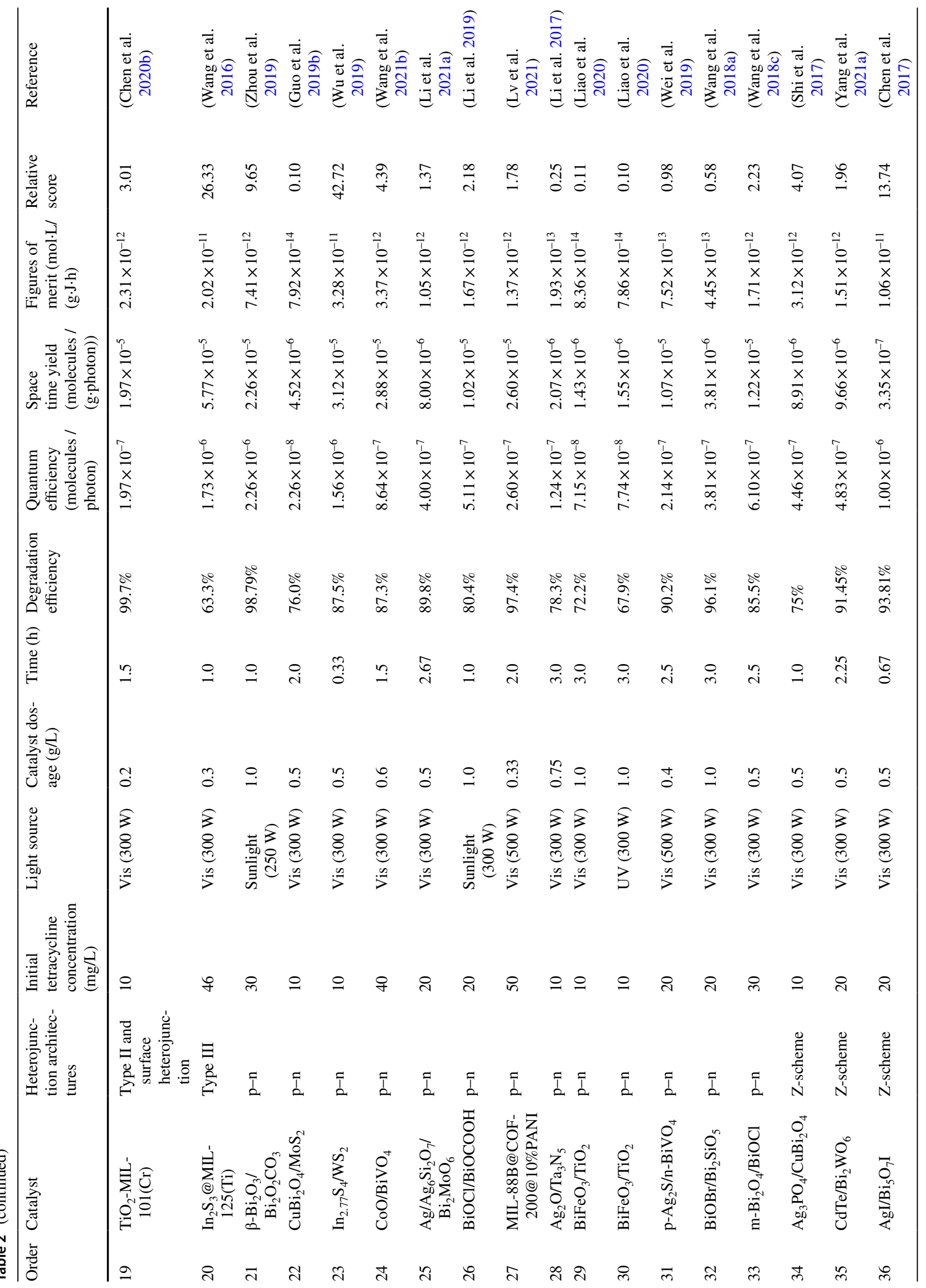




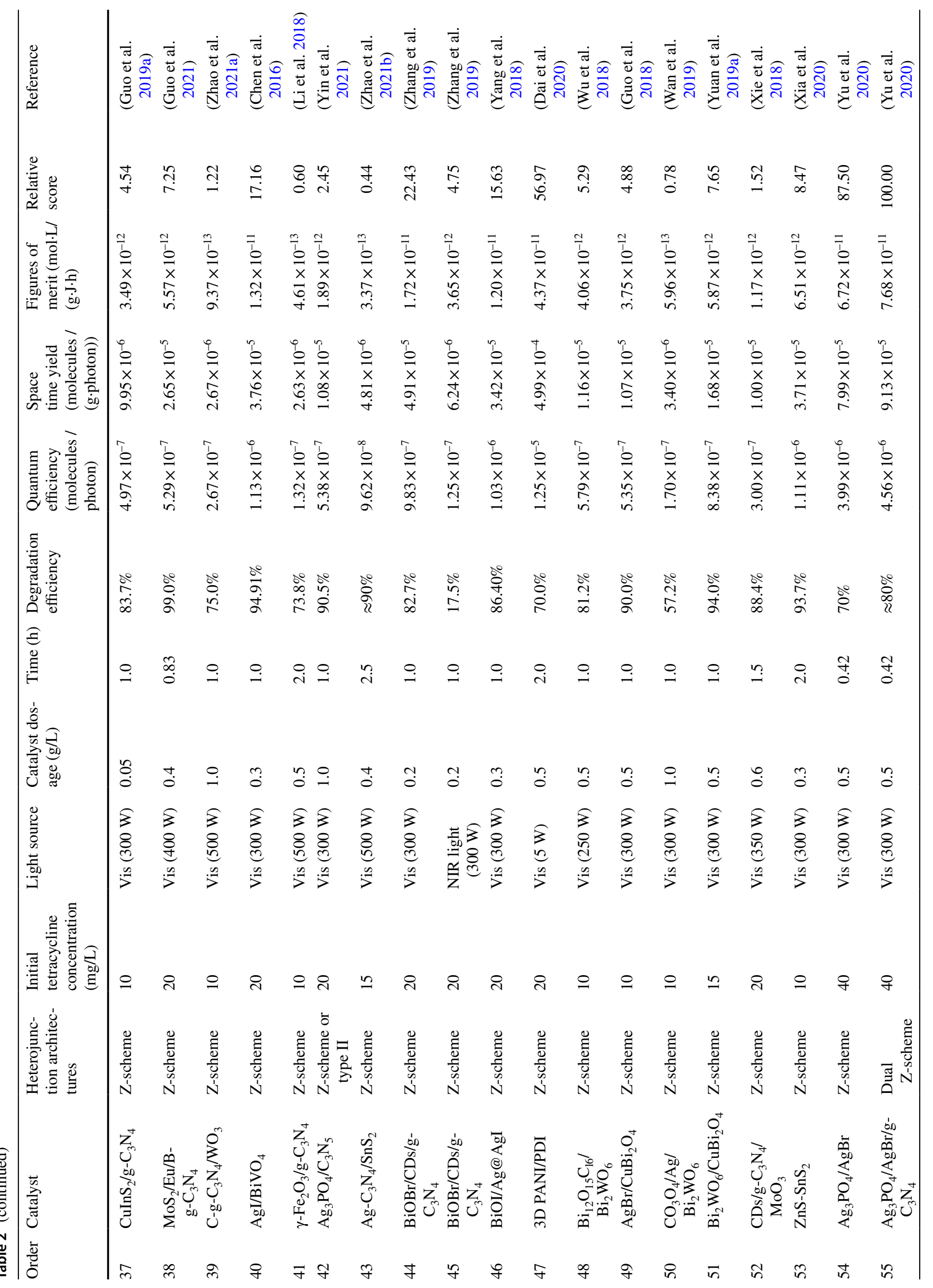




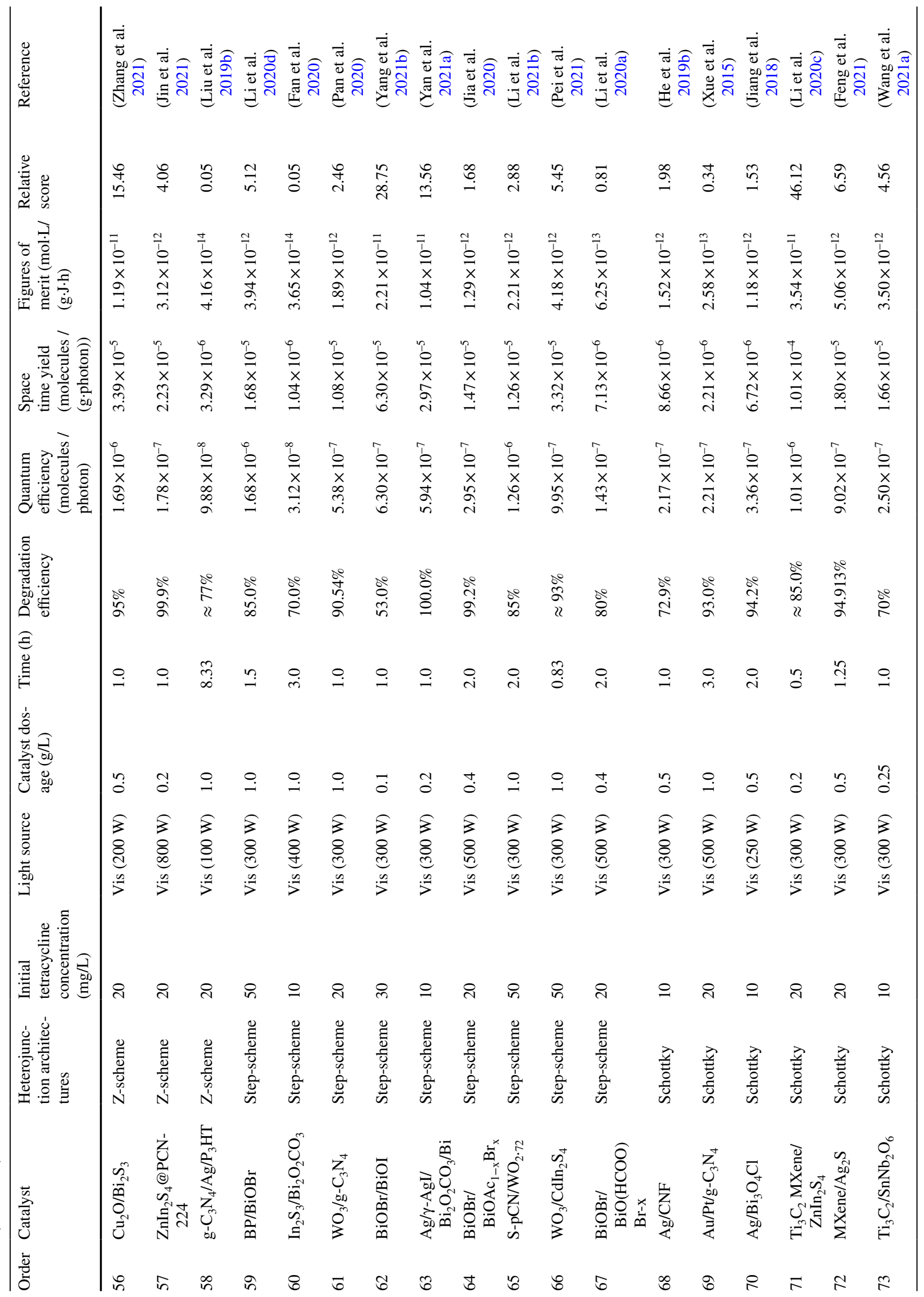




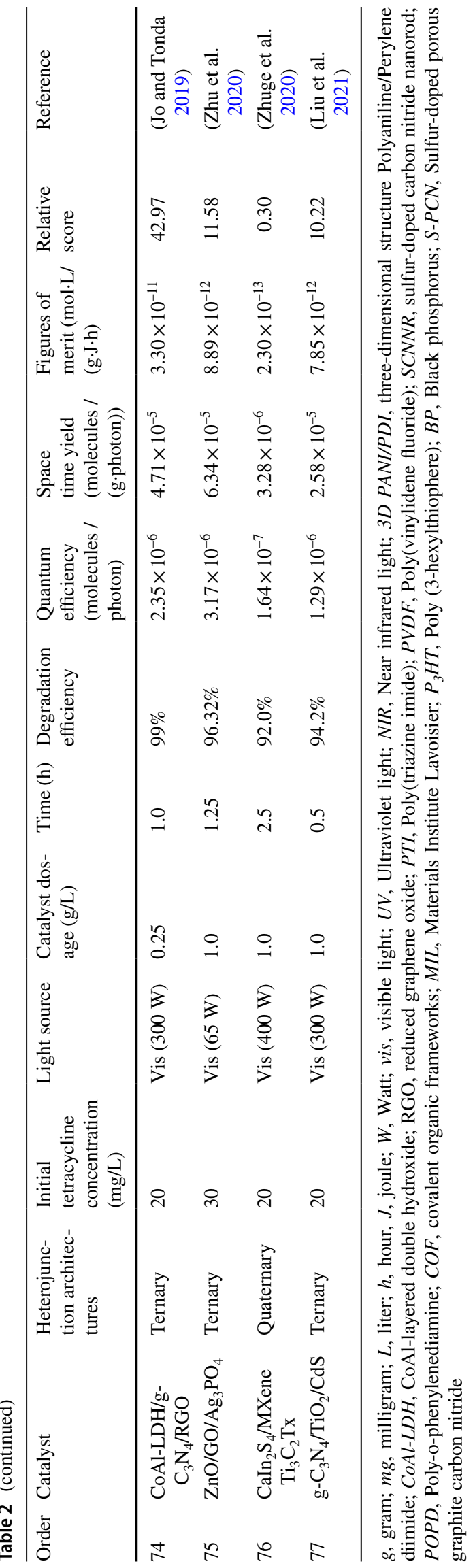

\section{Conclusion}

Over the past few decades, tetracycline antibiotic is one of the most common and persistent environmental pollutants, threatening ecological and human health worldwide. Recent research has demonstrated that heterojunction photocatalysis is an ideal and promising method for improving the separation/migration of electron-hole pair and remediating tetracycline-contaminated aquatic environments. However, the particular application of heterojunction semiconductor photocatalysts still suffers from several significant limitations. Therefore, future research should address the following bottlenecks.

Firstly, performance evaluation is an objective option to screen excellent photocatalytic materials with outstanding photo-activity. A few studies have about systematically assessed and compared the photocatalytic performance of different catalysts during photocatalytic degradation. Besides, only quantum efficiency, space time yield, and figures of merit have been used as evaluation metrics, ignoring thermodynamical indices, such as temperature that can greatly influence the rate of photocatalytic degradation. Therefore, more inferred numeric metrics, performance evaluation methods, formulae and mathematical models should be exhibited in the future for an advanced photocatalytic performance assessment. Secondly, the toxic effects of the intermediates formed during photocatalytic degradation of tetracycline antibiotic are unknown. Therefore, toxicology assessment of tetracycline degradation intermediates is necessary. Future studies should also focus on accelerating the decomposition of tetracycline and other drugs into $\mathrm{CO}_{2}$, $\mathrm{H}_{2} \mathrm{O}$, and other small molecular inorganics to decrease the production of toxic intermediates. Additionally, the plausible mechanism involving the transfer of photogenerated electrons and holes in heterojunction systems composed of more than two semiconductor photocatalysts remains unknown and requires relevant reflection and studies. 

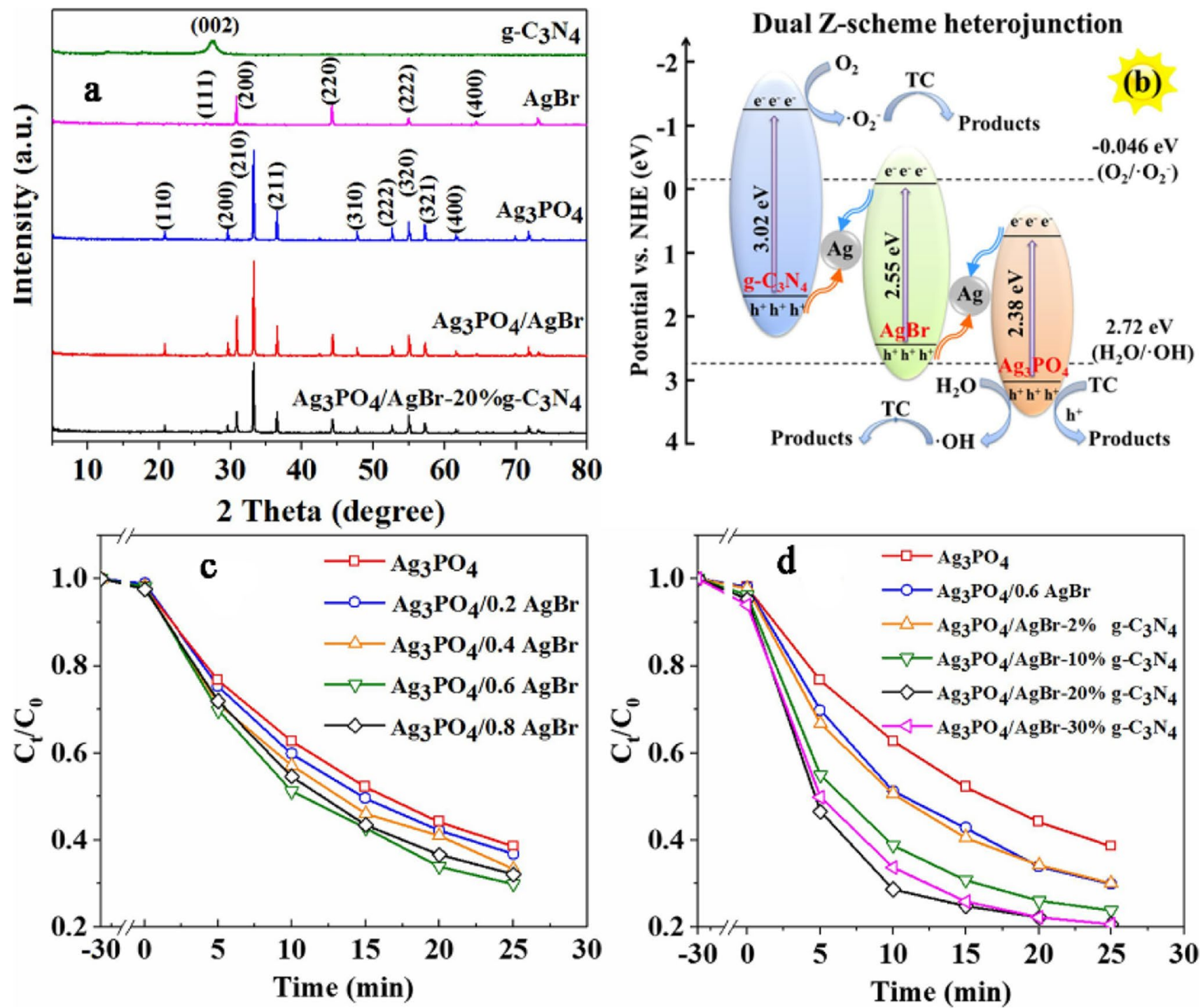

Fig. 14 a X-ray diffraction patterns of $\mathrm{g}_{-} \mathrm{C}_{3} \mathrm{~N}_{4} \mathrm{AgBr}, \mathrm{Ag}_{3} \mathrm{PO}_{4}$, $\mathrm{Ag}_{3} \mathrm{PO}_{4} / \mathrm{AgBr}$, and $\mathrm{Ag}_{3} \mathrm{PO}_{4} / \mathrm{AgBr} / \mathrm{g}-\mathrm{C}_{3} \mathrm{~N}_{4}$ b Photocatalytic degradation mechanism of tetracycline by $\mathrm{Ag}_{3} \mathrm{PO}_{4} / \mathrm{AgBr} / \mathrm{g}-\mathrm{C}_{3} \mathrm{~N}_{4}$ : metallic $\mathrm{Ag}$ acted as the electron transfer mediator to build the dual $\mathrm{Z}$-scheme heterojunction. $\mathbf{c}$ The effect of $\mathrm{AgBr}$ content on photocatalytic degradation of tetracycline using $\mathrm{Ag}_{3} \mathrm{PO}_{4} / \mathrm{AgBr}$ under the visible light irra-

diation. $\mathbf{d}$ The effect of $\mathrm{g}-\mathrm{C}_{3} \mathrm{~N}_{4}$ content on photocatalytic degradation of tetracycline using $\mathrm{Ag}_{3} \mathrm{PO}_{4} / \mathrm{AgBr} / \mathrm{g}-\mathrm{C}_{3} \mathrm{~N}_{4}$ under visible light irradiation (Reprinted with permission of Elsevier from Yu et al. 2020). $\mathrm{e}^{-}$, electron; $\mathrm{h}^{+}$, hole; $\mathrm{O}_{2}{ }^{\cdot-}$, superoxide radical; $\cdot \mathrm{OH}$ hydroxyl radical. $\mathrm{TC}$, tetracycline 
Fig. 15 a Morphologic structure of PANI/PDI. b Photocatalysis mechanism of PANI/PDI heterojunction photocatalysts under visible light irradiation: direct Z-scheme heterojunction mechanism. $\mathbf{c}$ and $\mathbf{d}$ Scanning electron microscopy images of 3D PANI/PDI: PDI were uniformly dispersed in the $3 \mathrm{D}$ network structure of PANI (Reprinted with permission of Elsevier from Dai et al. 2020). PANI, Polyaniline; PDI, Perylene diimide. 3D, threedimension
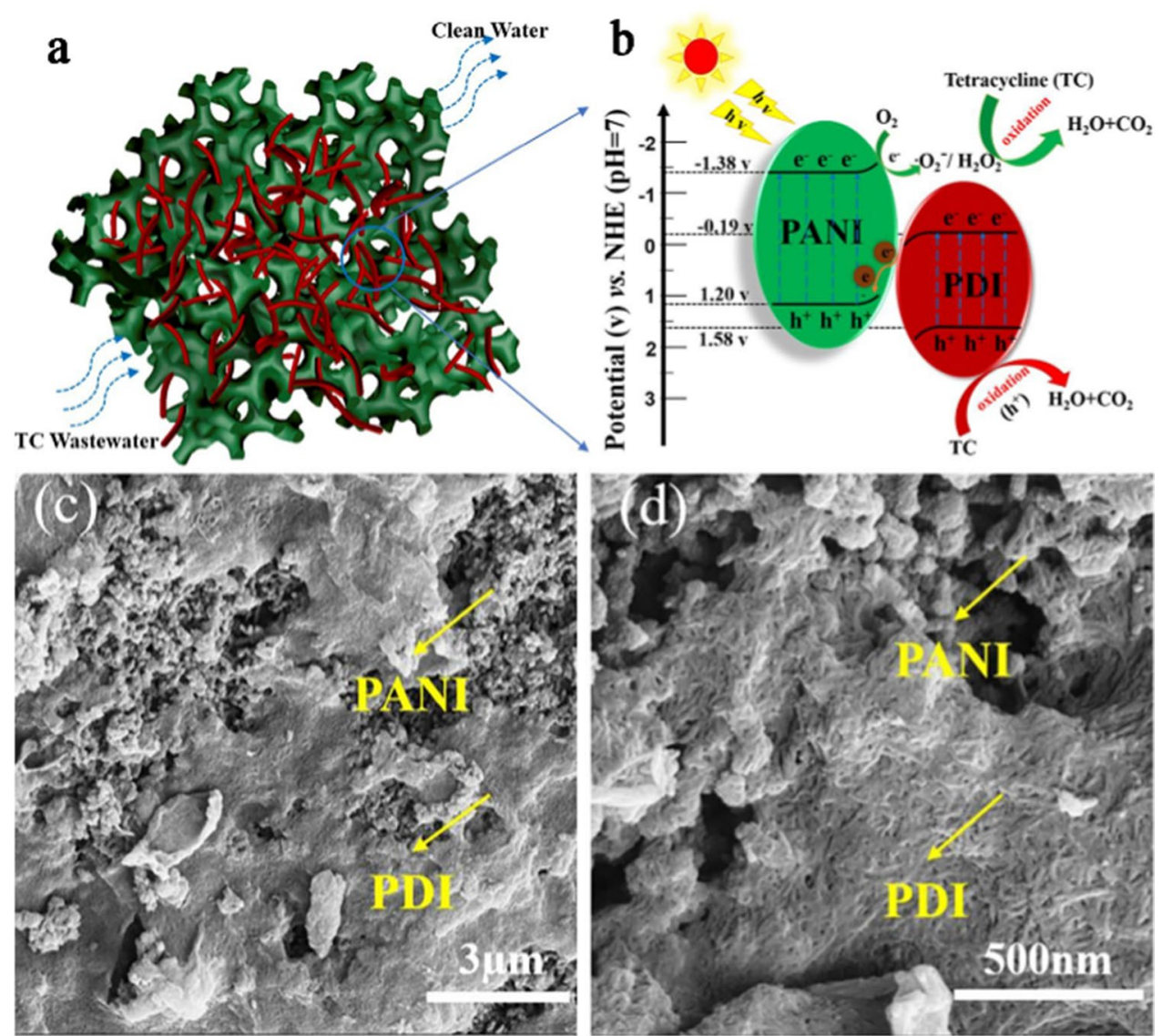

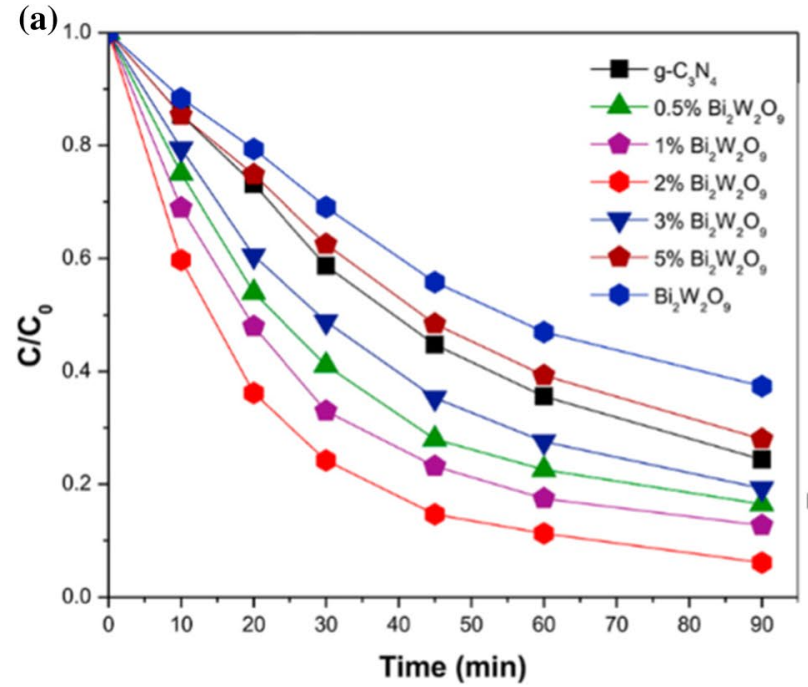

Fig. 16 a Photocatalytic removal of tetracycline using $\mathrm{Bi}_{2} \mathrm{~W}_{2} \mathrm{O}_{9}$, g- $\mathrm{C}_{3} \mathrm{~N}_{4}$ and $\mathrm{Bi}_{2} \mathrm{~W}_{2} \mathrm{O}_{9} / \mathrm{g}-\mathrm{C}_{3} \mathrm{~N}_{4}$ under sunlight illumination. b Chargecarrier separation process for $\mathrm{Bi}_{2} \mathrm{~W}_{2} \mathrm{O}_{9} / g-\mathrm{C}_{3} \mathrm{~N}_{4}$ : different positions of the valence and conduction bands of $\mathrm{Bi}_{2} \mathrm{~W}_{2} \mathrm{O}_{9}$ and $\mathrm{g}-\mathrm{C}_{3} \mathrm{~N}_{4}$ built a (b)

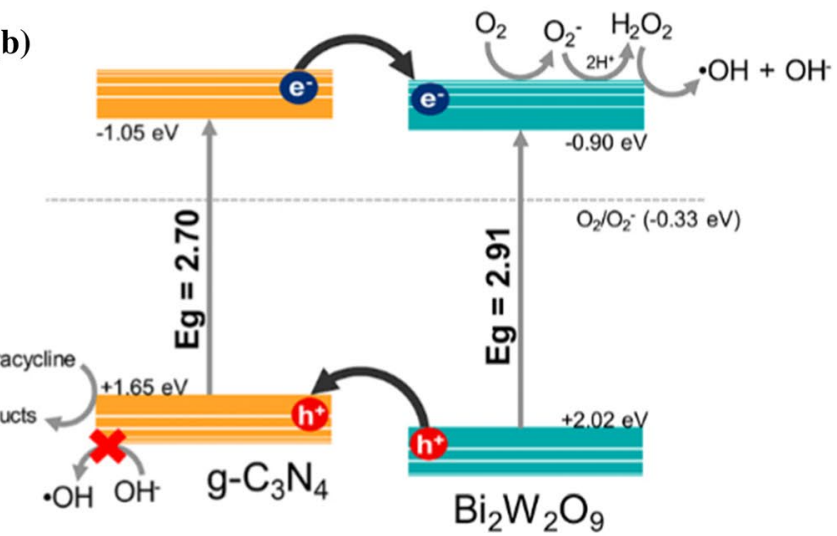

type II heterojunction system. (Reprinted with permission of Elsevier from Obregón et al. 2020). $\mathrm{e}^{-}$, electron; $\mathrm{h}^{+}$, hole; $\mathrm{O}_{2}{ }^{-{ }^{-}}$, superoxide radical; $\cdot$ OH hydroxyl radical; $\mathrm{E}_{\mathrm{g}}$, energy gap 
Acknowledgements This work was supported by the National Natural Science Foundation of China (82073607), Hunan Provincial Natural Science Foundation of China (2019JJ40399), and Novel coronavirus pneumonia emergency special science and technology plan of Changsha City (kq2001035). In addition, Xinghou He would like to thank Prof. Ping Ding and Dr. Pian Wu of Central South University Xiangya School of Public Health for their selfless help during he studied for bachelor degree in Central South University. Xinghou also want to thank, Xinghua He of Yunna normal university for his assistance in providing original figures for this paper, and love and support from Hongkong Culture Regeneration Research Society over the past years.

\section{Declarations}

Conflict of interest The authors declare that they do not have any conflict of interest.

\section{References}

Abbas N, Rubab N, Kim KH, Chaudhry R, Manzoor S, Raza N, Tariq M, Lee J, Manzoor S (2021) The photocatalytic performance and structural characteristics of nickel cobalt ferrite nanocomposites after doping with bismuth. J Coll Interface Sci 594:902-913. https://doi.org/10.1016/j.jcis.2021.03.094

Acharya L, Nayak S, Pattnaik SP, Acharya R, Parida K (2020) Resurrection of boron nitride in p-n type-II boron nitride/B-doped-g$\mathrm{C}_{3} \mathrm{~N}_{4}$ nanocomposite during solid-state $\mathrm{Z}$-scheme charge transfer path for the degradation of tetracycline hydrochloride. J Coll Interface Sci 566:211-223. https://doi.org/10.1016/j.jcis.2020. 01.074

Akhil D, Lakshmi D, Senthil Kumar P, Vo D-VN, Kartik A (2021) Occurrence and removal of antibiotics from industrial wastewater. Environ Chem Lett 19:1477-1507. https://doi.org/10.1007/ s10311-020-01152-0

Alshamsi HA, Beshkar F, Amiri O, Salavati-Niasari M (2021) Porous hollow $\mathrm{Ag} / \mathrm{Ag}_{2} \mathrm{~S} / \mathrm{Ag}_{3} \mathrm{PO}_{4}$ nanocomposites as highly efficient heterojunction photocatalysts for the removal of antibiotics under simulated sunlight irradiation. Chemosphere 274:129765. https:// doi.org/10.1016/j.chemosphere.2021.129765

Ani IJ, Akpan UG, Olutoye MA, Hameed BH (2018) Photocatalytic degradation of pollutants in petroleum refinery wastewater by $\mathrm{TiO}_{2}$ - and $\mathrm{ZnO}$-based photocatalysts: Recent development. J Clean pro 205:930-954. https://doi.org/10.1016/j.jclepro.2018. 08.189

Anwer H, Park J-W (2018) Synthesis and characterization of a heterojunction $\mathrm{rGO} / \mathrm{ZrO}_{2} / \mathrm{Ag}_{3} \mathrm{PO}_{4}$ nanocomposite for degradation of organic contaminants. J Hazard Mater 358:416-426. https://doi. org/10.1016/j.jhazmat.2018.07.019

Anwer H, Mahmood A, Lee J, Kim K-H, Park J-W, Yip ACK (2019) Photocatalysts for degradation of dyes in industrial effluents: Opportunities and challenges. Nano Res 12:955-972. https:// doi.org/10.1007/s12274-019-2287-0

Barhoumi N, Oturan N, Ammar S, Gadri A, Oturan MA, Brillas E (2017) Enhanced degradation of the antibiotic tetracycline by heterogeneous electro-Fenton with pyrite catalysis. Environ Chem Lett 15:689-693. https://doi.org/10.1007/s10311-017-0638-y

Chen F, Yang Q, Sun J, Yao F, Wang S, Wang Y, Wang X, Li X, Niu C, Wang D, Zeng G (2016) Enhanced Photocatalytic Degradation of Tetracycline by $\mathrm{AgI} / \mathrm{BiVO}_{4}$ Heterojunction under Visible-Light Irradiation: Mineralization Efficiency and Mechanism. ACS Appl Mater Interfaces 8:32887-32900. https://doi.org/10.1021/acsami. 6b12278
Chen F, Yang Q, Yao F, Wang S, Sun J, An H, Yi K, Wang Y, Zhou Y, Wang L, Li X, Wang D, Zeng G (2017) Visible-light photocatalytic degradation of multiple antibiotics by AgI nanoparticle-sensitized $\mathrm{Bi}_{5} \mathrm{O}_{7} \mathrm{I}$ microspheres: Enhanced interfacial charge transfer based on Z-scheme heterojunctions. J Catal 352:160-170. https:// doi.org/10.1016/j.jcat.2017.04.032

Chen F, Liu L-L, Zhang Y-J, Wu J-H, Huang G-X, Yang Q, Chen J-J, Yu H-Q (2020a) Enhanced full solar spectrum photocatalysis by nitrogen-doped graphene quantum dots decorated $\mathrm{BiO} 2-\mathrm{x}$ nanosheets: Ultrafast charge transfer and molecular oxygen activation. Appl Catal B: Environ. https://doi.org/10.1016/j.apcatb. 2020.119218

Chen J, Zhang X, Shi X, Bi F, Yang Y, Wang Y (2020b) Synergistic effects of octahedral $\mathrm{TiO}_{2}$-MIL-101(Cr) with two heterojunctions for enhancing visible-light photocatalytic degradation of liquid tetracycline and gaseous toluene. J Coll Interface Sci 579:37-49. https://doi.org/10.1016/j.jcis.2020.06.042

Cortes MALRM, Hamilton JWJ, Sharma PK, Brown A, Nolan M, Gray KA, Byrne JA (2019) Formal quantum efficiencies for the photocatalytic reduction of $\mathrm{CO}_{2}$ in a gas phase batch reactor. Catal Today 326:75-81. https://doi.org/10.1016/j.cattod.2018.10.047

Daghrir R, Drogui P (2013) Tetracycline antibiotics in the environment: a review. Environ Chem Lett 11:209-227. https://doi.org/ 10.1007/s10311-013-0404-8

Dai W, Jiang L, Wang J, Pu Y, Zhu Y, Wang Y, Xiao B (2020) Efficient and stable photocatalytic degradation of tetracycline wastewater by 3D Polyaniline/Perylene diimide organic heterojunction under visible light irradiation. Chem Eng J. https://doi.org/10.1016/j. cej.2020.125476

Di Bartolomeo A (2016) Graphene Schottky diodes: An experimental review of the rectifying graphene/semiconductor heterojunction. Phys Rep 606:1-58. https://doi.org/10.1016/j.physrep.2015.10. 003

Fan H, Zhou H, Li W, Gu S, Zhou G (2020) Facile fabrication of 2D/2D step-scheme $\mathrm{In}_{2} \mathrm{~S}_{3} / \mathrm{Bi}_{2} \mathrm{O}_{2} \mathrm{CO}_{3}$ heterojunction towards enhanced photocatalytic activity. Appl Surf Sci. https://doi.org/ 10.1016/j.apsusc.2019.144351

Feng X, Yu Z, Sun Y, Shan M, Long R, Li X (2021) 3D MXene/ $\mathrm{Ag}_{2} \mathrm{~S}$ material as Schottky junction catalyst with stable and enhanced photocatalytic activity and photocorrosion resistance. Sep Purif Technol. https://doi.org/10.1016/j.seppur.2021.118606

Fu J, Xu Q, Low J, Jiang C, Yu J (2019) Ultrathin 2D/2D WO $/ \mathrm{g}_{-} \mathrm{C}_{3} \mathrm{~N}_{4}$ step-scheme $\mathrm{H}_{2}$-production photocatalyst. Appl Catal B: Environ 243:556-565. https://doi.org/10.1016/j.apcatb.2018.11.011

Guo F, Shi W, Wang H, Han M, Guan W, Huang H, Liu Y, Kang $Z$ (2018) Study on highly enhanced photocatalytic tetracycline degradation of type $\mathrm{AgI} / \mathrm{CuBi}_{2} \mathrm{O}_{4}$ and $\mathrm{Z}$-scheme $\mathrm{AgBr} / \mathrm{CuBi}_{2} \mathrm{O}_{4}$ heterojunction photocatalysts. J Hazard Mater 349:111-118. https://doi.org/10.1016/j.jhazmat.2018.01.042

Guo F, Shi W, Li M, Shi Y, Wen H (2019a) 2D/2D Z-scheme heterojunction of $\mathrm{CuInS}_{2} / \mathrm{g}-\mathrm{C}_{3} \mathrm{~N}_{4}$ for enhanced visible-light-driven photocatalytic activity towards the degradation of tetracycline. Sep Purif Technol 210:608-615. https://doi.org/10.1016/j.seppur.2018.08.055

Guo F, Li M, Ren H, Huang X, Hou W, Wang C, Shi W, Lu C (2019b) Fabrication of p-n $\mathrm{CuBi}_{2} \mathrm{O}_{4} / \mathrm{MoS}_{2}$ heterojunction with nanosheets-on-microrods structure for enhanced photocatalytic activity towards tetracycline degradation. Appl Surf Sci 491:8894. https://doi.org/10.1016/j.apsusc.2019.06.158

Guo P, Zhao F, Hu X (2021) Fabrication of a direct Z-scheme heterojunction between $\mathrm{MoS}_{2}$ and $\mathrm{B} / \mathrm{Eu}-\mathrm{g}-\mathrm{C}_{3} \mathrm{~N}_{4}$ for an enhanced photocatalytic performance toward tetracycline degradation. $\mathrm{J}$ Alloys Compd. https://doi.org/10.1016/j.jallcom.2021.159044

Hasija V, Kumar A, Sudhaik A, Raizada P, Singh P, Van Le Q, Le TT, Nguyen V-H (2021) Step-scheme heterojunction photocatalysts for solar energy, water splitting, $\mathrm{CO}_{2}$ conversion, and bacterial 
inactivation: a review. Environ Chem Lett. https://doi.org/10. 1007/s10311-021-01231-w

He F, Lu Z, Song M, Liu X, Tang H, Huo P, Fan W, Dong H, Wu X, Han S (2019a) Selective reduction of $\mathrm{Cu}^{2+}$ with simultaneous degradation of tetracycline by the dual channels ion imprinted POPD-CoFe $\mathrm{O}_{4}$ heterojunction photocatalyst. Chem Eng $\mathrm{J}$ 360:750-761. https://doi.org/10.1016/j.cej.2018.12.034

He F, Wang S, Zhao H, Wang Y, Zhang J, Yan Q, Dong P, Tai Z, Chen L, Wang Y, Zhao C (2019b) Construction of Schottky-type Agloaded fiber-like carbon nitride photocatalysts for tetracycline elimination and hydrogen evolution. Appl Surf Sci 485:70-80. https://doi.org/10.1016/j.apsusc.2019.04.164

He F, Meng A, Cheng B, Ho W, Yu J (2020a) Enhanced photocatalytic $\mathrm{H} 2$-production activity of $\mathrm{WO}_{3} / \mathrm{TiO}_{2}$ step-scheme heterojunction by graphene modification. Chinese J Catal 41:9-20. https://doi. org/10.1016/s1872-2067(19)63382-6

He X, Wang A, Wu P, Tang S, Zhang Y, Li L, Ding P (2020b) Photocatalytic degradation of microcystin-LR by modified $\mathrm{TiO}_{2}$ photocatalysis: A review. Sci Total Environ 743:140694. https://doi. org/10.1016/j.scitotenv.2020.140694

He M, Sun K, Suryawanshi MP, Li J, Hao X (2021a) Interface engineering of $\mathrm{p}-\mathrm{n}$ heterojunction for kesterite photovoltaics: A progress review. J Energy Chem 60:1-8. https://doi.org/10.1016/j. jechem.2020.12.019

He X, Wu P, Wang S, Wang A, Wang C, Ding P (2021b) Inactivation of harmful algae using photocatalysts: Mechanisms and performance. J Clean pro. https://doi.org/10.1016/j.jclepro.2020. 125755

Heidari S, Haghighi M, Shabani M (2020) Sono-photodeposition of $\mathrm{Ag}$ over sono-fabricated mesoporous $\mathrm{Bi}_{2} \mathrm{Sn}_{2} \mathrm{O}_{7}$-two dimensional carbon nitride: Type-II plasmonic nano-heterojunction with simulated sunlight-driven elimination of drug. Chem Eng J. https:// doi.org/10.1016/j.cej.2019.123418

Huang H, Liu C, Ou H, Ma T, Zhang Y (2019) Self-sacrifice transformation for fabrication of type-I and type-II heterojunctions in hierarchical BixOyIz/g- $\mathrm{C}_{3} \mathrm{~N}_{4}$ for efficient visible-light photocatalysis. Appl Surf Sci 470:1101-1110. https://doi.org/10.1016/j. apsusc.2018.11.193

Ifebajo AO, Oladipo AA, Gazi M (2018) Efficient removal of tetracycline by $\mathrm{CoO} / \mathrm{CuFe} 2 \mathrm{O} 4$ derived from layered double hydroxides. Environ Chem Lett 17:487-494. https://doi.org/10.1007/ s10311-018-0781-0

Jia X, Han Q, Liu H, Li S, Bi H (2020) A dual strategy to construct flowerlike $\mathrm{S}$-scheme $\mathrm{BiOBr} / \mathrm{BiOAc} 1-\mathrm{Br}$ heterojunction with enhanced visible-light photocatalytic activity. Chem Eng J. https://doi.org/10.1016/j.cej.2020.125701

Jiang W, Luo W, Zong R, Yao W, Li Z, Zhu Y (2016) Polyaniline/ carbon nitride nanosheets composite hydrogel: A separation-free and high-efficient photocatalyst with 3D hierarchical structure. Small 12:4370-4378. https://doi.org/10.1002/smll.201601546

Jiang D, Wang T, Xu Q, Li D, Meng S, Chen M (2017) Perovskite oxide ultrathin nanosheets/g- $\mathrm{C}_{3} \mathrm{~N}_{4} 2 \mathrm{D}-2 \mathrm{D}$ heterojunction photocatalysts with significantly enhanced photocatalytic activity towards the photodegradation of tetracycline. Appl Catal B: Environ 201:617-628. https://doi.org/10.1016/j.apcatb.2016. 09.001

Jiang E, Liu X, Che H, Liu C, Dong H, Che G (2018) Visible-lightdriven $\mathrm{Ag} / \mathrm{Bi}_{3} \mathrm{O}_{4} \mathrm{Cl}$ nanocomposite photocatalyst with enhanced photocatalytic activity for degradation of tetracycline. RSC Adv 8:37200-37207. https://doi.org/10.1039/c8ra07482h

Jin P, Wang L, Ma X, Lian R, Huang J, She H, Zhang M, Wang Q (2021) Construction of hierarchical ZnIn $\mathrm{S}_{4} @ \mathrm{PCN}-224$ heterojunction for boosting photocatalytic performance in hydrogen production and degradation of tetracycline hydrochloride. Appl Catal B: Environ. https://doi.org/10.1016/j.apcatb.2020.119762
Jo WK, Tonda S (2019) Novel CoAl-LDH/g- $\mathrm{C}_{3} \mathrm{~N}_{4} / \mathrm{RGO}$ ternary heterojunction with notable $2 \mathrm{D} / 2 \mathrm{D} / 2 \mathrm{D}$ configuration for highly efficient visible-light-induced photocatalytic elimination of dye and antibiotic pollutants. J Hazard Mater 368:778-787. https://doi. org/10.1016/j.jhazmat.2019.01.114

Kumar L, Ragunathan V, Chugh M, Bharadvaja N (2021) Nanomaterials for remediation of contaminants: a review. Environ Chem Lettdoi. https://doi.org/10.1007/s10311-021-01212-Z

Lai C, Xu F, Zhang M, Li B, Liu S, Yi H, Li L, Qin L, Liu X, Fu Y, An N, Yang H, Huo X, Yang X, Yan H (2021) Facile synthesis of $\mathrm{CeO}_{2}$ /carbonate doped $\mathrm{Bi}_{2} \mathrm{O}_{2} \mathrm{CO}_{3} \mathrm{Z}$-scheme heterojunction for improved visible-light photocatalytic performance: Photodegradation of tetracycline and photocatalytic mechanism. J Coll Interface Sci 588:283-294. https://doi.org/10.1016/j.jcis.2020.12.073

Lu LL, Wu BY, Shi W, Cheng P (2019) Metal-organic frameworkderived heterojunctions as nanocatalysts for photocatalytic hydrogen production. Inorg Chem Front 6:3456-3467. https:// doi.org/10.1039/c9qi00964g

Li Q, Li FT (2020) Recent advances in surface and interface design of photocatalysts for the degradation of volatile organic compounds. Adv Coll Interface Sci 284:102275. https://doi.org/10.1016/j.cis. 2020.102275

Li S, Hu S, Xu K, Jiang W, Liu Y, Leng Z, Liu J (2017) Construction of fiber-shaped silver oxide/tantalum nitride $\mathrm{p}-\mathrm{n}$ heterojunctions as highly efficient visible-light-driven photocatalysts. J Coll Interface Sci 504:561-569. https://doi.org/10.1016/j.jcis.2017.06.018

Li C, Yu S, Che H, Zhang X, Han J, Mao Y, Wang Y, Liu C, Dong $\mathrm{H}$ (2018) Fabrication of Z-Scheme Heterojunction by Anchoring Mesoporous $\gamma-\mathrm{Fe}_{2} \mathrm{O}_{3}$ Nanospheres on $\mathrm{g}-\mathrm{C}_{3} \mathrm{~N}_{4}$ for Degrading Tetracycline Hydrochloride in Water. ACS Sustain Chem Eng 6:16437-16447. https://doi.org/10.1021/acssuschemeng.8b03500

Li S, Chen J, Liu Y, Xu K, Liu J (2019) In situ anion exchange strategy to construct flower-like $\mathrm{BiOCl} / \mathrm{BiOCOOH}$ p-n heterojunctions for efficiently photocatalytic removal of aqueous toxic pollutants under solar irradiation. J Alloys Compd 781:582-588. https://doi. org/10.1016/j.jallcom.2018.12.114

Li S, Han Q, Jia X, Hannan Zahid A, Bi H (2020a) Room-temperature one-step synthesis of tube-like $\mathrm{S}$-scheme $\mathrm{BiOBr} / \mathrm{BiO}(\mathrm{HCOO})$ $\mathrm{Br}-\mathrm{x}$ heterojunction with excellent visible-light photocatalytic performance. Appl Surf Sci. https://doi.org/10.1016/j.apsusc. 2020.147208

Li S, Chen J, Hu S, Wang H, Jiang W, Chen X (2020b) Facile construction of novel $\mathrm{Bi}_{2} \mathrm{WO}_{6} / \mathrm{Ta}_{3} \mathrm{~N}_{5} \mathrm{Z}$-scheme heterojunction nanofibers for efficient degradation of harmful pharmaceutical pollutants. Chem Eng J. https://doi.org/10.1016/j.cej.2020.126165

Li S, Shao L, Yang Z, Cheng S, Yang C, Liu Y, Xia X (2020c) Constructing $\mathrm{Ti}_{3} \mathrm{C}_{2}$ MXene/ZnIn $\mathrm{S}_{4}$ heterostructure as a Schottky Catalyst for photocatalytic environmental remediation. Green Energy Environ. https://doi.org/10.1016/j.gee.2020.09.005

Li X, Xiong J, Gao X, Ma J, Chen Z, Kang B, Liu J, Li H, Feng Z, Huang J (2020d) Novel BP/BiOBr S-scheme nano-heterojunction for enhanced visible-light photocatalytic tetracycline removal and oxygen evolution activity. J Hazard Mater 387:121690. https:// doi.org/10.1016/j.jhazmat.2019.121690

Li S, Xue B, Chen J, Liu Y, Zhang J, Wang H, Liu J (2021a) Constructing a plasmonic p-n heterojunction photocatalyst of 3D Ag/ $\mathrm{Ag}_{6} \mathrm{Si}_{2} \mathrm{O}_{7} / \mathrm{Bi}_{2} \mathrm{MoO}_{6}$ for efficiently removing broad-spectrum antibiotics. Sep Purif Technol 254:117579. https://doi.org/10.1016/j. seppur.2020.117579

Li X, Kang B, Dong F, Zhang Z, Luo X, Han L, Huang J, Feng Z, Chen Z, Xu J, Peng B, Wang ZL (2021b) Enhanced photocatalytic degradation and $\mathrm{H}_{2} / \mathrm{H}_{2} \mathrm{O}_{2}$ production performance of S-pCN/WO272 $\mathrm{S}$-scheme heterojunction with appropriate surface oxygen vacancies. Nano Energy 81:105671

Liao X, Li T-T, Ren H-T, Mao Z, Zhang X, Lin J-H, Lou C-W (2020) Enhanced photocatalytic performance through the ferroelectric 
synergistic effect of $\mathrm{p}$ - $\mathrm{n}$ heterojunction $\mathrm{BiFeO} 3 / \mathrm{TiO}_{2}$ under visible-light irradiation. Ceram Int. https://doi.org/10.1016/j.ceram int.2020.12.195

Liu Q, Wang J (2019) Dye-sensitized solar cells based on surficial $\mathrm{TiO}_{2}$ modification. Sol Energy 184:454-465. https://doi.org/10.1016/j. solener.2019.04.032

Liu Y, Kong J, Yuan J, Zhao W, Zhu X, Sun C, Xie J (2018) Enhanced photocatalytic activity over flower-like sphere $\mathrm{Ag} / \mathrm{Ag}_{2} \mathrm{CO}_{3} /$ $\mathrm{BiVO}_{4}$ plasmonic heterojunction photocatalyst for tetracycline degradation. Chem Eng J 331:242-254. https://doi.org/10.1016/j. cej.2017.08.114

Liu D, Li B, Wu J, Liu Y (2019a) Photocatalytic oxidation removal of elemental mercury from flue gas. Rev Environ Chem Lett 18:417-431. https://doi.org/10.1007/s10311-019-00957-y

Liu F, Nguyen T-P, Wang Q, Massuyeau F, Dan Y, Jiang L (2019b) Construction of Z-scheme g- $\mathrm{C}_{3} \mathrm{~N}_{4} / \mathrm{Ag} / \mathrm{P} 3 \mathrm{HT}$ heterojunction for enhanced visible-light photocatalytic degradation of tetracycline (TC) and methyl orange (MO). Appl Surf Sci 496:143653. https://doi.org/10.1016/j.apsusc.2019.143653

Liu Y, Tian J, Wei L, Wang Q, Wang C, Xing Z, Li X, Yang W, Yang C (2021) Modified g- $\mathrm{C}_{3} \mathrm{~N}_{4} / \mathrm{TiO}_{2} / \mathrm{CdS}$ ternary heterojunction nanocomposite as highly visible light active photocatalyst originated from $\mathrm{CdS}$ as the electron source of $\mathrm{TiO}_{2}$ to accelerate Z-type heterojunction. Sep Purif Technol. https://doi.org/10.1016/j.seppur.2020.117976

López YC, Viltres H, Gupta NK, Acevedo-Peña P, Leyva C, Ghaffari Y, Gupta A, Kim S, Bae J, Kim KS (2021) Transition metalbased metal-organic frameworks for environmental applications: a review. Environ Chem Lett 19:1295-1334. https://doi.org/10. 1007/s10311-020-01119-1

Louangsouphom B, Wang X, Song J, Wang X (2018) Low-temperature preparation of a N-TiO $/$ macroporous resin photocatalyst to degrade organic pollutants. Environ Chem Lett 17:1061-1066. https://doi.org/10.1007/s10311-018-00827-z

Low J, Yu J, Jaroniec M, Wageh S, Al-Ghamdi AA (2017) Heterojunction Photocatalysts. Adv Mater. https://doi.org/10.1002/adma. 201601694

Low J, Dai B, Tong T, Jiang C, Yu J (2019) In Situ irradiated X-Ray photoelectron spectroscopy investigation on a direct Z-scheme $\mathrm{TiO}_{2} / \mathrm{CdS}$ composite film photocatalyst. Adv Mater. https://doi. org/10.1002/adma.201802981

Lu C, Guo F, Yan Q, Zhang Z, Li D, Wang L, Zhou Y (2019a) Hydrothermal synthesis of type II ZnIn2S4/BiPO4 heterojunction photocatalyst with dandelion-like microflower structure for enhanced photocatalytic degradation of tetracycline under simulated solar light. J Alloys Compd. https://doi.org/10.1016/j.jallcom.2019. 151976

Lu Z, Peng J, Song M, Liu Y, Liu X, Huo P, Dong H, Yuan S, Ma Z, Han S (2019b) Improved recyclability and selectivity of environment-friendly MFA-based heterojunction imprinted photocatalyst for secondary pollution free tetracycline orientation degradation. Chem Eng J 360:1262-1276. https://doi.org/10. 1016/j.cej.2018.10.200

Luo B, Xu D, Li D, Wu G, Wu M, Shi W, Chen M (2015) Fabrication of a $\mathrm{Ag} / \mathrm{Bi}_{3} \mathrm{TaO}_{7}$ Plasmonic Photocatalyst with Enhanced Photocatalytic Activity for Degradation of Tetracycline. ACS Appl Mater Interfaces 7:17061-17069. https://doi.org/10.1021/ acsami.5b03535

Lv S-W, Liu J-M, Yang F-E, Li C-Y, Wang S (2021) A novel photocatalytic platform based on the newly-constructed ternary composites with a double $\mathrm{p}-\mathrm{n}$ heterojunction for contaminants degradation and bacteria inactivation. Chem Eng J. https://doi.org/10.1016/j. cej.2020.128269

Ma Z, Hu L, Li X, Deng L, Fan G, He Y (2019) A novel nano-sized $\mathrm{MoS}_{2}$ decorated $\mathrm{Bi}_{2} \mathrm{O}_{3}$ heterojunction with enhanced photocatalytic performance for methylene blue and tetracycline degradation. Ceram Int 45:15824-15833. https://doi.org/10. 1016/j.ceramint.2019.05.085

Madhura L, Singh S, Kanchi S, Sabela M, Bisetty K, Inamuddin, (2018) Nanotechnology-based water quality management for wastewater treatment. Environ Chem Lett 17:65-121. https:// doi.org/10.1007/s10311-018-0778-8

Mahamallik P, Saha S, Pal A (2015) Tetracycline degradation in aquatic environment by highly porous $\mathrm{MnO}_{2}$ nanosheet assembly. Chem Eng J 276:155-165. https://doi.org/10.1016/j.cej.2015.04.064

Marschall R (2014) Semiconductor Composites: Strategies for Enhancing Charge Carrier Separation to Improve Photocatalytic Activity. Adv Funct Mater 24:2421-2440. https://doi.org/10.1002/ adfm.201303214

Motlagh HF, Haghighi M, Shabani M (2019) Sono-solvothermal fabrication of ball-flowerlike Bi2O7Sn2-Bi7O9I3 nanophotocatalyst with efficient solar-light-driven activity for degradation of antibiotic tetracycline. Sol Energy 180:25-38. https://doi.org/10. 1016/j.solener.2019.01.021

Nemiwal M, Zhang TC, Kumar D (2021) Recent progress in $\mathrm{g}^{-} \mathrm{C}_{3} \mathrm{~N}_{4}$, $\mathrm{TiO}_{2}$ and $\mathrm{ZnO}$ based photocatalysts for dye degradation: Strategies to improve photocatalytic activity. Sci Total Environ. https:// doi.org/10.1016/j.scitotenv.2020.144896

Ni J, Wang W, Liu D, Zhu Q, Jia J, Tian J, Li Z, Wang X, Xing Z (2020) Oxygen vacancy-mediated sandwich-structural $\mathrm{TiO}_{2}-\mathrm{X} /$ ultrathin $\mathrm{g}-\mathrm{C}_{3} \mathrm{~N}_{4} / \mathrm{TiO}_{2}$-x direct $\mathrm{Z}$-scheme heterojunction visiblelight-driven photocatalyst for efficient removal of high toxic tetracycline antibiotics. J Hazard Mater. https://doi.org/10.1016/j. jhazmat.2020.124432

Obregón S, Ruíz-Gómez MA, Rodríguez-González V, Vázquez A, Hernández-Uresti DB (2020) A novel type-II $\mathrm{Bi}_{2} \mathrm{~W}_{2} \mathrm{O}_{9} / \mathrm{g}-\mathrm{C}_{3} \mathrm{~N}_{4}$ heterojunction with enhanced photocatalytic performance under simulated solar irradiation. Mater Sci Semicond Process 113:105056. https://doi.org/10.1016/j.mssp.2020.105056

Palanivel B, Shkir M, Alshahrani T, Mani A (2021) Novel $\mathrm{NiFe}_{2} \mathrm{O}_{4}$ deposited S-doped g- $\mathrm{C}_{3} \mathrm{~N}_{4}$ nanorod: Visible-light-driven heterojunction for photo-Fenton like tetracycline degradation. Diamond Relat Mater. https://doi.org/10.1016/j.diamond.2020.108148

Pan T, Chen D, Xu W, Fang J, Wu S, Liu Z, Wu K, Fang Z (2020) Anionic polyacrylamide-assisted construction of thin 2D-2D $\mathrm{WO}_{3} / \mathrm{g}-\mathrm{C}_{3} \mathrm{~N}_{4}$ Step-scheme heterojunction for enhanced tetracycline degradation under visible light irradiation. J Hazard Mater 393:122366. https://doi.org/10.1016/j.jhazmat.2020.122366

Pei C-Y, Chen Y-G, Wang L, Chen W, Huang G-B (2021) Step-scheme $\mathrm{WO}_{3} / \mathrm{CdIn}_{2} \mathrm{~S}_{4}$ hybrid system with high visible light activity for tetracycline hydrochloride photodegradation. Appl Surf Sci. https://doi.org/10.1016/j.apsusc.2020.147682

Peng X, Luo W, Wu J, Hu F, Hu Y, Xu L, Xu G, Jian Y, Dai H (2021) Carbon quantum dots decorated heteroatom co-doped core-shell $\mathrm{Fe}(0) @ \mathrm{POCN}$ for degradation of tetracycline via multiply synergistic mechanisms. Chemosphere 268:128806. https://doi.org/ 10.1016/j.chemosphere.2020.128806

Qi K, Cheng B, Yu J, Ho W (2017) A review on $\mathrm{TiO}_{2}$-based Z-scheme photocatalysts. Chinese J Catal 38:1936-1955. https://doi.org/ 10.1016/S1872-2067(17)62962-0

Rajput H, Kwon EE, Younis SA, Weon S, Jeon TH, Choi W, Kim K-H (2021) Photoelectrocatalysis as a high-efficiency platform for pulping wastewater treatment and energy production. Chem Eng J 412:128612. https://doi.org/10.1016/j.cej.2021.128612

Raza N, Raza W, Gul H, Azam M, Lee J, Vikrant K, Kim K-H (2020) Solar-light-active silver phosphate/titanium dioxide/silica heterostructures for photocatalytic removal of organic dye. J Clean pro. https://doi.org/10.1016/j.jclepro.2020.120031

Raza N, Raza W, Gul H, Kim KH (2021) ZnO-ZnTe hierarchical superstructures as solar-light-activated photocatalysts for azo dye removal. Environ Res 194:110499. https://doi.org/10.1016/j. envres.2020.110499 
Ren L, Zhou W, Sun B, Li H, Qiao P, Xu Y, Wu J, Lin K, Fu H (2019) Defects-engineering of magnetic $\gamma-\mathrm{Fe}_{2} \mathrm{O}_{3}$ ultrathin nanosheets/ mesoporous black $\mathrm{TiO}_{2}$ hollow sphere heterojunctions for efficient charge separation and the solar-driven photocatalytic mechanism of tetracycline degradation. Appl Catal B: Environ 240:319-328. https://doi.org/10.1016/j.apcatb.2018.08.033

Sajan CP, Wageh S, Al-Ghamdi AA, Yu J, Cao S (2016) TiO2nanosheets with exposed 001 facets for photocatalytic applications. Nano Res 9:3-27. https://doi.org/10.1007/s12274-015-0919-3

Saravanan A, Kumar PS, Vo D-VN, Yaashikaa PR, Karishma S, Jeevanantham S, Gayathri B, Bharathi VD (2020) Photocatalysis for removal of environmental pollutants and fuel production: a review. Environ Chem Lett 19:441-463. https://doi.org/10.1007/ s10311-020-01077-8

Shi W, Guo F, Yuan S (2017) In situ synthesis of Z-scheme Ag 3 PO $4 / \mathrm{CuBi} 2 \mathrm{O} 4$ photocatalysts and enhanced photocatalytic performance for the degradation of tetracycline under visible light irradiation. Appl Catal B: Environ 209:720-728. https://doi.org/ 10.1016/j.apcatb.2017.03.048

Shi H, Ni J, Zheng T, Wang X, Wu C, Wang Q (2019) Remediation of wastewater contaminated by antibiotics. Rev Environ Chem Lett 18:345-360. https://doi.org/10.1007/s10311-019-00945-2

Shi Y, Li J, Wan D, Huang J, Liu Y (2020a) Peroxymonosulfateenhanced photocatalysis by carbonyl-modified $\mathrm{g}-\mathrm{C}_{3} \mathrm{~N}_{4}$ for effective degradation of the tetracycline hydrochloride. Sci Total Environ 749:142313. https://doi.org/10.1016/j.scitotenv.2020. 142313

Shi Y, Yan Z, Xu Y, Tian T, Zhang J, Pang J, Peng X, Zhang Q, Shao M, Tan W, Li H, Xiong Q (2020b) Visible-light-driven AgBr$\mathrm{TiO}_{2}$-Palygorskite photocatalyst with excellent photocatalytic activity for tetracycline hydrochloride. J Clean pro. https://doi. org/10.1016/j.jclepro.2020.124021

Shi Z, Zhang Y, Shen X, Duoerkun G, Zhu B, Zhang L, Li M, Chen $\mathrm{Z}$ (2020c) Fabrication of $\mathrm{g}-\mathrm{C}_{3} \mathrm{~N}_{4} / \mathrm{BiOBr}$ heterojunctions on carbon fibers as weaveable photocatalyst for degrading tetracycline hydrochloride under visible light. Chem Eng J. https://doi.org/ 10.1016/j.cej.2020.124010

Soltani T, Tayyebi A, Lee BK (2019) Photolysis and photocatalysis of tetracycline by sonochemically heterojunctioned $\mathrm{BiVO}_{4} /$ reduced graphene oxide under visible-light irradiation. J Environ Manag 232:713-721. https://doi.org/10.1016/j.jenvman.2018.11.133

Soni V, Raizada P, Kumar A, Hasija V, Singal S, Singh P, HosseiniBandegharaei A, Thakur VK, Nguyen V-H (2021) Indium sulfide-based photocatalysts for hydrogen production and water cleaning: a review. Environ Chem Lett 19:1065-1095. https:// doi.org/10.1007/s10311-020-01148-w

Talaiekhozani A, Rezania S, Kim K-H, Sanaye R, Amani AM (2021) Recent advances in photocatalytic removal of organic and inorganic pollutants in air. J Clean pro 278:123895. https://doi.org/ 10.1016/j.jclepro.2020.123895

Nguyen TD, Nguyen VH, Nanda S, Vo DVN, Nguyen VH, Tran TV, Nong LX, Nguyen TT, Bach LG, Abdullah B, Hong SS, Nguyen $\mathrm{TV}$ (2020) $\mathrm{BiVO}_{4}$ photocatalysis design and applications to oxygen production and degradation of organic compounds: a review. Environ Chem Lett 18:1779-1801. https://doi.org/10. 1007/s10311-020-01039-0

Vellingiri K, Vikrant K, Kumar V, Kim K-H (2020) Advances in thermocatalytic and photocatalytic techniques for the room/low temperature oxidative removal of formaldehyde in air. Chem Eng J. https://doi.org/10.1016/j.cej.2020.125759

Vikrant K, Park CM, Kim K-H, Kumar S, Jeon E-C (2019) Recent advancements in photocatalyst-based platforms for the destruction of gaseous benzene: Performance evaluation of different modes of photocatalytic operations and against adsorption techniques. J Photoch Photobio C. https://doi.org/10.1016/j.jphot ochemrev.2019.08.003
Vikrant K, Kim K-H, Dong F, Giannakoudakis DA (2020) Photocatalytic Platforms for Removal of Ammonia from Gaseous and Aqueous Matrixes: Status and Challenges. ACS Catal 10:86838716. https://doi.org/10.1021/acscatal.0c02163

Wan J, Xue P, Wang R, Liu L, Liu E, Bai X, Fan J, Hu X (2019) Synergistic effects in simultaneous photocatalytic removal of $\mathrm{Cr}(\mathrm{VI})$ and tetracycline hydrochloride by Z-scheme $\mathrm{Co} 3 \mathrm{O} 4 / \mathrm{Ag} / \mathrm{Bi}_{2} \mathrm{WO}_{6}$ heterojunction. Appl Surf Sci 483:677-687. https://doi.org/10. 1016/j.apsusc.2019.03.246

Wang H, Zhang L, Chen Z, Hu J, Li S, Wang Z, Liu J, Wang X (2014) Semiconductor heterojunction photocatalysts: design, construction, and photocatalytic performances. Chem Soc Rev 43:52345244. https://doi.org/10.1039/c4cs00126e

Wang H, Yuan X, Wu Y, Zeng G, Dong H, Chen X, Leng L, Wu Z, Peng L (2016) In situ synthesis of In2S3@ MIL-125(Ti) coreshell microparticle for the removal of tetracycline from wastewater by integrated adsorption and visible-light-driven photocatalysis. Appl Catal B: Environ 186:19-29. https://doi.org/10. 1016/j.apcatb.2015.12.041

Wang J, Zhang G, Li J, Wang K (2018a) Novel Three-Dimensional Flowerlike $\mathrm{BiOBr} / \mathrm{Bi}_{2} \mathrm{SiO}_{5} \mathrm{p}-\mathrm{n}$ Heterostructured Nanocomposite for Degradation of Tetracycline: Enhanced Visible Light Photocatalytic Activity and Mechanism. ACS Sustain Chem Eng 6:14221-14229. https://doi.org/10.1021/acssuschemeng.8b02869

Wang J, Zhi D, Zhou H, He X, Zhang D (2018b) Evaluating tetracycline degradation pathway and intermediate toxicity during the electrochemical oxidation over a $\mathrm{Ti} / \mathrm{Ti}_{4} \mathrm{O}_{7}$ anode. Water Res 137:324-334. https://doi.org/10.1016/j.watres.2018.03.030

Wang J, Zhang Z, Wang X, Shen Y, Guo Y, Wong PK, Bai R (2018c) Synthesis of novel p-n heterojunction $\mathrm{m}-\mathrm{Bi}_{2} \mathrm{O}_{4} / \mathrm{BiOCl}$ nanocomposite with excellent photocatalytic activity through ion-etching method. Chinese J Catal 39:1792-1803. https://doi.org/10.1016/ s1872-2067(18)63142-0

Wang W, Han Q, Zhu Z, Zhang L, Zhong S, Liu B (2019) Enhanced photocatalytic degradation performance of organic contaminants by heterojunction photocatalyst $\mathrm{BiVO}_{4} / \mathrm{TiO}_{2} / \mathrm{RGO}$ and its compatibility on four different tetracycline antibiotics. Adv Powder Technol 30:1882-1896. https://doi.org/10.1016/j.apt.2019.06. 006

Wang J, Zhang Q, Deng F, Luo X, Dionysiou DD (2020) Rapid toxicity elimination of organic pollutants by the photocatalysis of environment-friendly and magnetically recoverable step-scheme $\mathrm{SnFe}_{2} \mathrm{O}_{4} / \mathrm{ZnFe}_{2} \mathrm{O}_{4}$ nano-heterojunctions. Chem Eng J. https://doi. org/10.1016/j.cej.2019.122264

Wang H, Chen L, Sun Y, Yu J, Zhao Y, Zhan X, Shi H (2021a) $\mathrm{Ti}_{3} \mathrm{C}_{2}$ Mxene modified $\mathrm{SnNb}_{2} \mathrm{O}_{6}$ nanosheets Schottky photocatalysts with directed internal electric field for tetracycline hydrochloride removal and hydrogen evolution. Sep Purif Technol. https://doi. org/10.1016/j.seppur.2021.118516

Wang S, Zhao L, Huang W, Zhao H, Chen J, Cai Q, Jiang X, Lu C, Shi W (2021b) Solvothermal synthesis of $\mathrm{CoO} / \mathrm{BiVO}_{4}$ p-n heterojunction with micro-nano spherical structure for enhanced visible light photocatalytic activity towards degradation of tetracycline. Mater Res Bull. https://doi.org/10.1016/j.materresbu 11.2020 .111161

Wei Z, Xinyue T, Xiaomeng W, Benlin D, Lili Z, Jiming X, Yue F, Ni S, Fengxia Z (2019) Novel p-n heterojunction photocatalyst fabricated by flower-like $\mathrm{BiVO}_{4}$ and $\mathrm{Ag}_{2} \mathrm{~S}$ nanoparticles: Simple synthesis and excellent photocatalytic performance. Chem Eng J 361:1173-1181. https://doi.org/10.1016/j.cej.2018.12.120

Wei Z, Liu J, Shangguan W (2020) A review on photocatalysis in antibiotic wastewater: Pollutant degradation and hydrogen production. Chinese J Catal 41:1440-1450. https://doi.org/10.1016/ s1872-2067(19)63448-0

Wu Z, Yan X, Shen H, Li J, Shi W (2018) Enhanced visible-lightdriven photocatalytic activity of $\mathrm{Bi} 12 \mathrm{O} 15 \mathrm{Cl} / 6 / \mathrm{Bi}_{2} \mathrm{WO}_{6} \mathrm{Z}$-scheme 
heterojunction photocatalysts for tetracycline degradation. Mater Sci Eng B 231:86-92. https://doi.org/10.1016/j.mseb.2018.10. 003

Wu X-F, Li H, Su J-Z, Zhang J-R, Feng Y-M, Jia Y-N, Sun L-S, Zhang W-G, Zhang M, Zhang C-Y (2019) Full spectrum responsive $\mathrm{In}_{2.77} \mathrm{~S}_{4} / \mathrm{WS}_{2}$ p-n heterojunction as an efficient photocatalyst for $\mathrm{Cr}(\mathrm{VI})$ reduction and tetracycline oxidation. Appl Surf Sci 473:992-1001. https://doi.org/10.1016/j.apsusc.2018.12.219

Xia B, Deng F, Zhang S, Hua L, Luo X, Ao M (2020) Design and synthesis of robust $\mathrm{Z}$-scheme $\mathrm{ZnS}^{-\mathrm{SnS}_{2}} \mathrm{n}$-n heterojunctions for highly efficient degradation of pharmaceutical pollutants: Performance, valence/conduction band offset photocatalytic mechanisms and toxicity evaluation. J Hazard Mater 392:122345. https://doi.org/10.1016/j.jhazmat.2020.122345

Xie Z, Feng Y, Wang F, Chen D, Zhang Q, Zeng Y, Lv W, Liu G (2018) Construction of carbon dots modified $\mathrm{MoO}_{3} / \mathrm{g}-\mathrm{C}_{3} \mathrm{~N}_{4} \mathrm{Z}$-scheme photocatalyst with enhanced visible-light photocatalytic activity for the degradation of tetracycline. Appl Catal B: Environ 229:96-104. https://doi.org/10.1016/j.apcatb.2018.02.011

Xu C, Ravi Anusuyadevi P, Aymonier C, Luque R, Marre S (2019) Nanostructured materials for photocatalysis. Chem Soc Rev 48:3868-3902. https://doi.org/10.1039/c9cs00102f

Xu Q, Zhang L, Cheng B, Fan J, Yu J (2020a) S-Scheme Heterojunction Photocatalyst Chem 6:1543-1559. https://doi.org/10.1016/j. chempr.2020.06.010

$\mathrm{Xu}$ Y, You Y, Huang $\mathrm{H}$, Guo Y, Zhang Y (2020b) $\mathrm{Bi}_{4} \mathrm{NbO}_{8} \mathrm{Cl}\{001\}$ nanosheets coupled with $\mathrm{g}_{-} \mathrm{C}_{3} \mathrm{~N}_{4}$ as $2 \mathrm{D} / 2 \mathrm{D}$ heterojunction for photocatalytic degradation and $\mathrm{CO}_{2}$ reduction. J Hazard Mater 381:121159. https://doi.org/10.1016/j.jhazmat.2019.121159

Xue J, Ma S, Zhou Y, Zhang Z, He M (2015) Facile Photochemical Synthesis of $\mathrm{Au} / \mathrm{Pt} / \mathrm{g}-\mathrm{C}_{3} \mathrm{~N}_{4}$ with Plasmon-Enhanced Photocatalytic Activity for Antibiotic Degradation. ACS Appl Mater Interfaces 7:9630-9637. https://doi.org/10.1021/acsami.5b01212

Yan X, Qin J, Ning G, Li J, Ai T, Su X, Wang Z (2019) A novel poly(triazine imide) hollow tube/ $\mathrm{ZnO}$ heterojunction for tetracycline hydrochloride degradation under visible light irradiation. Adv Powder Technol 30:359-365. https://doi.org/10.1016/j.apt. 2018.11.013

Yan Q, Fu Y, Zhang Y, Wang H, Wang S, Cui W (2021a) Ag/ $\gamma-\mathrm{AgI} /$ $\mathrm{Bi}_{2} \mathrm{O}_{2} \mathrm{CO}_{3} / \mathrm{Bi}$ S-scheme heterojunction with enhanced photocatalyst performance. Sep Purif Technol 263:118389. https://doi.org/ 10.1016/j.seppur.2021.118389

Yan X, Ji Q, Wang C, Xu J, Wang L (2021b) In situ construction bismuth oxycarbonate/bismuth oxybromide Z-scheme heterojunction for efficient photocatalytic removal of tetracycline and ciprofloxacin. J Colloid Interface Sci 587:820-830. https://doi.org/ 10.1016/j.jcis.2020.11.043

Yang Y, Zeng Z, Zhang C, Huang D, Zeng G, Xiao R, Lai C, Zhou C, Guo H, Xue W, Cheng M, Wang W, Wang J (2018) Construction of iodine vacancy-rich BiOI/Ag@ AgI Z-scheme heterojunction photocatalysts for visible-light-driven tetracycline degradation: Transformation pathways and mechanism insight. Chem Eng J 349:808-821. https://doi.org/10.1016/j.cej.2018.05.093

Yang R, Zhu Z, Hu C, Zhong S, Zhang L, Liu B, Wang W (2020) Onestep preparation (3D/2D/2D) $\mathrm{BiVO}_{4} / \mathrm{FeVO}_{4} @ \mathrm{rGO}$ heterojunction composite photocatalyst for the removal of tetracycline and hexavalent chromium ions in water. Chem Eng J. https://doi.org/ 10.1016/j.cej.2020.124522

Yang P, Chen C, Wang D, Ma H, Du Y, Cai D, Zhang X, Wu Z (2021a) Kinetics, reaction pathways, and mechanism investigation for improved environmental remediation by $0 \mathrm{D} / 3 \mathrm{D} \mathrm{CdTe} / \mathrm{Bi}_{2} \mathrm{WO}_{6}$ Z-scheme catalyst. Appl Catal B: Environ. https://doi.org/10. 1016/j.apcatb.2021.119877

Yang X, Chen Z, Zhao W, Liu C, Qian X, Chang W, Sun T, Shen C, Wei G (2021b) Construction of porous-hydrangea BiOBr/ $\mathrm{BiOI} n-n$ heterojunction with enhanced photodegradation of tetracycline hydrochloride under visible light. J Alloys Compd. https://doi.org/10.1016/j.jallcom.2021.158784

Yang X, Chen Z, Zhao W, Liu C, Qian X, Zhang M, Wei G, Khan E, Hau Ng Y, Sik Ok Y (2021c) Recent advances in photodegradation of antibiotic residues in water. Chem Eng J 405:126806. https://doi.org/10.1016/j.cej.2020.126806

Yin H, Cao Y, Fan T, Zhang M, Yao J, Li P, Chen S, Liu X (2021) In situ synthesis of $\mathrm{Ag}_{3} \mathrm{PO}_{4} / \mathrm{C}_{3} \mathrm{~N}_{5} \mathrm{Z}$-scheme heterojunctions with enhanced visible-light-responsive photocatalytic performance for antibiotics removal. Sci Total Environ 754:141926. https://doi. org/10.1016/j.scitotenv.2020.141926

Younis SA, Kwon EE, Qasim M, Kim K-H, Kim T, Kukkar D, Dou X, Ali I (2020) Metal-organic framework as a photocatalyst: Progress in modulation strategies and environmental/energy applications. Prog Energy Combust Sci. https://doi.org/10.1016/j.pecs. 2020.100870

Yu C, Zhou W, Yu JC, Liu H, Wei L (2014a) Design and fabrication of heterojunction photocatalysts for energy conversion and pollutant degradation. Chinese J Catal 35:1609-1618. https://doi.org/10. 1016/s1872-2067(14)60170-4

Yu J, Low J, Xiao W, Zhou P, Jaroniec M (2014b) Enhanced photocatalytic $\mathrm{CO}_{2}$-reduction activity of anatase $\mathrm{TiO}_{2}$ by coexposed $\{001\}$ and $\{101\}$ facets. J Am Chem Soc 136:8839-8842. https://doi. org/10.1021/ja5044787

Yu W, Zhang S, Chen J, Xia P, Richter MH, Chen L, Xu W, Jin J, Chen S, Peng T (2018) Biomimetic Z-scheme photocatalyst with a tandem solid-state electron flow catalyzing $\mathrm{H}_{2}$ evolution. J Mater Chem A 6:15668-15674. https://doi.org/10.1039/c8ta02922a

Yu H, Wang D, Zhao B, Lu Y, Wang X, Zhu S, Qin W, Huo M (2020) Enhanced photocatalytic degradation of tetracycline under visible light by using a ternary photocatalyst of $\mathrm{Ag}_{3} \mathrm{PO}_{4} / \mathrm{AgBr} / \mathrm{g}$ $\mathrm{C}_{3} \mathrm{~N}_{4}$ with dual Z-scheme heterojunction. Sep Purif Technol. https://doi.org/10.1016/j.seppur.2019.116365

Yuan X, Shen D, Zhang Q, Zou H, Liu Z, Peng F (2019a) Z-scheme $\mathrm{Bi}_{2} \mathrm{WO}_{6} / \mathrm{CuBi}_{2} \mathrm{O}_{4}$ heterojunction mediated by interfacial electric field for efficient visible-light photocatalytic degradation of tetracycline. Chem Eng J 369:292-301. https://doi.org/10.1016/j. cej.2019.03.082

Yuan X, Jiang L, Liang J, Pan Y, Zhang J, Wang H, Leng L, Wu Z, Guan R, Zeng G (2019b) In-situ synthesis of 3D microspherelike $\mathrm{In}_{2} \mathrm{~S}_{3} / \mathrm{InVO}_{4}$ heterojunction with efficient photocatalytic activity for tetracycline degradation under visible light irradiation. Chem Eng J 356:371-381. https://doi.org/10.1016/j.cej. 2018.09.079

Zhang M, Lai C, Li B, Huang D, Zeng G, Xu P, Qin L, Liu S, Liu X, Yi H, Li M, Chu C, Chen Z (2019) Rational design 2D/2D BiOBr/ $\mathrm{CDs} / \mathrm{g}-\mathrm{C}_{3} \mathrm{~N}_{4} \mathrm{Z}$-scheme heterojunction photocatalyst with carbon dots as solid-state electron mediators for enhanced visible and NIR photocatalytic activity: Kinetics, intermediates, and mechanism insight. J Catal 369:469-481. https://doi.org/10.1016/j.jcat. 2018.11.029

Zhang R, Li Y, Zhang W, Sheng Y, Wang M, Liu J, Liu Y, Zhao C, Zeng K (2021) Fabrication of $\mathrm{Cu}_{2} \mathrm{O} / \mathrm{Bi}_{2} \mathrm{~S}_{3}$ heterojunction photocatalysts with enhanced visible light photocatalytic mechanism and degradation pathways of tetracycline. J Mol Struct. https:// doi.org/10.1016/j.molstruc.2020.129581

Zhao C, Ran F, Dai L, Li C, Zheng C, Si C (2021a) Cellulose-assisted construction of high surface area Z-scheme C-doped g- $\mathrm{C}_{3} \mathrm{~N}_{4} /$ $\mathrm{WO}_{3}$ for improved tetracycline degradation. Carbohydr Polym 255:117343. https://doi.org/10.1016/j.carbpol.2020.117343

Zhao W, Li Y, Zhao P, Zhang L, Dai B, Xu J, Huang H, He Y, Leung DYC (2021b) Novel Z-scheme Ag- $\mathrm{C}_{3} \mathrm{~N}_{4} / \mathrm{SnS}_{2}$ plasmonic heterojunction photocatalyst for degradation of tetracycline and $\mathrm{H}_{2}$ production. Chem Eng J. https://doi.org/10.1016/j.cej.2020.126555

Zheng X, Liu Y, Liu X, Li Q, Zheng Y (2021) A novel PVDF-TiO $@$ g$\mathrm{C}_{3} \mathrm{~N}_{4}$ composite electrospun fiber for efficient photocatalytic 
degradation of tetracycline under visible light irradiation. Ecotoxicol Environ Saf 210:111866. https://doi.org/10.1016/j. ecoenv.2020.111866

Zhi L, Zhang S, Xu Y, Tu J, Li M, Hu D, Liu J (2020) Controlled growth of AgI nanoparticles on hollow $\mathrm{WO}_{3}$ hierarchical structures to act as Z-scheme photocatalyst for visible-light photocatalysis. J Coll Interface Sci 579:754-765. https://doi.org/10. 1016/j.jcis.2020.06.126

Zhou K, Li Y (2012) Catalysis Based on Nanocrystals with WellDefined Facets. Angew Chem Int Ed 51:602-613. https://doi. org/10.1002/anie.201102619

Zhou H, Qu Y, Zeid T, Duan X (2012) Towards highly efficient photocatalysts using semiconductor nanoarchitectures. Energy Environ Sci. https://doi.org/10.1039/c2ee03447f

Zhou H, Zhong S, Shen M, Yao Y (2019) Composite soft templateassisted construction of a flower-like $\beta$-Bi2O3/Bi2O2CO3 heterojunction photocatalyst for the enhanced simulated sunlight photocatalytic degradation of tetracycline. Ceram Int 45:1503615047. https://doi.org/10.1016/j.ceramint.2019.04.240

Zhu P, Duan M, Wang R, Xu J, Zou P, Jia H (2020) Facile synthesis of $\mathrm{ZnO} / \mathrm{GO} / \mathrm{Ag}_{3} \mathrm{PO}_{4}$ heterojunction photocatalyst with excellent photodegradation activity for tetracycline hydrochloride under visible light. Colloid Surface A. https://doi.org/10.1016/j.colsu rfa.2020.125118

Zhuge Z, Liu X, Chen T, Gong Y, Li C, Niu L, Xu S, Xu X, Alothman ZA, Sun CQ, Shapter JG, Yamauchi Y (2020) Highly efficient photocatalytic degradation of different hazardous contaminants by $\mathrm{CaIn}_{2} \mathrm{~S}_{4}-\mathrm{Ti}_{3} \mathrm{C}_{2} \mathrm{Tx}$ Schottky heterojunction: An experimental and mechanism study. Chem Eng J 421:127838. https://doi.org/ 10.1016/j.cej.2020.127838

Publisher's Note Springer Nature remains neutral with regard to jurisdictional claims in published maps and institutional affiliations. 